Historic, archived document

Do not assume content reflects current scientific knowledge, policies, or practices. 



\section{UNITED STATES \\ DEPARTMENT OF AGRICULTURE \\ CIRCULAR No. 333}

Washington, D.C.

January 1935

\section{SAMPLE PLOTS IN \\ SILVICULTURAL RESEARCH}

By
THE DIVISION OF SILVICS, BRANCH OF RESEARCH FOREST SERVICE

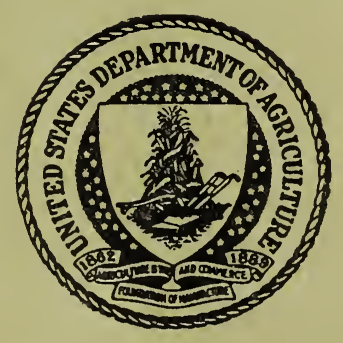




\title{
SAMPLE PLOTS IN SILVICULTURAL RESEARCH
}

\author{
By the Division of Silvics, Branch of Research, Forest Service 1
}

\section{CONTENTS}

Page | Collection of plot data-Continued. Page

Introduction

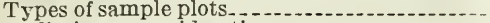

Preliminary considerations

Qualifications of the investigator

Plan of work

Need of care in recording plot establishment

Crew organization

Number and distribution of plots and subplots

Size and shape of plots and subplots......

Isolation strips

Plot establishment-..-

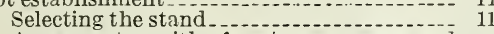

Agreements with forest managers and owners .

Locating plots within the stand

Surveying and demarcating plots........- 14

Numbering plots, subplots, and plot sec-

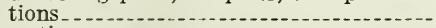

Location survey

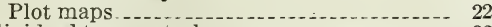

Individual tree control
Numbering trees and marking the measure-

Numbering trees and marking the measure-

Numbering reproduction ...............

Plots in plantations

Protection of plots

Plot treatment ...

Collection of plot data

Field notes and forms..................... 34

Tree measurements..................... 34

Tree description and classification -....---. 46

Stem and crown maps

Plot description .......

Plot description

Remeasurements

Reports and office records _.................... 57

Report on plot establishment............ 57

Progress reports _....... 59

Field record ..... 59

Plot index

Preservation and filing of field records

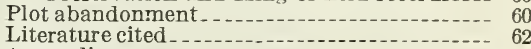

Appendix

Typical field forms used in sample-plot

work by the United States Forest. Service_ 66

Instruments, accessories, tools, and stationery used in sample-plot work

Abbreviations and numerical code for use in sample-plot work

Symbols used in sample-plot mapping -..- 76

Description of ponderosa pine tree classes as developed by Dunning ..........- 76

Swedish tree classification

Methods of preparing volume and yield

tables ............................... 79

Forest Service policy regarding experimental forests, natural areas, and primitive areas.

Specimen agreement providing for experimental use of private area ............... 89

\section{INTRODUCTION}

Successful production of forest crops, as of other crops, depends in very large measure upon detailed knowledge of the crops' growth requirements and growth characteristics. For American forests and forest species, information of this kind is very incomplete. In the past quarter century, foresters and others have by observation acquired certain data on the growth and behavior of our forest

1 Acknowledgment is made of cooperation in the preparation of this manual by a committee representing the Society of American Foresters, including O. A. Alderman, F. S. Baker, F. W. Besley, A. C Cline, F. C. Craighead, Duncan Dunning, J. A. Ferguson, Carl Hartley, W. R. Hine, G. A. Pearson, Edmund Secrest, J. N. Spaeth, and E. N. Irunns, chairman. So many of the silviculturists in the various Federal forest experiment stations have contributed to the manual that it is impossible to mention them all. Especially helpful has been the work of J. H. Buell, Perkins Corille, F. H. Erre, and I. T. Haig. The textual presentation is to a considerable extent the work of $E$. $N$. Munns. 
species, but these apply to only a few of our many commercial forest types. Further, much of this information deals only with certain stages in the life history of the forest; thus for some of the pines we know how to achieve a certain degree of success in reproducing stands naturally, but know little or nothing of the cultural methods needed for success in bringing the stands to maturity.

European experience gives us little help. Most of the forestry methods earliest used in North America were borrowed from Europe almost without change. Some of these, although highly satisfactory in Europe, failed here. Our species, our soils, our climate, our economic conditions are so radically different from those of European countries that what holds true on one continent does not necessarily hold true on the other.

Information needed as a basis for forest management can be acquired in several ways. The trial and error method takes much time and is costly. Faced by the fact that our forest supplies are dwindling and that our growing stock is already inadequate, we cannot justifiably place our dependence upon this method. The empirical investigative method also is unsatisfactory. Its results, while indicative, are inconclusive. Too often, after long and involved study the investigator finds himself not far from where he started. Here again, too much time is required. The research method alone appears satisfactory. It holds promise of results within the shortest possible period, and of results that will stand the test of time. Also, in the long run it is the cheapest method. In the research method the problem is broken down and its parts studied separately, replications are made to eliminate the influence of accident, and controls are provided to insure definite comparative results.

The sample-plot method has been found to be the most effective way of studying the growth and behavior of forest stands. A plot can be small enough to permit rather careful observation of developments and at the same time large enough to be truly representative of the forest.

To obtain really exact comparative data would require the impossible procedure of comparing conditions on a given plot after a given treatment with conditions on the same plot, in the same period, after no treatment. The sample-plot method calls for a comparison of conditions on a given plot after treatment with contemporary conditions on an untreated plot which it closely resembled before treatment in the characteristics which the experiment involves. This method is adequate if the plots are, in fact, random samples of the experimental area, but is incorrectly applied if treatment is allocated to systematically arranged plots or to areas chosen arbitrarily. When only 1 of 2 comparable plots is to be treated, for example, the choice of the area to be treated should be made absolutely by chance, as by the toss of a coin. This system of sampling is based on the assumption that differences in the unknown factors of site are unrelated to the plot arrangement.

In some fields of scientific endeavor it is a relatively simple matter to obtain basic data under carefully controlled conditions, and to repeat an experiment at will. Even in dealing with some kinds of plant material it is possible to keep the factors of an experiment 
under a high degree of control. Soils of uniform texture can be used; temperatures can be controlled by growing the plants in a greenhouse; watering can be applied artificially; length of day can be artificially extended or reduced; and the pedigree of the plants may be known. In dealing with annual field crops greater difficulty is encountered; but with care some factors can be controlled very closely, and if it is necessary to repeat the experiment no great difficulty stands in the way. In forestry, such control and ready repetition are practically out of the question. 'The forest is a longtime crop, the individual specimens are large, the units of measurement are not always exact, and rolumes often cannot be measured easily or with a high degree of accuracr. Furthermore, genetic characteristics are not fixed, environmental factors cannot be so reliably measured, and the previous history of the area. which is often a major controlling factor, is seldom known. These difficulties create an extreme need of care in planning and in conducting silvicultural experiments.

The great need of information on forestry measures has caused many men to undertake research on their particular problems. Too often, the desire to get something under way quickly or to take advantage of transient farorable conditions has led an investigator into tasks for which he was not adequately trained or for which he had not made adequate preparations. In numerous instances, inexperienced and incompetent workers detailed to establish a series of sample plots have failed to take into account some of the essential particulars. As a result, much investigative effort has vielded conflicting or fragmentary answers, or no answers at all, to the questions it was intended to solve.

It is the purpose of this circular to present to foresters with research responsibilities an outline of the technic of sample-plot procedure, in order that the standards of such work may be raised, that findings from studies of data obtained in one region may be applicable in other regions, and that silvicultural research as a whole may yield conclusire results in less time. The publication deals with the requirements of good silvicultural research as these are known in 193t. Since the wide range of forest conditions and the large number of forest species in the United States make it impossible to present all the different refinements of technic that apply locally, this discussion attempts only to outline the technic that is generally applicable, leaving it to the individual worker to exercise his own initiative, ability, and ingenuity in deciding which methods apply best to conditions in a given locality.

The publication is concerned primarily with field methods. In most cases the purpose of the work will dictate the method of compiling the data. It should be remembered the real value derived from plots comes from the analysis of data, not from establishment.

This presentation of research methods is not to be taken as an effort to standardize research. Such an effort would be highly undesirable. Research can progress only if research agencies are permitted freedom of thought and action. So long as these agencies maintain the high standards of accuracy and thoroughness and the continuity required by silvicultural research, they are entitled to considerable latitude as to the details of procedure. 


\section{TYPES OF SAMPLE PLOTS}

For the purposes of this circular, the following plot definitions ${ }^{2}$ are adopted:

Permanent sample plots are small representative areas on which derelopments are followed by means of repeated measurements or examinations continuing through a period usually exceeding 10 years.

Temporary sample plots are similar areas on which measurements are taken or conditions examined at the time of plot establishment with no intention that subsequent derelopments on them shall be studied.

Semipermanent sample plots are those on which measurements of stand conditions are taken, but where the derelopment of the indiridual trees is not followed in subsequent remeasurements.

A subplot or quadrat (pl. 1, A) is a small division laid out within a sample plot for the purpose of studying reproduction or other regetation too abundant to be studied on the whole sample plot, or for the purpose of studying the effect of special conditions or treatments.

A plot section is a major division of a sample plot laid off to facilitate numbering and mapping the trees and as a means of using data from different parts of the plot separately.

Control plots are permanent sample plots so established as to form a base or norm to which the response of treated plots may be referenced.

Untreated plots are permanent sample plots established for the purpose of following through the life of a stand influenced only by natural factors. ${ }^{4}$

In every study involving a comparison of treatment with no treatment, it should be remembered that "no treatment" is in fact a special case of "treatment" and that control plots are just as important as any of the treated plots, and subject to the same rules.

\section{PRELIMINARY CONSIDERATIONS}

\section{QUALIFICATIONS OF THE INVESTIGATOR}

Correct establishment of sample plots is not such a simple matter as many foresters believe. It requires thorough preparation, a high degree of skill, and a knowledge of many requirements and many dangers inrolved. Any man undertaking to establish sample plots for use in silvicultural research should first of all have imagination, thoroughness. and accuracy; should know and appreciate the problem at hand: should understand the specific factors involved: should be acquainted with the literature of his general problem and with work being done upon the problem; should be familiar with the region and type in which the work is to be done; and should have a rudimentary knowledge of statistical methods. Of these

\footnotetext{
2 Further explanation of terms used in the circluar mas be found in definitions adopted by the Society of American Foresters (25) ${ }^{3}$

${ }^{3}$ Italic numbers in parentheses refer to Literature Cited. p. 62.

"The classification " untreated plots" corers growth or yield plots which are established in overstocked. normal, or understocked stands in order to determine such matters as the application of sield tables, the progress of growth, or mortalits. A much larger number of these growth plots than has been established in studies thus far undertaken appears to be needed to cover the range of sites and of stocking commonly found in our present immature forests.
} 
qualifications, two demand special emphasis: Knowledge of the region and knowledge of statistics.

Unless the investigator has a thorough knowledge of the region or type, he cannot determine whether his samples are truly representative. The necessary acquaintance with the region can be gained only through well-directed personal experience in the woods. Extensive surveys or investigations are the simplest means of gaining an insight into stand characteristics over a wide area.

He who deals with samples necessarily deals with statistics. For every investigator who works with sample plots, statistical methods ${ }^{5}$ are one of the essential tools of his trade, needed in every phase of plot work from establishment to final analysis of data. They constitute the only means of dealing satisfactorily with questions arising constantly in every part of a silvicultural study, such as whether the plots are comparable, how many measurements should be taken, what degree of reliability can be expected, how much of the variation in the results is due to the method of treatment and how much to other variables, and what is the estimate of error.

\section{PLAN OF WORK}

Even with a well-thought-out plan, the quantity of work required to collect the basic data of a single silvicultural experiment often seems staggering. Good advance planning, however, makes it possible to obtain many data with a minimum of effort, and in such form as to lend themselves readily to analysis. Statistical analysis of the data will show the degree to which apparent relationships are significant and how far indications can be relied upon.

First of all, the purpose of the study should be carefully formulated. Much time can profitably be devoted to defining the purpose in advance. The choice of methods of procedure can then be made more easily, and it will be unlikely that any needed measurement will be overlooked or a mass of unnecessary details included.

Fisher has said that "Nature will best respond to a logical and carefully thought out questionnaire; indeed, if we ask her a single question, she will often refuse to answer until some other topic has been discussed" (26). Furthermore, the plots of a given project, if properly laid out, are likely not only to contribute toward answers to most of the direct questions asked by the experimenter but to yield information on other subjects. Before beginning a silvicultural experiment the investigator should set down categorically the questions to which in his opinion the experiment may be expected to indicate an answer. Questions thus listed define the nature of the data to be collected and often help in deciding upon the details of methods to be followed in collecting them.

\footnotetext{
5 Outstanding works on the fundamentals of statistical methods include texts by Yule (82) and Fisher (2\%). Descriptions of special statistical technics applicable to forestry problems are available in many other works $(1,12,13,14,22,29,30,32,33$, $37,38,39,75,7 \%, 81)$. See also SMITH, B. B. THE USE OF PUNCHED CARD TABULATING EQUIPMENT IN MULTIPLE CORRELATION PROBLEMS. U.S. Dept. Agr., Bur. Agr. Econ. 1923. [Mimeographed.] Methods of preparing volume and yield tables are discussed in the appendix (p. 79). As statistical methods are now rather generally established in biological work and their application to forest research is not particularly difficult, it has seemed logical to omit from this publication a specific discussion of biometry as applied to forestry.
} 
Decisions should be made as far in advance of field work as is possible regarding the number, size, shape, and distribution and grouping of plots and subplots, width of isolation strips, and size of area outside the plot that is to be treated or retained for further work. Advance decision is necessary also as to the kind and number of measurements and other data to be taken, how these are to be taken and recorded, and what instruments are to be used.

The methods to be used in compiling the data should always be considered before the system of recording them is decided upon. Thus, if some device such as a punch-card tabulating machine can be used, provision for its use should be made in coding and recording the data in the field. (See appendix, p. 73, for numerical code applicable to sample-plot work.)

Establishment of the plots is only the beginning of the job; the necessity of periodic remeasurements constitutes a mortgage upon the future. The establishment of a series of permanent plots during the slack time of one season may easily result in a burdensome schedule of work during a subsequent season when demands on time are greater. Whenever possible, a study involving a series of plots should be so planned that remeasurements are staggered over the years and thus no one season's work is made much heavier than another's.

The plan cannot be hard and fast; field and other conditions will inevitably necessitate changes in it from time to time. The investigator should be constantly on the alert for new ideas and extra data that will aid in the solution of silvicultural problems. An active mind should supplement every working plan, no matter how complete $(6)$.

A detailed plan of work for the study should be written before the field work of plot establishment is begun. This should begin with a clear-cut statement of the purpose of the study and of each plot. Next a set of definitions to be used throughout the study should be prepared. These should be so complete and unequivocal that, if necessary, a second worker wholly unfamiliar with the previous work can take up the study at any point and carry it on to its conclusion.

The written plan should describe the conditions to be met in the experiment, such as the site, age, density, and normality of the stand. Any factors, such as soil conditions, topography, drainage, slope, or exposure, that are to be considered in the study, should be outlined, doubtful points cleared up, and alternative proposals as to future procedure described.

The plan should record specifically the number, size, shape, and distribution of plots and subplots, the width of isolation strips, the kind and number of measurements to be taken, the methods of measurement, the instruments to be used, and related matters. The progressive steps in plot establishment should be described in full. If the plots are to be given some form of treatment, the plan should outline the methods to be followed. Trees to be cut or trees to be left should be described, method of logging or otherwise removing products outlined, and the question of slash disposal settled. Beyond this, there should be an indication of the time or season when the treatment should be carried out. 
A systematic scheme for recording the data should be included in the written plan. The forms to be used should be prescribed, with column headings specifically indicating what data are to be recorded. Abbreviations and symbols to be used throughout the study should be set down. (See appendix, pp. 73 and 76.)

\section{NEED OF CARE IN RECORDING PLOT ESTABLISHMENT}

Anyone who establishes a permanent sample plot should recognize that he thereby assumes responsibility for furnishing future workers with a complete picture of conditions on the plot at the time of its establishment. Not only must each plot be properly marked and all measurements be in perfect order, but all notes and records must be full and complete. Otherwise, the plots may fail to yield the desired results and those who in later years become responsible for their care and for analysis of the data may be led into serious mistakes. Many a silvicultural study has failed to give even partial answers to the questions involved largely because the person who established the plots failed to make some of the essential measurements or failed to make a systematic record of his observations.

The need of care in making plot records is intensified by the improbability that the worker who establishes a given series of plots will himself remeasure the plots over a long period. In very few instances have plots been remeasured over a period of 20 years, or even 15 years, under the personal direction of the same man by whom they were established.

\section{CREW ORGANIZATION}

Under most circumstances, the most efficient crew for sample-plot work is one composed of three men. The leader of the party should be a permanent member of the research organization responsible for the work. Before going into the field he should become thoroughly acquainted with the purpose and plan of the study, and with existing plot data. The two other members need not be permanent members of the organization, but should be acquainted with forest practices and with the instruments used in the work and should be thoroughly reliable. If a 2 -man crew is used, the helper should be familiar with sample-plot procedure. Details of organization will vary according to the character of the plots and other features of the plan of work. The smoothness with which the work proceeds will depend upon the experience of the crew members and, especially, upon their energy and their interest in the work.

\section{NUMBER AND DISTRIBUTION OF PLOTS AND SUBPLOTS}

How many sample plots are needed to solve a given problem involving treatment depends upon the conditions of the experiment and the degree of accuracy demanded in the results. The general tendency is to establish too few plots. Foresters have too frequently failed to realize the complexity of a silvicultural problem or to ask themselves how probable it is that the answer obtained from one pair of contrasted plots would agree very closely with the answer from 
another set of plots established, so far as they could judge, under the same conditions. Too often they have, in fact, made sweeping deductions regarding the effect of a single treatment in the absence of dependable evidence that the treatment had any significant effect.

Defects are inevitable in a comparison of treatments based on a single pair of plots. Uncontrolled factors inherent in climate, in soil conditions, in slope or other factors of site, in biological conditions, or in stand history frequently have a greater part in the apparent response to treatment than the controlled factors, or at least create differences that partially or entirely mask the differences due to the factors under control. The only remedy is to make enough replications to test the significance of the observed differences. There is safety in numbers.

Replication serves two purposes: it effects a high degree of precision by diminishing the standard error of the experimental comparisons, and it provides an estimate of error. Both of these are needed in any experiment. The former can be obtained by care in the conduct of the work, but the latter, essential to any reliable scientific study, can be obtained by no means other than replication. The latter purpose has often been overlooked, partly because so much emphasis was given the former.

In silvicultural research, satisfactory replications can sometimes be obtained by dividing large plots and treating the data from each division as if they came from a separate plot. One advantage of dividing plots is that it helps to detect unusual conditions existing on one part of a plot and not on others. The desirable size and number of divisions depend upon the uniformity of conditions on the plot as a whole and upon the conditions and purpose of the experiment. For example, a plot of one-tenth of an acre in dense reproduction might well be divided into 10 parts, while a plot of 100 acres in a mature and open pine stand might not be suited to division. The possibilities that lie in plot division have not been fully explored in silvicultural research. It must be remembered that division does not eliminate variables due to time.

Before plots are established the stand should be thoroughly examined for uniformity. Obviously, the more nearly conditions in the pairs of treated and control plots are alike before treatment, the fewer are the replications needed to obtain a result of a given degree of accuracy. The kinds of variation most frequently overlooked include differences in average diameter, density, diameter distribution, stem distribution, species composition, basal area, volume, site, and soil conditions (type, depth, texture, and drainage). Plots established one above another on a slope are unlikely to yield comparable data, because of differences in soil, site, or drainage entailed by such relative location. Plots on south slopes are usually unsuitable to be compared with plots on north slopes, because of differences in such factors as humidity, frost, snow accumulation and melt, and length of growing season.

Response to treatment may be profoundly affected if the treatment is given during abnormally dry or abnormally wet years, or at a time when weather conditions are at a peak of cyclic changes. 

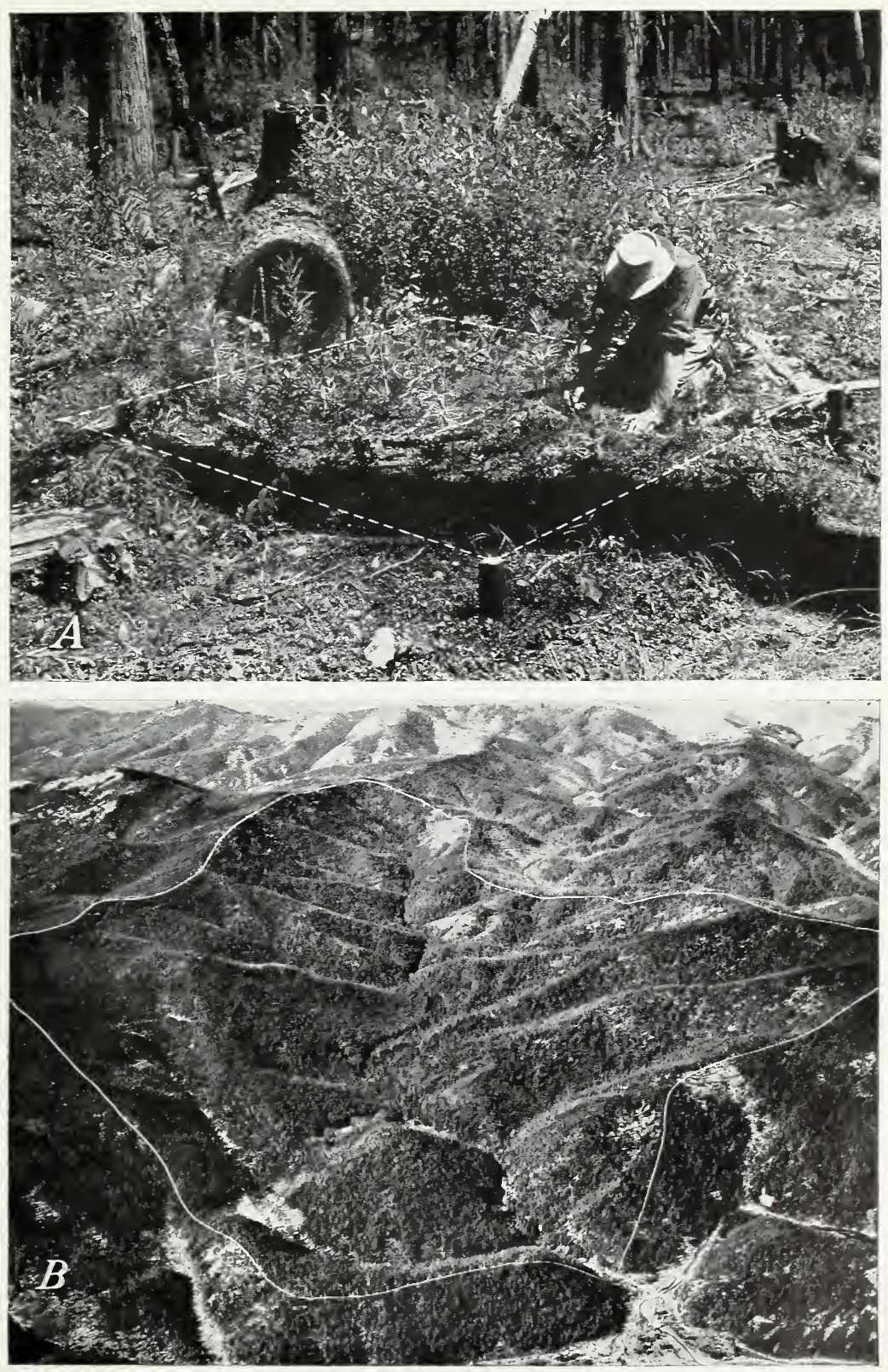

A. Quadrat used in studying details of forest reproduction on a cut-over area. The man holds one of the wire pins used to mark tree seedlings. The dotted line drawn on the photograph aids in locating exactly the boundary of the quadrat. B, Deception Creek Experimental Forest. Coeur d'Alene National Forest, Idako. A photograph on which the boundaries of an experimental area are outlined affords. valuable aid in relocating such an area or plot, as well as an indication of general conditions on it. 

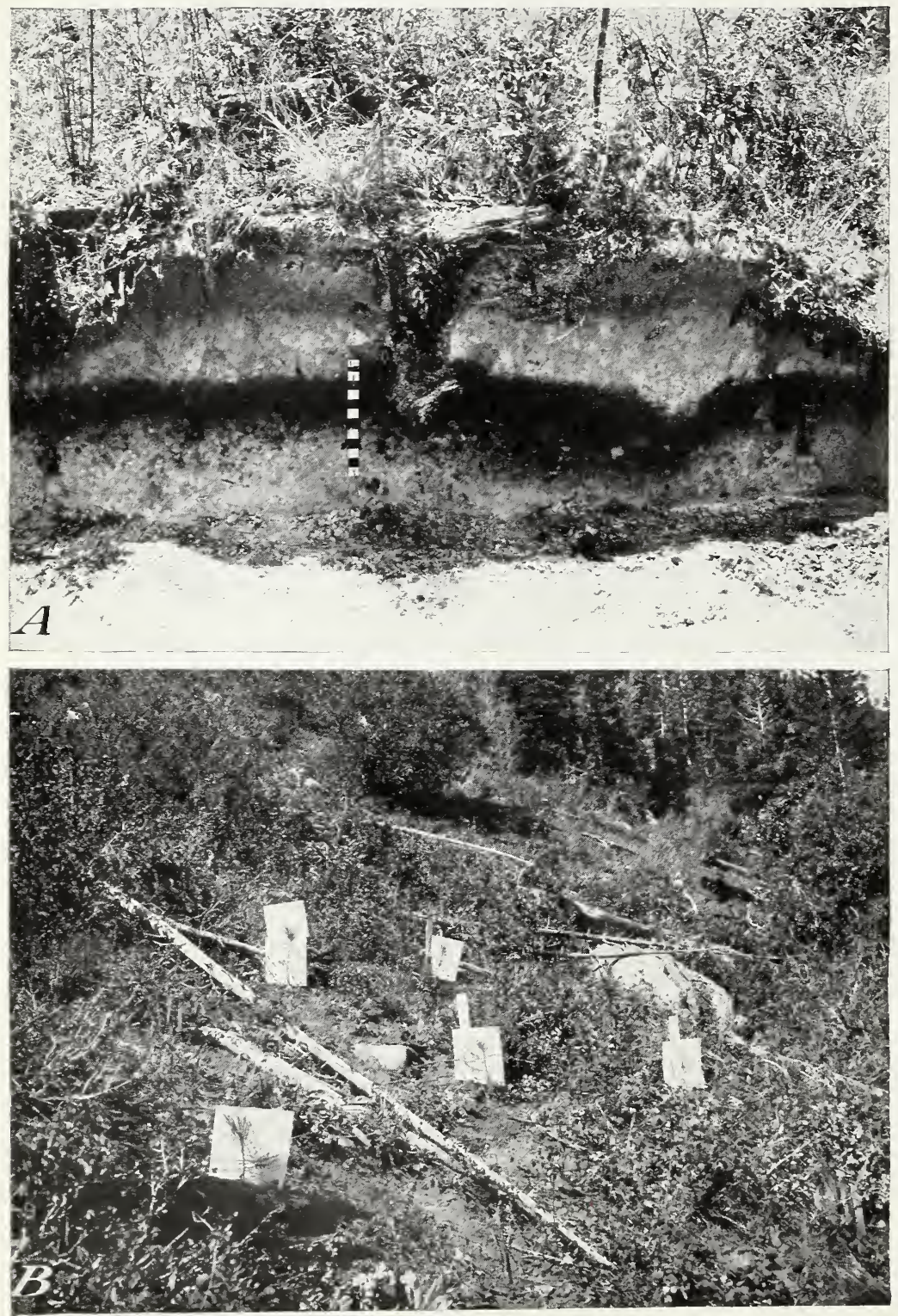

$A$, Soil profile illustrating the important influence of soil conditions on development of regetation. Here , Sold probation, has caused stunting of a longleaf pine taproot. Iethod of photographing seedlings. 
An experiment cannot be considered complete, therefore, until plots have been established, and measurements made, during a sufficient number of different years to show the significance of annual differences in weather.

Under some circumstances replications, while increasing the area required in a study, may fail to give any greater accuracy. In many field-crop investigations, this difficulty has been largely overcome by confining the comparisons from which both errors and estimates are derived to limited areas, through various plot arrangements. Such schemes, of which the Latin square (28) is typical, should be used more extensively in forest research. No one system of plot arrangement has yet been proved the best. In fact, in forest research so few studies of arrangement have been made that the field can be considered practically unexplored. A wide variety of possibilities are open. Only by practical tests largely paralleling those made in field-crop investigations can the best, most economical, and most practical method be determined.

For subplots laid out for the purpose of studying quantitatively or qualitatively the reproduction on a sample plot, the proper number and distribution can be determined statistically (68). Here the plot is the area being sampled.

\section{SIZE AND SHAPE OF PLOTS AND SUBPLOTS}

How small a sample plot will include enough trees to furnish averages of the required representative character depends on the density of the stand, variations as to diameter and height, the number of different crown classes, the number of different species, etc. The number of trees should be sufficient to give a reasonably reliable distribution curve for such factors as diameter and height. Since density changes with age, a plot area that is ample for a young stand may be much too small when the stand becomes older.

As a general rule, a plot should be of such size that at the end of the experiment it will contain at least 100 trees of the predominating age class. Under ordinary circumstances it should rarely be large enough to contain more than 1,000 such trees at the end of the experiment, if only because of the work involved. Where the small size of suitable homogeneous stands subject to uniform conditions makes it impossible to establish plots of the size recommended, smaller plots are permissible.

Where conditions permit, the area of each plot should be an even multiple or simple fraction of an acre. Simplicity of area conversion is an advantage throughout the computation and interpretation of plot data.

A rectangular subplot may be of any desired length. If data are recorded separately for even units of length, new subplot divisions can be decided upon in the office after the data are examined: Recommended units of length and width are the chain and the one-tenth chain.

Subplots in small reproduction that is to be studied intensively should be small enough so that a man standing outside a subplot can reach any part of it. A convenient unit is the milacre (10 by 
10 links, or one one-thousandth of an acre). If seedlings and other small vegetation are to be mapped in detail, it may be much more convenient to use a number of half-milacre subplots (10 by 5 links). The smaller size is particularly advantageous where frequent examinations are necessary, and is highly desirable on steep slopes.

In studying herbaceous vegetation, as in ecological investigations, quadrats 1 or 2 feet square may well be used.

Sample plots should be compact. The shorter the perimeter, the less the problems of border influence and line trees; and the chance of homogeneity is greater for compact plots. On the other hand, the danger of inadequate sampling is greater in the case of square plots than in that of strip or line plots; and under some conditions, as in very open stands on cut-over areas or in semiarid regions, long narrow strip plots are usually preferable.

In most cases the length of a plot should not be more than 2.5 or 3 times its width.

Whenever uniformity of conditions permits a choice as to shape, the preference should go to rectangular plots the sides of which are even units of measure-especially if the stand is to be treated. Such plots are readily surveyed, mapped, and divided, and their boundaries are easily marked and relocated.

Under some conditions irregularity in shape is unavoidable, as where the forest type to be sampled occupies only a very narrow belt such as the bottom of a canyon. In such cases the plots should have as few sides as possible; and reentrant angles, and any angles less than $60^{\circ}$, should be avoided. Where the boundaries of the type area are so irregular as to be extremely difficult to survey on the ground, it is advisable to lay out a rectangular plot overlapping the area and plot on the map the exact portion of the plot on which the type occurs, either by traverse or by strip surveys. This portion can then be planimetered and the tree data taken and recorded accordingly.

Circular plots are easy to lay out, and since the perimeter of a circle is smaller in proportion to area than that of any other figure they are subject to the least possible border influence. To mark a circular boundary accurately, however, requires much time, especially in young stands. On circular plots there is greater danger of inaccuracy in all the operations of plot establishment than on rectangular plots, and satisfactory division is impossible; in general, therefore, circular shape is not recommended for permanent sample plots.

It cannot be emphasized too strongly that a sample plot's size and shape, as such, are of much less consequence than its representative character.

The desirable size and shape of subplots, and the desirable number per acre or plot, can best be determined through a special statistical study of the forest type and of plot conditions. For this purpose, one or several areas representing stand conditions comparable to those that can be expected to exist on the plots following treatment should be divided into a number of small subplots that can be combined into units of any desired size. The standard errors derived from these combinations will indicate what size is most desirable for the quadrats $(32,33)$. 


\section{ISOLATION STRIPS}

In order that conditions may be the same at the edges of a plot as in its interior, an area surrounding the plot on all sides should receive the same treatment as the plot. This area is then called the isolation strip. In general the chief factors to be considered in thus isolating plots are light and soil moisture; in many regions, equal weight must be given to evaporation, wind, and temperature.

The isolation strip should be so wide that any treatment accorded the stand outside the strip will not affect the plot. In studies involving treatment of young stands, such as weeding, thinning, or pruning, it is desirable that the width of this strip at least equal the height to which the dominant trees on the plot may be expected to grow during the course of the experiment. In studies involving natural seeding, it may be necessary to make the isolation strip so wide that seed from trees outside cannot blow across it to the plot. (In many cases, particularly where light-seeded species are involved or in regions of strong winds, a requirement that plots used in studies of natural seeding be absolutely protected from outside seeding could not be met.)

Neighboring plots that are to be treated differently should be separated by a double isolation strip, each plot having its own fullwidth strip.

The outside boundary of the isolation strip should be marked so that treatment of the stand outside will not encroach upon the strip and so that any subsequent plot treatment may cover the whole of the strip. The markings should be distinct from those used on the plot boundary.

Often it is advantageous that an extra area surrounding both plot and isolation strip be treated uniformly with them. This makes it possible, without disturbing the plot or the isolation strip, to supplement plot data through detailed study of changes in wood structure and quality, form, etc., that have taken place in trees treated uniformly with those on the plot.

In some studies, such as those of fire damage or natural reproduction of light-seeded species, it is highly advantageous to use a large area in order to obtain natural conditions. Thus an area to be burned experimentally must be large enough to develop typical forest-fire conditions, and the area cut over must be sufficiently large to eliminate marginal effects.

\section{PLOT ESTABLISHMENT ${ }^{6}$}

\section{SELECTING THE STAND}

The stand selected for the establishment of permanent sample plots must be representative of those to which the results of the plot study are to be applied; and its location, etc., must be such that the plots will be readily accessible, both at the time of establishment and throughout the study period, and will be assured of protection from all disturbing influences throughout that period.

${ }^{6}$ Instruments, tools, etc.. needed in plot establishment and in other plot work are listed in the appendix (p. 72 ). 
The investigator should -make certain that the area on which it is proposed to work is the best available for the purpose of his experiment. To do this he must judge the area on the basis of a thorough knowledge of the region and may need also to make a careful reconnaissance, taking into account not only the stands' condition, stocking, history, and adequacy for the study proposed but also climatic, physiographic, and geologic features. ${ }^{7}$

"Readily accessible", as used here, implies reasonable nearness to good transportation facilities and to suitable headquarters. It is highly important to remember that stands easily accessible today may become relatively inaccessible tomorrow through abandonment of logging railroads, trails, or roads, or through changes in highway location. Conversely, on national forests and other areas where road, trail, stock-driveway, or railroad location plans are available, these should be consulted in order not to place plots in the way of new construction.

Accessibility saves time on each visit to the plots, eliminates a temptation to slight them, and enhances any demonstrational value they may have.

Not only must the stand selected be extensive enough to accommodate satisfactorily all the plots proposed, including the required control or check plots and the isolation strips, but preferably it should be extensive enough to make possible future expansion of the experiment.

Selection of the stand may be affected by requirements as to labor, supplies, water, markets, and exclusion of grazing animals, or by other conditions either existing or foreseen.

For sample plots on which long-time studies are to be undertaken, permanent tenure and continuous protection must be assured. Permanent plots that cannot be safeguarded for at least 10 years are of questionable value, and most permanent plots should be available for at least 20 year's' use. The expected period of use is governed largely by such considerations as the age of the stand and its rate of growth. Naturally it is shorter for rapid-growing stands than for others. While some plots yield valuable results within a few years, usually the value of the results increases with mounting rapidity as the years pass. Undoubtedly, many plots originally established for short periods will be maintained for longer periods because of their increased value.

So far as possible, plots should be established on forest areas set aside for experimental purposes. ${ }^{8}$ Experimental forests offer the greatest security for investigative work because they are removed from the control of any agency not immediately interested in the results, because the policy governing them is definitely fixed, and because they can be developed in accordance with research needs. Such areas also permit concentration of experimental work, with consequent reduction in travel time and increase in effectiveness. Again, they permit the collection of certain pertinent basic data, such as meteorological and phenological records, that could not be collected on scattered plots.

\footnotetext{
7 Toumex, J. W. Foundatioxs of silviculture. v. 3. Ann Arbor, Mich. 1926. [Mimeographed.]

8 For Forest Service policy regarding establishment of experimental forests. see appendis, p. 86 .
} 
In the absence of an available area definitely dedicated to research, plots should be established on public rather than privately owned forests. Public ownership provides stability of tenure and of management policies, and a degree of protection usually greater than that on private land. On privately owned lands economic influences operate to bring about rapid changes in ownership or policies. often in spite of the owner's wishes. Eren the best of leases expire, and cooperative agreements terminate, often at times when the value of the plots is at its maximum. Corporations are more likely to hold land under a continuing policy than individuals.

Even on a public forest, before selecting a stand for plot establishment it is necessary to give careful consideration to present and prospective modification or use of the area as in timber sales, recreation, or grazing, and to the possibility of the area's being removed from research use as by reservation for municipal watershed protection.

\section{AGREEMENTS WITH FOREST MANAGERS AND OWNERS}

Before sample-plot work is begun on a publicly owned forest other than an experimental forest, approval of any needed restrictions should be obtained from the supervisory officer in charge of the area. As soon as field work on the plots is completed, both the supervisory officer and the resident ranger, guard, or caretaker should be supplied with maps and data showing exactly the area to which restrictions apply. If possible, it should be arranged that the local supervisory officer risit the plots in company with one of the responsible research workers.

Then plots must be located on private land, full cooperation of the owner should be obtained in advance. The extent and location of the area involved should be shown on a map, and the owner's agreement to whatever restrictions must be placed on its use should be obtained in writing. A specimen form of agreement for this purpose is given in the appendix (p. 89).

\section{LOCATING PLOTS WITHIN THE STAND}

Plots should be located well within the selected stand, so that plot conditions may be truly representative and free of the influence of surroundings not typical of the stand. Particularly should they be so located as to be free of "border" influences such as exist along roads and at the edges of clearings, fields, or other openings in the stand. Highways have an especially marked influence upon soil drainage, upon crown development, upon the minor vegetation near the break in the canopy, and upon air morement. (See discussion of isolation strips, p. 11.)

Plot location should aim at uniformity as to geologic factors (rock outcrops, soil depth, and soil character), physiographic factors (slope, exposure, elevation, and drainage), history (as to fire, cutting, grazing, insects, diseases, wind), and stand factors (crown cover, density, stocking, age, species composition, and distribution of tree sizes), unless differences due to variation in these factors are to be studied; and in the latter case uniformity within the individual plots is desirable, in conjunction with divergence between 
them. Small openings in the stand such as often result from the action of wind. insects. diseases, or fire, from culling. and from other causes may be included if they are typical of the stand and site, except that they probably should not be included in yield plots.

Proper location of a plot within a stand calls for the exercise of good judgment and requires considerable preliminary work. In choosing a plot location the investigator should at all times guard against personal bias. When it has been determined by careful examination that the area meets the conditions of the experiment in a general way, a more detailed and thorough scrutiny is in order. This may involve a preliminary tally of diameters by species, to check composition and diameter distribution; the preparation of a heightdiameter curve, or several such curres in various portions of the stand, to check site; borings to determine age; a check of history, especially fire history: and a preliminary study of the soil ${ }^{9}$ as to its texture and depth (especially, the depth of the $\mathrm{A}$ and $\mathrm{B}$ horizons) and the character of the subsoil. An example of soil conditions haring an important influence on tree derelopment is shown in plate 2 .

The next step is to establish tentatively the boundaries of the plot or plots. This can be done by running twine along the proposed boundaries, taking care onl $y$ to keep the lines approximately straight. The plots so laid out are again examined to make sure that they are in general comparable. Often it is necessary to establish subplots and to analyze the data for these in order to be positive that the plots are homogeneous. that statistically no significant differences exist among them. and that thes are thoroughly comparable. Some shifting of lines may be necessary to eliminate a portion of a plot where the number of trees per unit is below the acceptable standard, to aroid a rock outcrop, or to get the plot arrangement that is the best possible from all points of riew.

Time spent in the preliminary surrey of a plot is well spent, if it assures due consideration of all the factors concerned.

\section{SURVEYING AND DEMARCATING PLOTS}

\section{SURVEY OF PLOT}

The accuracy of all data on an areal basis derived from a sample plot depends upon the accuracy with which the plot is surveyed. Converselr, the accuracy required in surveying plots depends upon the accuracy desired in the areal data to be obtained from study of the plots. On permanent plots additional need of accuracy arises from the fact that it may sometime be necessary to relocate a section of the boundary or even a corner.

Absolute accuracy in sample-plot work is of course out of the question, because biological phenomena incapable of absolute measurement are involved and because perfect sampling of the

\footnotetext{
9 A knowledge of soils and of methods of classifying soils is greatly needed in forest research in order to make sure that plot conditions are uniform. Through recent derelopments in the technic of soil analysis it has become possible to make an approximate check of soil characteristics with relatively little labor. The Bouyoucos hydrometer method (11) enables one to determine the main features of soil texture in about 15 minutes with relatirely simple laboratory equipment. Microchemical methods make possible rapid analysis of soils for important plant nutrients $(53, \tau 6)$. Classification of soils. according to percentage of sand. silt, clay, and various combinations of these, is easily effected by use of the Whitney diagram or some variation of it (17).
} 
areas to which the research findings are to be applied is impossible as regards either stand, sites, or topography. This fact, however, does not lessen the need of care in the survey or in any other feature of plot measurement.

The smaller the plot, the greater the need of accuracy in the survey.

In many studies an accuracy of about 1 in 500 will suffice. This may be expected when a staff compass and steel tape are used.

The usefulness of the compass has decided limitations where magnetic attraction is present, where slopes are steep, where stands are dense, or on plots haring more than four sides. The compass is subject. also, to considerable instrumental error.

When the compass is used with an angle mirror, the results are more precise if only $90^{\circ}$ angles are involved. In this case the compass is used not as a compass but merely as a convenient sighting instrument. In surveying plots of less than half an acre, the angle mirror can be used alone $(65)$.

In capable hands the transit is a highly satisfactory instrument for surveying sample plots, although it is rather expensive and somewhat cumbersome and its use consumes much time. By the use of a transit, survey accuracy can be increased to 1 in 1,000. As an added check, the diagonals of rectangular plots may be measured..$^{10}$ Directions for surveying such as are given in various manuals and texts should be carefully followed.

Steel tapes should be considered standard for linear measurements. A tape graduated into links instead of feet is conrenient for laying out plots containing even acres or simple fractions of an acre. A surveyor's link chain has certain advantages over a tape for laying out small quadrats, because it can be bent around corners and can be fastened at convenient intervals with chaining pins. When the links become worn, howerer, such a chain is inaccurate. When horizontal distances are to be measured on a slope, a "topographic" tape, used with an Abney level fitted with a corresponding topographic limb, sares time and gives measurements as precise as those obtainable with compass and chain $(66)$. The survey notes should show the Abney readings on all lines.

On steep, brushy slopes, stadia surreys consume much less time and are often more accurate than direct measurement.

Instruments used in plot surveys are shown in plate 3.

Sample-plot areas should be measured horizontally and the data expressed in terms of horizontal area. As slope apparently influences growth, ${ }^{11}$ it is important that degree of slope be indicated.

In many instances preliminary lines can be run accurately with the aid of a reflecting surface such as an aluminum notebook holder or the bottom of a pie pan. If the reflected beam of light is flashed up and down along the line, the head chainman can sight back and thus keep accurately on line. To what distance such a beam can be used depends upon brightness of sky, time of day, direction of line.

$10 \mathrm{~A}$ plot-survey method in which use is made of plane table, alidade, and tape is described by Thrupp ( 74 .

11 McArdle and Meyer (4\%), taking a slope of from 20 to 30 percent as normal in Douglas fir stands, found the yield on level ground 5 percent less than normal, that on a 30 - to 50-percent slope 5 percent greater than normal, and that on an 80 -percent slope 10 percent less than normal. The relationship of slope to growth needs much further 
and density of undergrowth. Under ordinary circumstances it serves to signal through fairly heavy brush for about 200 feet.

In forests containing much deciduous growth, the survey can be made more easily after the leaves have fallen.

Cutting of brush and undergrowth along survey lines should be held to the minimum, and no other disturbance not made necessary by the conditions of the experiment should be tolerated.

Trees designating plot boundaries may be marked temporarily by scratching blazes on the bark or by striking the trunk with a sack of loosely woven material, such as a cotton sock, containing powdered paint or chalk. In many cases it is preferable to outline the boundaries temporarily with string. For this purpose a stout cord or carpet twine serves satisfactorily. Such cord may be used later, also, in dividing the plot.

Blazing, scarring, or other defacing of trees in any stand should be avoided unless it has a valid and clearly understood purpose; promiscuous blazing in connection with research projects is particularly reprehensible.

Trees on the line should be counted as within the plot if more than half the diameter at the stump is inside the line. Where actual "line trees", that is, trees the stems of which are at the time of plot establishment exactly bisected by the line, are encountered, alternate individuals should be considered "in " and "out", with the invariable exception that line trees leaning into the plot should be considered "in" and line trees leaning out of the plot should be considered "out." Trees on the line should be so specifically and clearly designated at the time of the survey as to inclusion or exclusion that in future years no question will arise in this regard.

The survey of a plot boundary should not be considered complete until the error of closure has been determined and found to be within the error previously decided upon as allowable. If the error of closure is too large the survey must be repeated.

Full and complete notes should be kept of all surveying in connection with plot establishment. These should record the date, the crew personnel, the kind of instruments used, the error of closure, the weather, and, if a compass is used, the magnetic declination.

\section{DIVIDING A PLOT}

Dividing a plot into sections, as has been mentioned, permits replication, makes it possible to arrange tree numbers systematically, and facilitates the mapping of stems. Furthermore, division of a large plot into a series of subplots in checkerboard fashion makes it possible to salvage a portion of the plot if some accident fatally disturbs stand conditions on another portion.

Any final plot division should be postponed until the survey of the plot has been made to check. Ordinarily, however, while plot boundaries are being established division stakes or flags may be temporarily set along them. If the plot is rectangular and not too large, such stakes should be set at regular intervals all around the boundary and corresponding stakes on opposite sides of the plot then connected with strings, which will divide the plot into rectangular 

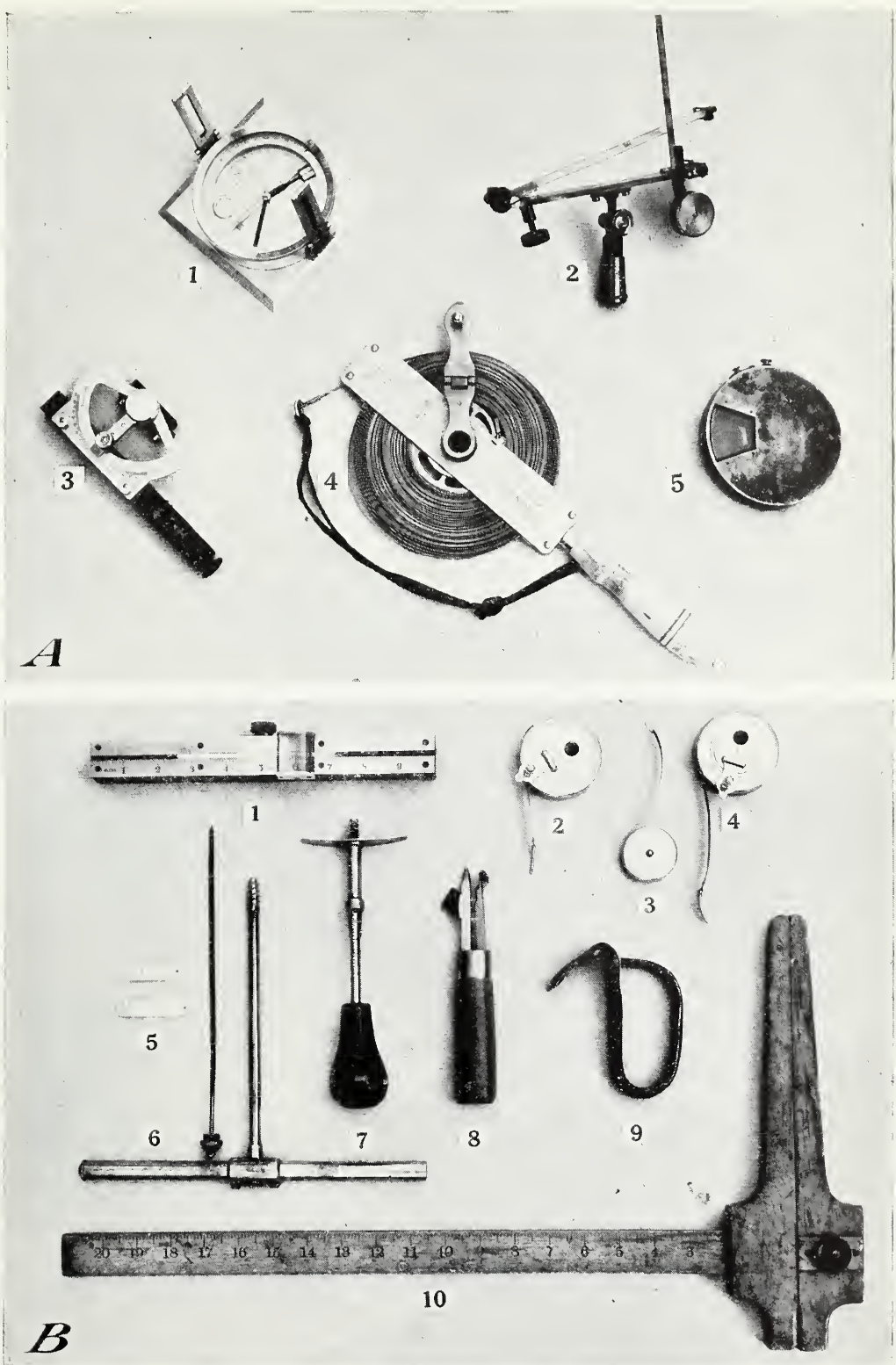

INSTRUMENTS USED IN SAMPLE-PLOT WORK.

$A$, Surveying and height-measuring instruments: 1, Standard United States Forest Service compass; 2. Klaussner hypsometer; 3 , Abney level; 4 , steel tape and reel (a buckskin loop on the head end of the tape is easier to manage under forest conditions than the handle commonly used by surveyors); 5 , standard United States Forest Service hypsometer. $B$, Other common instruments: 1, Incrementcore measuring device (a core is shown in the slot beneath the magnifying glass). 2,3,4, Diameter tapes: 2 has a steel pin to hold the end in place, 3 a loop, and 4 a hook. 5 , Tags made by embossing numbers on aluminum tape, nail hole at right end. 6, Inerement borer with dagger extractor. 7, Swedish bark punch. 8, Timber seribe. 9, Bark blazer or serateher. 10, Wooden calipers, United States Forest Service type. 

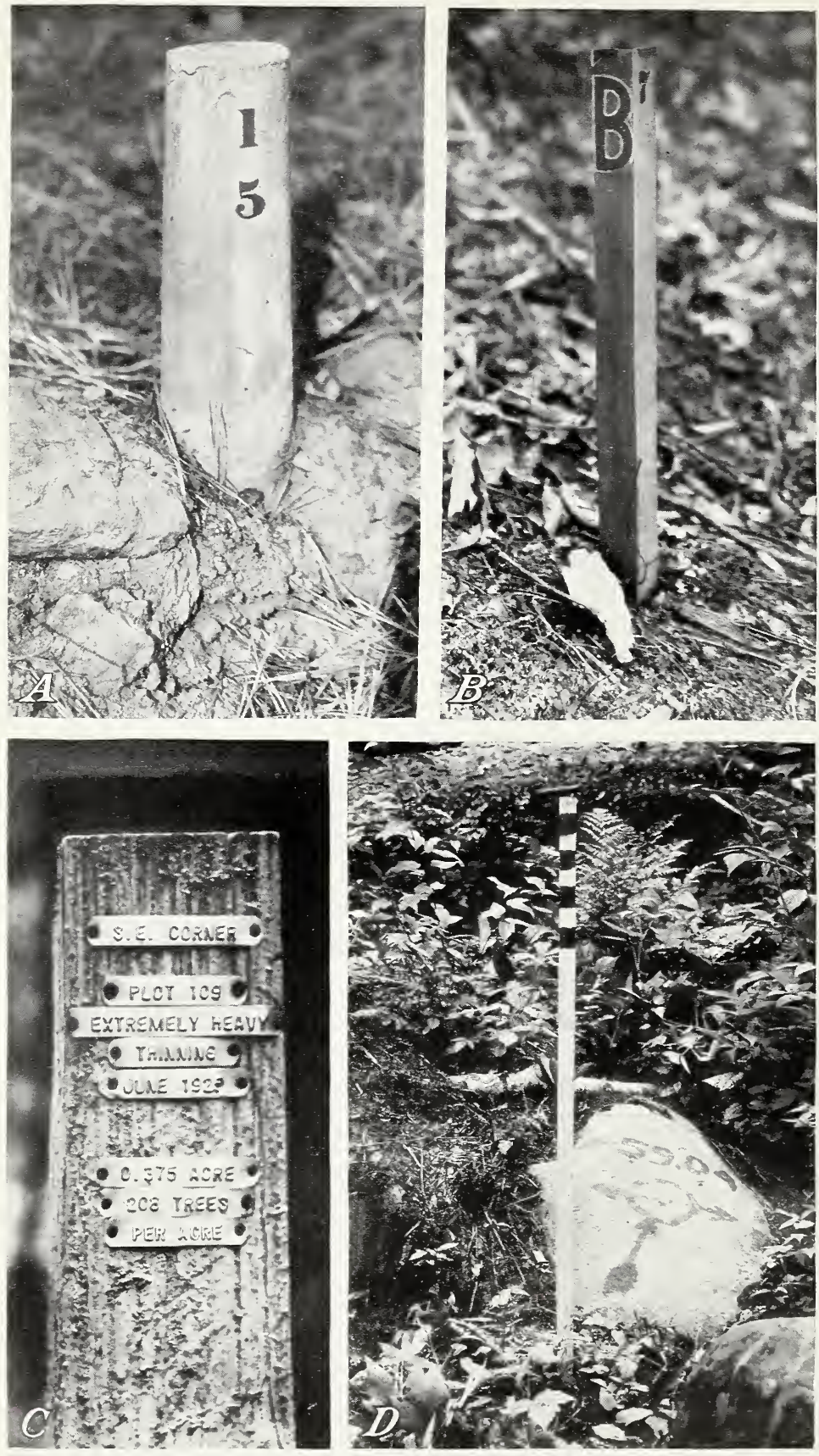

MARKERS FOR SAMPLE-PLOT CORNERS.

$A$, Concrete post (for specifications, see p.18) for major corners. $B$, Angle iron (here indicating plot ;, corner B). $C$, Wooden post carrying aluminum-tape tags on which plot data are embossed. $D$, Plot corner mark etched on boulder, with painted description and with striped 1-inch pipe as witness. 
sections. These stakes should be made permanent markers. Intermediate lines can be established with the angle mirror, compass, or transit.

The size of plot divisions depends chiefly upon the character of the data to be gathered. The larger the trees on the plot and the smaller the plot, the less desirable it is to make small divisions. Small divisions made in young stands can later be combined.

Mapping and area calculations are simplified if the sides of the plot dirisions are in some readily usable unit such as 10 links, 1/2 chain, 10 feet, or 25 feet. On plots the sides of which are not multiples of any of these lengths, in order not to have a tier of odd-sized sections left along 1 or 2 sides of the plot (an arrangement in which, however, there is no harm) it may be thought preferable to make the sides of the sections proportional to the sides of the plot.

\section{DEMARCATING BOUNDARY AND CORNERS}

The plot boundary, and all plot corners, ends of line plots or transects, and other stations that will be used again-such as photographic, litter, or soil stations-must be permanently and conspicmously marked so that they can be relocated quickly and surely.

The boundary line may suitably be marked with blazes or paint spots placed to face the interior of the plot. Such marking should be done systematically. Trees on the line may be ringed or marked with vertical streaks of paint placed on opposite sides of the tree through which the line passes; trees outside the plot but near the line may bear streaks at a slight angle with the vertical, placed to face the line; trees farther from the line, streaks at a greater angle with the vertical; and trees at more than arm's length from the line, horizontal streaks.

Promiscuous marking of trees, either by painting or by blazing. should be carefully aroided. If the trees on the plot are numbered and properly marked, in later years there will be no question of which are in and which are out, except in the case of trees that later grow into the diameter class recorded.

In Europe, plot boundaries are often indicated exactly by a shallow ditch extending along the boundary either throughout its length or for a distance of from 20 to 50 feet from each corner. These ditches remain clearly in evidence for many years. They should not be used, however, where they will affect drainage or on slopes where they may cause abnormal erosion to develop.

Painting in connection with sample-plot work should be done with a good grade of zinc or lead paint, of conspicuous color, known to be weather-resistant. The tannin and resin of the bark of various species react differently to different paints; but so little is known on the subject that no further specific recommendations can be made. ${ }^{12}$ Certain automobile and wagon enamels weather well, retain their bright colors, and tend to bind the bark to which they are applied. Bright yellow, bright orange, sky blue, and white are all conspicuous in the woods. White is not recommended where sample-

\footnotetext{
12 Reports on experience with different brands of paint in sample-plot marking will be welcomed by the Division of Silvics, Forest Service, Washington, D.C.

$87471^{\circ}-35-2$
} 
plot work is to be done in snow. Aluminum paint promises to give satisfaction on trees having a dark bark.

Posts of durable wood, concrete, stone, iron pipe, reinforcing steel, or angle iron may be used to mark the permanent stations on sample plots. They should be so firmly set in the ground that frost cannot heave them. Lengths of angle iron, since they nest together, can be packed more easily than round pipe. Angle iron used alone sometimes is badly affected by frost heaving. To avoid this, a small plate 6 or 8 inches wide may be riveted or otherwise fastened to one side of the angle bar close to the lower end. When this plate is driven into the soil it usually holds firmly. If one plate is inadequate, a second plate should be fastened on the other angle. Reinforcing steel cut to proper length is especially useful for subplot corners. In loose soils an iron post can be anchored more firmly if the end to be set in the ground is bent into an $L$ or a $J$, or perforated and fitted with an iron crossbar. To be conspicuous. posts should overtop ordinary weeds and grass and should be painted a bright color. Wooden markers should be protected from fire by stones or dirt piled at the base.

Specifications for a concrete post suitable for use as a sampleplot marker are as follows:

Use 1 part portland cement, 2 parts clean sharp sand, and 3 parts clean gravel or crushed rock that will pass a $3 / 4$-inch screen. Only so much water should be used that the mortar will completely coat the coarser materials, that all the particles of the aggregates will adhere, and that, when the concrete is tamped, the water will just flush to the surface without quaking. Concrete should be thoroughly mixed (preferably for $1 \frac{1}{2}$ minutes in a concrete mixer) and tamped in form. Inside of form should be smeared with oil or grease (old engine oil is suitable) before concrete is poured. For reinforcing, 1/2-inch deformed reinforcing rod 23 inches long should be used. Post should be cast upside down, by placing cap, tied to reinforcing rod, face down in form and pouring concrete into larger end of form. Outside surface of post should be smooth. Post should be allowèd to remain in form 24 hours, and after remoral should be kept moist for 1 week while curing. The form should be thoroughly cleaned after each casting.

A post made according to these specifications is shown in plate 4 and figure 1.

If a corner falls upon rock and it is impracticable to choose another location for the line, the corner point should be scratched or chiseled deeply in the stone and suitable reference or witness markers established.

Several different methods of marking plot corners are illustrated in plate 4.

Plot corners should be marked with the plot and corner numbers. This inscription should preferably be painted on the corner post. It may be stamped on a tag and wired to the post. On a wooden post it may be scribed, carved, or outlined with nails, and the directions of adjacent boundary lines may be indicated by a cross on the top. One corner of each subplot should bear the subplot number.

The markers for each class of station should be distinctive. Those for plot corners should be the most prominent. Other stations may be denoted with smaller markers, each series of which is differentiated from the others by the use of different-colored paint or different symbols. Confusion among the various types of markers can be avoided by properly locating and indicating them on the plot map. 
Although the discussion in this section applies primarily to permanent plots, the repeated measurements or examination of semipermanent and temporary plots and of strip-cruise lines are often so valuable that all such plots and lines should always be marked with durable posts or in some other permanent way. Bark blazes made with a hatchet or bark scratcher along the boundaries of temporary plots as a means of exact relocation require

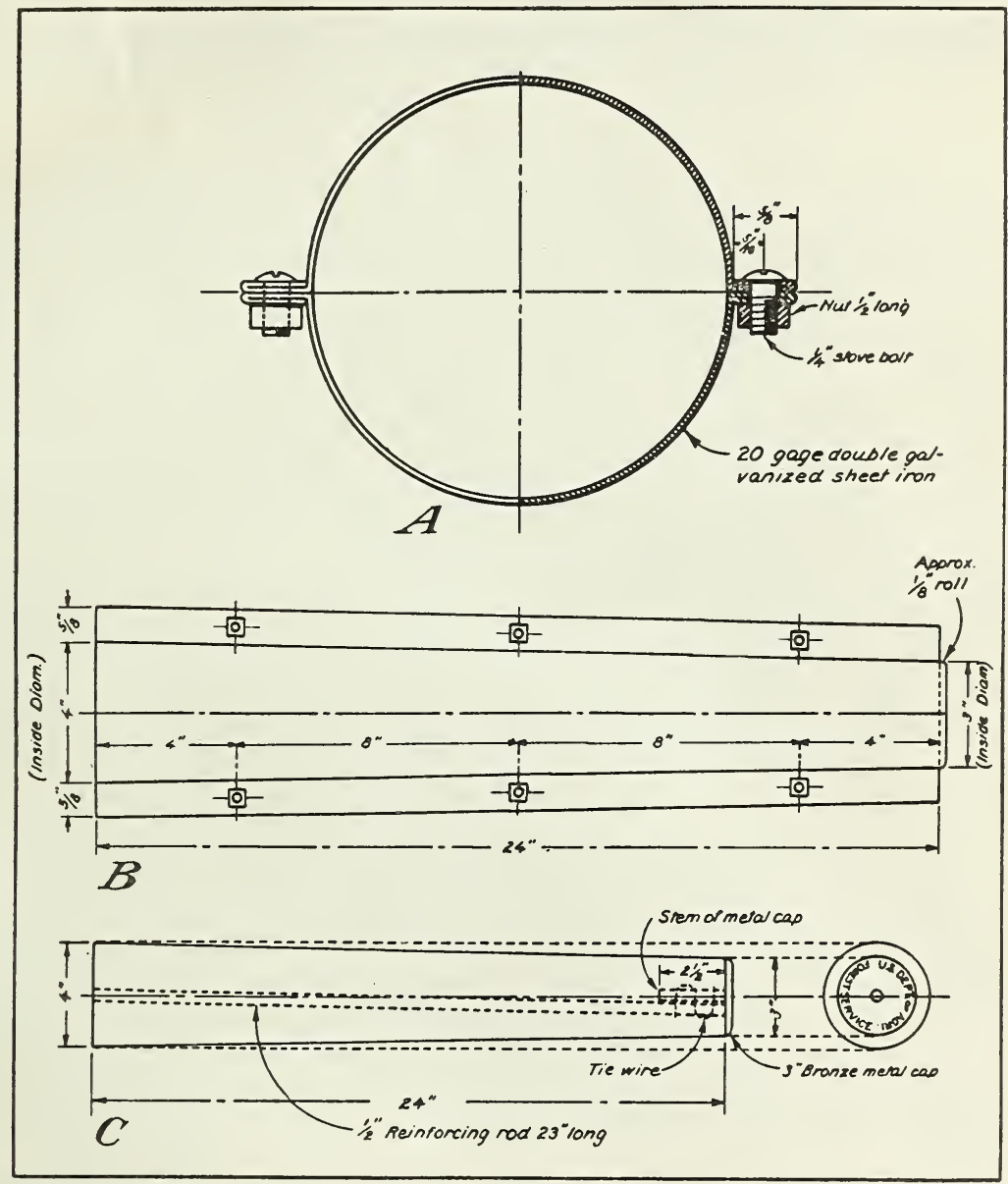

Figure 1.-Construction of concrete post: $A$, top view ; $B$, elevation; $C$, completed post.

little extra time and last for many years. At least one corner, or the center, of each temporary plot should be permanently marked, and at least the starting and ending points of strip-cruise lines.

\section{SURVEY OF SUBPLOTS}

Subplots (or quadrats) should be surveyed at least as accurately as plots. They should never be laid out with a compass. A rigid frame should be used to lay them out, or their diagonals should be checked. 
Subplots should be laid out on the slope rather than horizontally, if they are to be mapped. This eliminates the bothersome necessity of allowing for slope in measuring the coordinates of each tree, and the data can be reduced to a horizontal-area basis by the use of a simple converting factor. Furthermore, the vegetation on subplots can be mapped more easily if measurements are taken along the slope. For subplots thus laid out slope must be carefully recorded, in order to facilitate conversion to an acre basis.

The location of all subplots irregularly placed should be referenced to plot-boundary stations or to regularly placed subplots.

\section{PLOT CORNER TIE-INS AND WITNESSES}

Each plot corner should be tied in by bearing and distance to 1 or 2 witness trees or, if trees suitable for this use are lacking, to witness stakes or large rocks set for the purpose. Numbered trees within the plot are excellent witnesses, if they are to remain in the stand throughout the experiment. If stakes or other artificial markers must be used as witness points, they may be placed one on each side of the corner in such a way that they and the corner form a straight line. Another method is to place the witness markers on the plot boundaries about 20 feet each way from the corner of the plot. In very young stands, shallow ditches extending 3 or 4 feet from the corner along adjacent sides of the plot may be used to indicate the corner's position.

Blazes on witness trees should face the plot corner. If paint is used to mark witness trees, double bands should be painted around the tree at about eye height, with a vertical stripe crossing these on the side of the tree facing the corner. Small enameled signs bearing the name of the agency responsible for the plot and a blank space for painting in the plot number may be tacked on witness trees.

\section{NUMBERING PLOTS, SUBPLOTS, AND PLOT SECTIONS}

Where a considerable number of plots are involved, some scheme for designating each individual plot should be worked out in advance and carefully followed. Generally speaking, all plots in a given locality should be numbered consecutively as established, regardless of differences of purpose. Where several parties from one research agency are at work in the same locality at the same time, it may be necessary to use before each plot number a letter designating the party. In order to avoid later confusion, the number of an abandoned plot should not be given to a new plot in the same locality.

Each group of consecutively numbered plots should be called by some appropriate and distinctive name, such as that of the State, the forest, or the drainage. Each plot should be designated by this name plus the plot number, e.g., Virginia 8, Shasta 5, or Pinto Creek 13. County names, because of duplication between States, often would fail to distinguish the plot groups of an interstate research organization. ${ }^{13}$

13 If the plots established by an interstate organization are numbered serialiy in each of the States in its territory, the number of the latest plot established in a State is an index of the quantity of sample-plot work under way in that State. This plan is not feasible if the agency has several parties at work establisbing plots at the same time. 
The subplots on each plot should be numbered in a single series.

Several schemes are used for numbering plot sections. By one, the rows of sections are numbered across the plot from left to right, and the tiers of sections are lettered accordingly. Each unit is then distinguished by a letter and a number, as B-3. By another scheme the units are numbered consecutively back and forth across the plot like the sections in a township. The coordinate scheme has many more advantages than has the consecutive-numbering plan.

If plot data are to be put on punch cards. locality names should be coded and an entirely numerical scheme should be used to designate subplots and plot sections.

\section{LOCATION SURVEY}

Each sample plot or group of sample plots should be referenced to some permanent and readily definable object or point. The survey traverse should begin at the point selected as a tie and, whenever possible, should end at the "initial" corner of the plot or plot series. Objects such as Land Office survey corners, bench marks. railroad switches, bridges, and road or trail intersections make excellent reference points for plots not within experimental forests. Objects that can readily be moved, such as fence posts, loggingrailroad spurs, or posts set along highways, are much less desirable.

As an aid in relocating plots, distinctive markers calling attention to the plots should be established along the nearest road or trail. Small tin or cloth signs bearing appropriate wording and tacked on trees near the road or trail are often very helpful in showing the way to the plots and as a means of relocating the traverse line. A number of research agencies are now using special tin signs about 6 inches square for this purpose. These signs are especially helpful if they give the plot designation and the distance to the plot. Some agencies use signs along roads and trails not only to show where the plots are located but to inform the public as to the purpose of the plots and the conditions illustrated by them.

Photographs are helpful in showing the location of a plot or series of plots, as on a side hill or in relation to some outstanding topographic feature. This value is illustrated by the aerial photograph of the Deception Creek Experimental Forest, Coeur d'Alene National Forest, Idaho, that appears as plate 1, B. A series of photographs centering along the line of the plot-location survey not infrequently aids in relocating lines and finding plots without instruments, especially if trees along the line bear distinctive marking, either painting or blazing.

A "motor log " from the post office or some other unmistakable point in the nearest town to the place where the cars of visitors to the plots are to be parked is very useful. Distances should be read from a speedometer and recorded to the nearest one-tenth mile. The log should be complete enough to be followed easily by a person unfamiliar with the locality.

A location survey for temporary plots may not be necessary, but is helpful if the plots are reexamined. It need not be so accurate as that for permanent plots. 


\section{PLOT MAPS}

At least two general maps are needed. The first should be a sketch map showing the general location of the plot or series of plots and the tie-in trarerse. It should show the plot in relation to nearby roads, camp sites, streams, etc., and should be accompanied by clear and definite instructions for reaching the plot from a nearby town or from some other specific and generally known point. A highway and road log map showing the way from the nearest town is often helpful. For plots on an experimental forest, in some cases it will be unnecssary to prepare a special map of this character because all plots will be located on a map of the area.

The second map should show the position and, by appropriate symbol, the designation of all corners and permanent stakes, the position and character of each subplot, and the bearing and distance of each boundary line. Great care should be taken to make station designations on the map correspond exactly with those on the plot. The scale of the map and the area of the plot or plots should invariably be shown. In some cases it is well to indicate the position of each tree.

General plot maps are more convenient for use if north is toward the top of the page and all letters and figures read from one direction, preferably, the left. The maps should be of letter size ( 8 by $101 / 2$ inches) or, if that is impractical, of double letter size or of Atlas size (18 by 21 inches).

For many plots. one or sereral additional maps will be needed. Some will gire such details as the location of subplots, camera points, skid trails, slash piles, old logs, windfalls, and rock outcrops. In some ecological studies it is desirable to plot the location of patches of spreading plants such as honersuckle, squaw carpet, chaparral species, and bunch grasses. The purpose of the study largely determines what details should be shown, and how far it is necessary to show changes in plot appearance between one measurement and another.

Srmbols used in sample-plot mapping are shown in the appendix (p. 76$)$.

On detailed plot maps it is not essential to hare the north side of the plot at the top of the map; convenience in field work should gotern. Thus in many instances in which the plot is located on a slope. for greatest convenience in sketching, the mapper should face downhill. This makes the lower plot boundary parallel the top of the page.

On all maps north should be indicated br an arrow, and the plot corner numbers should be giren. The combination lessens the likelihood of confusion and error in either field or office work.

In mapping as in all other plot work, a high degree of accuracy is essential.

All maps should be dated and initialed.

\section{INDIVIDUAL TREE CONTROL}

\section{NUMBERING TREES AND MARKING THE MEASUREMENT POINT}

A control of indiridual tree measurements on a plot may be needed as a means of prerenting duplicate measurements. In per- 
manent plot work it is necessary as a means of studying the development of individual trees or classes of trees. ${ }^{14}$

If only a control of stand data, i.e., number of trees and basal area, is desired, chalk marks, bark scratches, or light blazes made on each live tree as it is measured will suffice. Powdered chalk and carpenter's chalk are both much more satisfactory for use on roughbarked trees than keel chalk or crayon. Light bark scratches and blazes can be made quickly with any one of several types of bark scratchers now on the market, such as that shown in plate 3. The most satisfactory method of making individual trees permanently identifiable is to give each an individual number. This is done usually by attaching a numbered metal tag to the tree or by painting a number on the bole. Several methods are shown in plate 5 . Each of these methods of identifying the tree has marked advantages and disadvantages. In some cases local conditions make one method decidedly superior to the other, in other cases the choice is entirely arbitrary.

Under some circumstances, such as in method-of-cutting studies, the identification of a tree cannot be left wholly to stem markings of any kind. Logging may so damage the markings on the trees that they cannot be restored with certainty. On plots located in parks and on other recreational areas, markings may be banned for esthetic reasons. In some situations, markings on trees provoke curiosity to such an extent that they are likely to be destroyed. In such conditions the trees should be identified by means of a stem. map (p. 50), either with or without individual tree markings.

In order that mortality may be correctly recorded, trees dead at the time of piot establishment should be cut down or heavily blazed so that at the next measurement there can be no doubt as to which trees have died during the interval.

\section{TAGS VERSUS PAINTED NUMBERS}

Tags are easily and quickly applied; they can be used on rough and on smooth-barked trees with equal facility, and ordinarily do not need renewal during the life of the experiment. On the other hand, nails driven into trees to hold tags may cause swellings that make diameter measurements inaccurate, or may cause splits several feet long. Tags can easily be removed by trespassers, and may be knocked off by falling trees or branches; they sometimes corrode so that the numbers become illegible (52); and they may be grown over by the trees and buried in the wood. On fire plots, tags are likely to be unsatisfactory because of melting. Further, if a tagged tree is eventually felled and sent to the mill, embedded nails may ruin the saw.

Painted numbers have the following advantages: They do not injure the trees in any way and can be read quickly at a distance; they cannot easily be removed or changed; no time is lost in preparing them, as in punching out tags; and their use permits numbering the trees independently of any series of numbers on ready-stamped

\footnotetext{
14 The discussion in this section relates primarily to trees in the 4-inch and larger diameter classes, although in some studies trees even of the 1-inch diameter class may be individually measured and recorded. Usually trees in the sapling stage or smaller are classed as reproduction (p. 48).
} 
tags. The objections to painting are that it takes longer to paint numbers than to place tags, especially on small trees; chemical compounds contained in the bark of certain tree species cause the paint to fade quickly, with the result that the numbers have to be repainted; the bark on some species scales freely; cracks in the bark, caused by growth, make numbers difficult to read if not often renewed; the smoothing of rough bark to receive the painted numbers sometimes affects the growth of the tree; and painted numbers may be effaced by fires.

\section{TAGGING}

The kind and size of tag to be used in marking sample-plot trees are largely matters of personal preference. Zinc, copper, brass, aluminum, iron, and tin tags have been used. Of these metals iron and tin are the least durable out-of-doors. Aluminum is lightest in weight. Small painted galvanized-iron or wooden panels have been used $(\mathrm{pl} .5, D)$.

Under conditions of fairly high atmospheric moisture, and especially in regions in which the atmosphere contains industrial gases, aluminum and zinc tags attached to trees by copper wire or nails are rapidly corroded by electrolytic action. There should be recognition of this phenomenon in the choice of tag and wire or nail material.

Tags may be bought already numbered in series, numbers may be stamped with hand dies on tags of soft metal like copper or zinc, or tags of aluminum ribbon may be numbered on an embossing machine. Figures one-half to three-fourths of an inch high on tags $1 \frac{1}{2}$ inches in diameter are easy to read, but the tags are bulky and are so conspicuous that they are likely to be stolen. Figures much less than one-fourth of an inch high, on the other hand, are hard to read.

Perhaps the greatest satisfaction is given by tags punched out of aluminum ribbon on an embossing machine. Such tags, shown in plates 3,4 , and $6, B$, can be made up as needed, and are light and easy to handle. The ribbon is thin and likely to tear, however, and in a hot forest fire may melt. Tags of fairly heavy aluminum ribbon three-fourths of an inch wide are the most satisfactory for use on large trees. For use on small trees and on reproduction, $1 / 2$-inch ribbon is usually adequate.

Durable nails should be used to affix tags to trees. Copper nails, brass escutcheon pins, or galvanized nails may be used. Copper nails when embedded in a tree are less injurious to saws than nails of other metals. Size depends to some extent on the size and growth rate of the trees. Galvanized wire nails $2 \frac{1}{2}$ to $31 / 2$ inches long, with shanks that slip easily through the holes in the tags and with heads large enough to hold the tags, are satisfactory in most cases. In species with such hard wood as hickory or white oak, difficulty is experienced with any type of nail.

Tags are usually hung at breast height.

The point of the nail should not be driven deeply into the wood. The shank should protrude sufficiently to allow for radial growth up to the time of the next remeasurement, and at that time it should be pulled out so that it again protrudes. On trees with very thick bark the nail need not be driven to the cambium, in which case it will not be grown over at all. In some species with moderately 

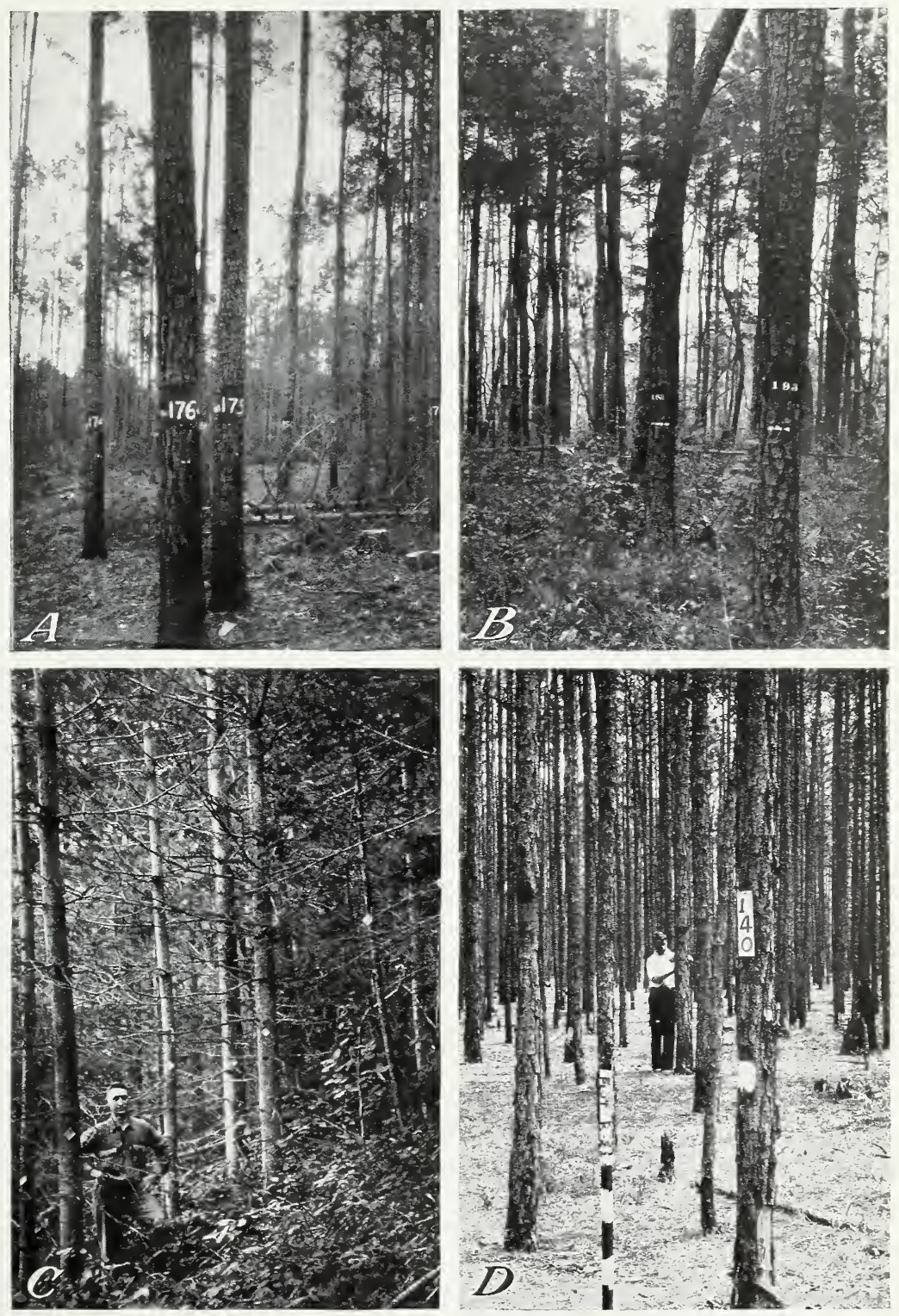

Methods of Numbering TRees on Permanent SAMple Plots.

$A$, Freehand numbers. $B$, Stenciled numbers. $C$, square tags, of galvanized iron, hand stamped. $D$, Panel tags. The breast-height point is marked in $A$ by a painted dot and in $B$ by a painted line, and in $C$ and $D$ is indicated by the position of the nail supporting the tag. 

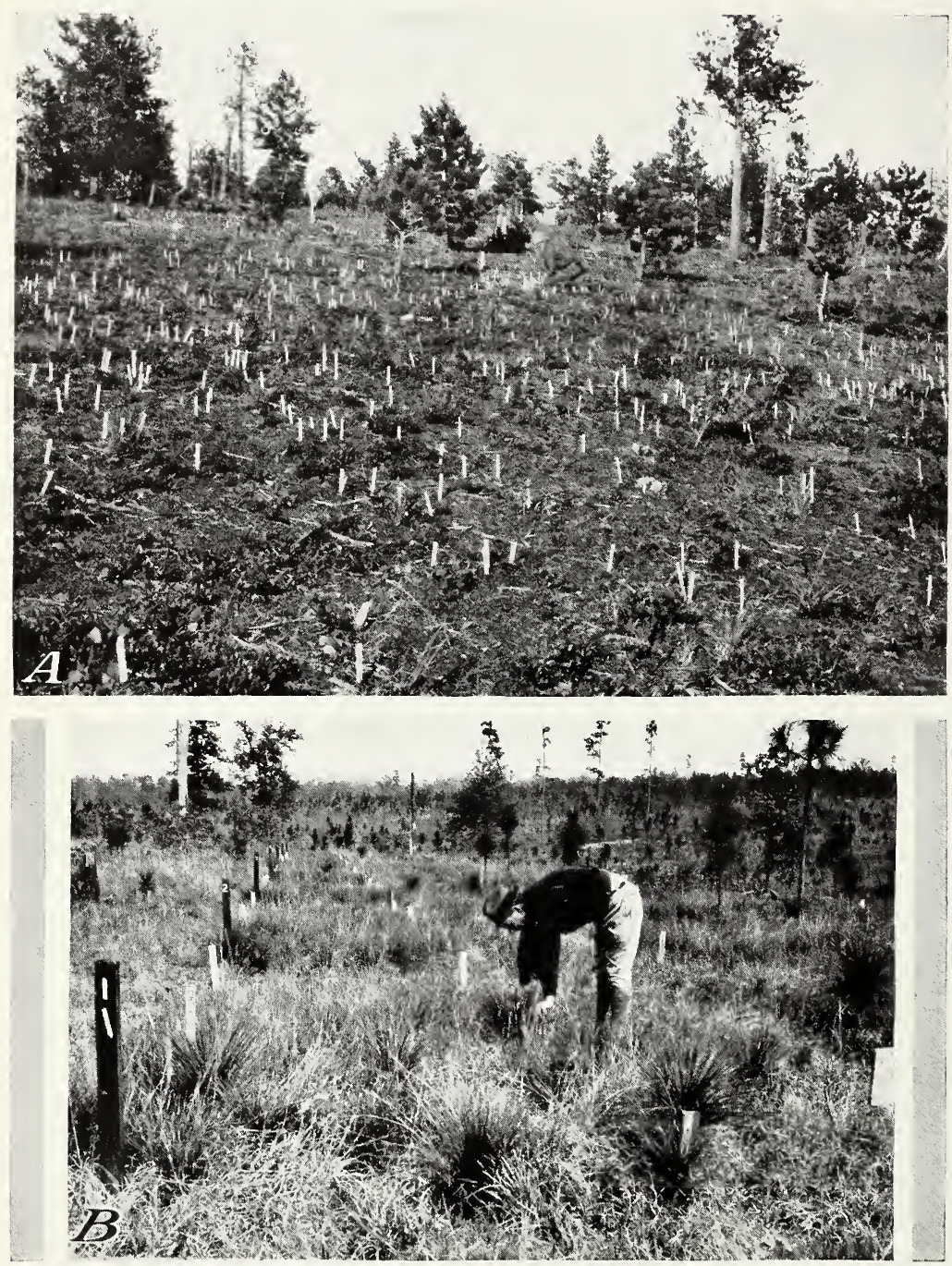

$A$, Seedlings, on a subplot, marked by small plant stakes. Numbers or records of the individual plants may be written on such stakes. $B$, Well-marked transect divided into quadrats. Corners are numbered, and the initial corner, at left, carries an aluminum-tape tag giving a few data on the plot series. A sign at extreme right describes the plot. 
thick bark the nail will be held tightly but not overgrown if its point barely penetrates the cambium. The nail should be driven in such a way that the head is very slightly lower than the point. The tag thus held rests at the head of the nail by reason of gravity, and is not so likely to be grown over or coated with pitch.

Tags made from metal tapes can be read in the field more quickly and with fewer errors if nailed at the left of the number, only one nail being used on each tag.

When a plot is abandoned, all nails and tags should be removed.

\section{PAINTING NUMBERS}

Numbers painted on trees should be placed a foot above breast height if the trees are not to be cut, and below stump height if the trees are to be cut. 'The figures should be large enough to be easily legible. In general, large figures are less subject than small ones to distortion by the splitting of bark that results from rapid growth. On rough-barked trees the place for the figures should be smoothed off with a draw knife or a stiff wire brush. In this operation, which is illustrated in plate $7, A$, the cambium should not be exposed and the bark should not be cut away at the point of diameter measurement. Just how the removal of bark affects growth is not fully understood. It may injure the cambium, retard growth, cause "pitch-soaking" of the wood, or lead to the development of adventitious sprouts. The area of thinned bark may serve, also, as a point of entrance for insect or disease, or may attract rodents such as porcupines.

It is not believed that painting has any direct effect upon the cambium, although some colors absorb heat and so may tend, when used on thin-barked trees, to stimulate growth in the region behind the painted area.

Figures may be painted freehand or by means of stencils or rubber stamps. ${ }^{15}$ Freehand numbering works better on large than on small trees, and stenciling is more effective on small than on large trees. Under present conditions, it appears necessary to go over stenciled figures with a fine brush in order to correct irregularities and to give the figures more body. Although this practice may seem to consume too much time, it is believed to reduce the time requirement for subsequent repainting. Painted numbers remain legible for from 5 to 15 years, according to the quality of the paint, the climate, and how much the bark cracks. Under optimum conditions, painting may last 20 years without great need of freshening. Under the most severe American conditions, high-grade paints and carefully applied numbers may not be legible for as long as 5 years.

Usually, the numbers can be read more readily if the digits are arranged vertically.

For freehand painting or stenciling almost any kind of durable paint can be used; among paints of good quality none has thus far been proved to give better service than another. Addition of a small quantity of turpentine seems to enable most commercial paints to penetrate the bark more thoroughly. If the paint is worked well

15 A rubber-stamping method is described by Berg (10). actual trials under American conditions is greatly needed, 
into the crevices of the bark the figures remain legible for a much longer period.

Rubber stamps are in much greater favor in Europe than in North America, owing largely to the fact that most sample-plot work there involves only relatively small trees. Rubber-stamped numbers are legible in much smaller sizes than numbers that are applied freehand. As American investigations turn more to immature stands it is reasonable to expect that we shall tend to substitute rubber-stamping for tagging. The practice of tagging has become so well established here, however, that the substitution of rubber-stamping cannot be expected to take place quickly.

No really adequate rubber stamps for use on trees have yet been developed in this country. The requirements for a rubber stamp to be used on trees are a soft spongy rubber, plain numerals, and a base and handle firm enough to withstand hard usage. The rubber base should be set into the wooden base, which at the thinnest part should not be less than half an inch thick. The handle and wooden base should preferably be in one piece, and of some hardwood such as maple. The numerals should be about 2 inches high, and should be narrow for their height.

In this country great difficulty is experienced, also, in procuring paint of the right quality for rubber-stamping. The paint must be lasting, must be of such consistency as not to run, and must be obtainable in small quantities for field use. In the Northeast a highgrade spar enamel has been found to possess some of the desired characteristics. For immediate use, the enamel should be slightly thickened with pure French zinc powder or by exposure to the air. The thickening can be hastened by spreading the enamel out in a shallow pan. Enamel of the proper consistency does not run when applied to the tree.

Almost any intelligent common laborer can do a fair job of painting, stenciling, or rubber-stamping numbers on trees. In fairly dense stands, it should be possible to paint or stamp about 100 trees per hour.

A tree-numbering method recently developed by forest entomologists, makes use of a paint gun with a fine nozzle. Compressed air for this gun may be developed in back-pack pumps such as are used in fighting forest fires. The paint is held in a mason jar attached to the gun. This method has many advantages: The fine spray is forced into all the cracks and crevices of the bark, so that bark smoothing is unnecessary; the numbering can be done freehand and very rapidly; the size of the letters can easily be adjusted to the size of the tree; and the work can be done by relatively inexperienced laborers. It is important that the paint be kept in a highly liquid state and free from any material that would clog the nozzle.

\section{PROCEDURE IN NUMBERING TREES}

The numbering of trees on any sample plot should be systematic. It should begin at a corner and proceed back and forth across the plot in rather narrow strips. A separate series of consecutive numbers should be used on each plot, and when any numbers drop out of the series that fact should be recorded. 
If the plot has been divided (p. 16), all the trees on a given section should be numbered before the next section is entered. Before any section is left a check should be made to insure that no trees have been missed. The sections should be worked systematically back and forth across the plot. This scheme furnishes such a convenient means of keeping a check on the numbering that it is justifiable to divide plots for this purpose alone.

The danger of overlooking trees and breaking the numerical succession is lessened if the progress of a man painting or stamping numbers on trees is so directed that while working on any given tree he can see the last preceding number. This arrangement helps materially, also, in remeasuring trees and in numbering new trees. It is particularly advantageous where the numbered trees are scattered. If the plot is divided, the numbers on each tier of sections may be placed to face the operator as he proceeds along the tier. This scheme makes numbers on adjacent tiers face in opposite directions.

On a hillside, unless it is very steep, numbers can be read most easily if placed on the uphill side of the trees.

Tags are less likely to be molested if placed so as not to be visible from a road or trail.

\section{NUMBERING NEW TREES}

For numbering additional trees at times of remeasurement, many different methods are used. In one, the new trees are given numbers that will indicate the time when they were numbered; for instance, the number "1-15" may be given to the fifteenth tree numbered at the time of the first reexamination. In another, the number indicates the tree's relative position in the stand; thus the number " $68 \mathrm{~A}$ " is given to a tree standing near tree no. 68 of the original series. Difficulty is encountered in getting such numbers stamped on tags at the time when they are needed. Neither of these schemes can be used without modification if the individual tree data are to be identified when placed on punch cards. The plan giving the greatest satisfaction in most cases is merely to continue the original series of numbers and to record in the field notes that certain trees mentioned by number were numbered at the time of the first remeasurement, that certain other trees also indicated by number were numbered at the second remeasurement, etc. The field notes should show for each new numbered tree the numbers of the nearest trees. This makes it possible to locate the new trees in an orderly fashion and saves much searching for missing trees at times of remeasurement.

In some instances, new trees may be so numerous as to justify renumbering all the trees. In such cases great care is required to make sure that old and new numbers are properly referenced.

In numbering new trees the same procedure should be followed as was followed in the original numbering on the same plot. This serves to keep the increase in the series always in the same direction and obviates confusion.

\section{BREAST-HEIGHT MARKINGS}

The point at which all diameter measurements are to be made should be marked on each numbered tree. It may be indicated by 
the position of the tree number or may be separatelr marked. If painted numbers cannot be put on without smoothing the bark they should not be placed at the point of measurement. If the tree is tagged the nail mar be driren at the diameter point. and the diameter tape allowed to rest on the nail while the measurement is being taken. If nails cannot be used without creating danger of a stelling that would distort the diameter measurement or a flow of pitch that would run down across the point of diameter measurement and so gum the tape, the tag mar be hung so that its lower end just misses the point of measurement or mar be placed at a measured distance abore or below this point. In ant case. the field notes should be specific as to the exact point at which the measurement is made.

If the diameter-measurement point is not exactly indicated br the position of the tag. it should be marked with a painted spot. small cross, or horizontal line. Obriousls, the bark at this point should not be disturbed. A narrow horizontal line about 6 inches long painted orer the bark ridges and well into the crerices serres admirably. Some part of this line will survire bark sloughing and fire or other injurr that would obliterate a mere spot of paint. In painting such lines the paint gun described on page 26 should give excellent results.

If calipers are to be used for diameter measurement two reading: will be made on each tree. at right angles to each other. and the two points where the caliper beam will hit the tree should be marked.

\section{ORIENTATION OF TREE MARKINGS}

Proper orientation of numbers and breast-height marks on trees may depend on several factors. Paint mar fade more rapidly on the south side than on a more shaded side of a tree. but may be quickly corered with lichens on the north side. Ordinarily, the most important consideration in numbering trees is ease in relocating the numbers consecutively. means toward which are discussed in the section Procedure in Numbering Trees.

\section{NUMBERING REPRODUCTION}

Reproduction more than 1.5 inches in breast-height diameter often can support indiridually numbered tags affixed with nails, and in some instances can support painted numbers. For the most part. however. individuals less than 3.6 inches in diameter can be identified more easily if marked with tags attached by wire either to the stem or to a branch. Seedlings less than 18 inches in height should be marked with tags fastened in the loops of wire pins. Very small unnumbered seedlings can be marked by pins. without tags. or br plant stakes. placed in the ground close beside them. Seedlings: marked with stakes are shown in plate 6.1 . Seedlings differing in rear of origin may be denoted br pins differing in color or shape.

Tags on seedlings are often difficult to locate. Hence the aluminum-tape tags described in the foregoing (p. 2t) are preferable to other kinds for this use because of their brightness and their resistance to tarnish, despite the fact that when attached to seedlings ther are sometimes so cherred br small animals that the figures are rendered illegible. These tags can be attached to the trees by means of 
soft pliable wire. The wire should be attached to the stem loosely. so as to provide for future growth. The branch or twig selected for tagging should be one that is not likely to die soon.

Tags used in marking reproduction should be attached as systematically as tags used on older trees. A definite height should be chosen within 6 inches of which the tag will be hung if possible. If the reproduction to be tagged is mostly less than 4.5 feet tall and has an average height of about 18 inches, the tags can be hung about 10 to 12 inches from the ground.

To facilitate quick relocation the tags should generally be hung on the south side, where they will catch the most light. On slopes they should be placed on the side most convenient for examination. Pins used without tags to mark very small seedlings should in each case be set on the same side of the seedling and at about the same distance from it.

In many cases, the necessity of tagging reproduction can be obviated by locating each individual on a map with reference to some definite point such as a quadrat corner. (This method of locating stems is described on page 52.)

Pins made of 10-gage telephone wire hold paint fairly well for 2 or 3 years. Enamel lasts longer and holds its color better.

Field notes should in every case be specific as to the height at which tags are attached to reproduction, the position of pins with reference to the seedlings they mark, and the color of the pins used for a given year.

\section{PLOTS IN PLANTATIONS}

Studies of the development of planted stands differ in purpose from studies of natural reproduction. Although like the latter they aim at determinations regarding survival and growth, they are largely concerned also with source of seed, size or age and condition of planting stock, method and season of planting, and suitability of species for given sites and localities. These latter considerations necessitate sample-plot methods different from those used in studies of growth and mortality alone.

In planting research the investigator has far greater control over the factors entering into a study than he has in research on natural stands. Sample-plot work dealing with natural stands is subject to restrictions due to the fact that such stands originate and develop principally by chance. In a study of the effect of thinning on second-growth stands, for example, plot location is governed by the location of available second-growth stands of the required species and age, with little opportunity for choice among areas on the basis of soil conditions, site, topography, altitude, or species intermixture. In a planting experiment, on the other hand, the investigator can establish his plots under conditions of site, topography, etc., selected almost at will.

Plots to be used in studying artificial regeneration must be so located that conditions affecting the test plantation will be closely comparable to those of the area or areas on which it is proposed to apply the results of the study. The area selected for the plots should be sufficiently large to permit installation of a complete series of tests, including replications in time. It should be readily accessible 
not only at seasons when trees are to be planted out but at all seasons. It should be well protected from trespass of all kinds, including damage from various forms of wild life and livestock.

More than ordinary care is needed to eliminate sources of error peculiar to this class of work. One of the greatest of these is variation in soil as to humic content, depth, texture, and drainage. Variation in humic content may affect moisture conditions and thus cause inequality in growth rate and in survival on different portions of the area; depth may markedly affect root development and soil temperature, and thus survival; texture may affect the ease of planting or the probability of frost heaving; drainage may affect root development, occurrence of frost, and thus survival, and may limit the season during which planting is possible. The topography of any series of reforestation plots should be substantially uniform, so that results will not be distorted by site variations, and should be such as to insure good air drainage and freedom from marked thermal belts, especially frost pockets. Erosion should be controlled, except in studies involving erosion effects. Steep slopes should be avoided, because soil or snow creep might affect survival, form, or growth rate.

The shape of the plot is a major consideration. Obviously, the square has a smaller periphery than any other rectangular figure. Use of strip plots, however, undoubtedly brings about a better representation of soil and site variations. Also, strip plots in which successive rows of trees differ in species, in age, or otherwise offer the best possible opportunity for comparing results with the different classes of stock represented. They permit such comparisons only during establishment and early life, however; as the trees develop, the value of the plots for such comparisons is destroyed by competition between adjacent rows. All things considered, probably the best shape of plot is a rather long narrow strip.

In a strip plot each row should include at least 20 trees. For a reasonably good random sample of site conditions without too great a periphery, the ratio between the plot's ends and sides should be not more than 1 inter-row space to each 20 trees in the row, or not more than 1 linear unit to 5 ; preferably, it should be not more than 1 linear unit to 10.

Optimum plot size depends largely on the purpose of the study, and the possible need of plots of known history for later investigations. In a study of planting technic, for example, if the trees are alike in species, age, and condition the number required may be relatively small. In such a study, which requires from 5 to 10 years, annual plantations of from 200 to 500 trees each will usually give reliable results. If a comparison is to be made not between planting methods but between seed sources, species, or species mixtures, it is best to establish a strip block of at least half an acre, and preferably much larger, within which a plot of from 200 to 500 trees will be studied.

Spacing has only a minor influence on the early development of the stand. In many planting investigations, consequently, it is permissible to set trees much more closely together than in a reforestation enterprise. For investigating only the initial establishment of trees it is preferable to adopt a spacing of 3 by 3 feet or 4 by 4 feet, in which case a single test will require a relatively small area. 
Where difference in species is a factor, the normal reforestation spacing of 6 by 6 feet should be used. On plots where growth and development of plantations are to be followed, a 6 - by 6 -foot spacing is preferable to closer or wider spacing unless variation in spacing is one of the factors in the experiment.

When the initial research project is completed, adjoining plots can be combined into a larger block to be used in further studies, if the stands are similar as to species, age, etc., and if the survival in indiridual blocks is sufficient to justify it. The initial plan of plot distribution and establishment should, when possible, be framed with a view to obtaining in the future, through such combination, good-sized blocks of stands approximately uniform as to age, seed source, species composition, and spacing.

Trees used in planting experiments should be set out in uniform rows regularly spaced. This will eliminate the need of marking each tree with a numbered pin or stake, as the individual tree can be identified by the number of the row and its position in the row. For identification in later years, however, it may be highly advantageous to number the individual plants.

In plantation studies a splendid opportunity is afforded to reduce error and increase the reliability of results through replication. Plot replications may be established in the form of the Latin square, or may follow any one of many other such schemes. Most planting research involves replication of plots over periods rarving. according to local conditions, from 5 to 20 years. The more variable the climatic conditions, especially during the most critical growth period, the more time the experiment requires.

Control plots should be established to provide adequate basic comparison. On these plots, when species or seed-source comparisons are involred, normal-sized stock representing a local strain of a commonly planted species should be planted by identical methods.

In dealing with species that produce seed only intermittently, an effort should be made to obtain in adrance sufficient seed of a single crop to provide for the project to its end, and to use only stock grown from this seed. This procedure is all the more desirable if selected individual trees are being used as a seed source.

\section{PROTECTION OF PLOTS}

Areas containing sample plots should be carefully protected from anything that would alter ecological conditions, such as cutting, grazing, fire, and camping, and from any other form of disturbance that conflicts with the experimental requirements. Since sample plots increase in value with age, eren greater watchfulness is needed as plots become older.

Protection needs vary with local conditions. Experimental forests should be posted against all trespass and protected in every possible way against unauthorized use. Circumstances on each such area dictate whether there is need of firebreaks, or of a patrol during the fire or camping season, and whether there is need of complete fencing against livestock.

For isolated plots, woven-wire fencing and warning signs may be required. It should be realized that any isolated plot is much 
more liable to loss than a plot within an area reserved for research purposes.

The question of whether plots should be protected against insects and diseases cannot be settled arbitrarily. If an insect or disease common to the region threatens plot trees, possibly the attack should be considered normal and any resulting loss accepted as part of the history. If an insect or disease is epidemic, then efforts should undoubtedly be made to control it. In the case of blister rust of white pine, the problem is complicated by the question whether removal of Ribes, as by digging up the roots, will affect the experiment. The investigator must decide which is the lesser of the two evils.

Unfortunately, agencies conducting forest research often find it necessary to protect sample plots from other agencies, and eren from forest administrators. All too often a busy forest administrator fails to recognize the value of plots, regarding them as something outside his range of interest or even as something that intrudes on his activities, rather than as an opportunity to understand more fully the conditions existing on the forest under his care and the possibilities of its development. The investigator should recognize this situation and endearor to meet it. This involves an effort to acquaint the administrator with the purpose of the plot, its value in management work, its value in time, and its cost of replacement. Having made this effort, the investigator should aggressively follow up any needless or wanton damage so as to prevent repetition of the offense.

\section{PLOT TREATMENT}

Specific methods for treating sample plots will not be described in this publication. Some general features of treatment that are of concern in most plot work will, however, be outlined.

Any cultural treatment accorded a plot should be completed within the shortest possible time, in order that the experiment may not be unduly complicated by variations corresponding to change of season. If an experimental cutting or thinning operation, for example, is allowed to drag out over a period of weeks or months, unseen or unrecorded seasonal changes in the stand during that period may greatly alter the dependability of the results. A considerable lapse of time between a cutting operation and subsequent measurements, although it sometimes does no harm, in most instances introduces errors that may cause confusion when the data are analyzed.

So far as possible, all cultural work should be carried out during the season of slowest change, i.e., during the dormant period. This principle calls for concentration of such work in the coldest season, normally from November to February, inclusive, the period being shorter in the South or at low elerations and longer in the North or at high elevations. For many of our forest tree species, data as to the actual time of year during which growth either in diameter or in height stands still or is greatly retarded are not available. Enough such data are available, however, to show that in mixed stands the growth of different species is not uniform. A season's diameter growth may be practically completed by one species before it is begun by another species in the same stand. Such variation 

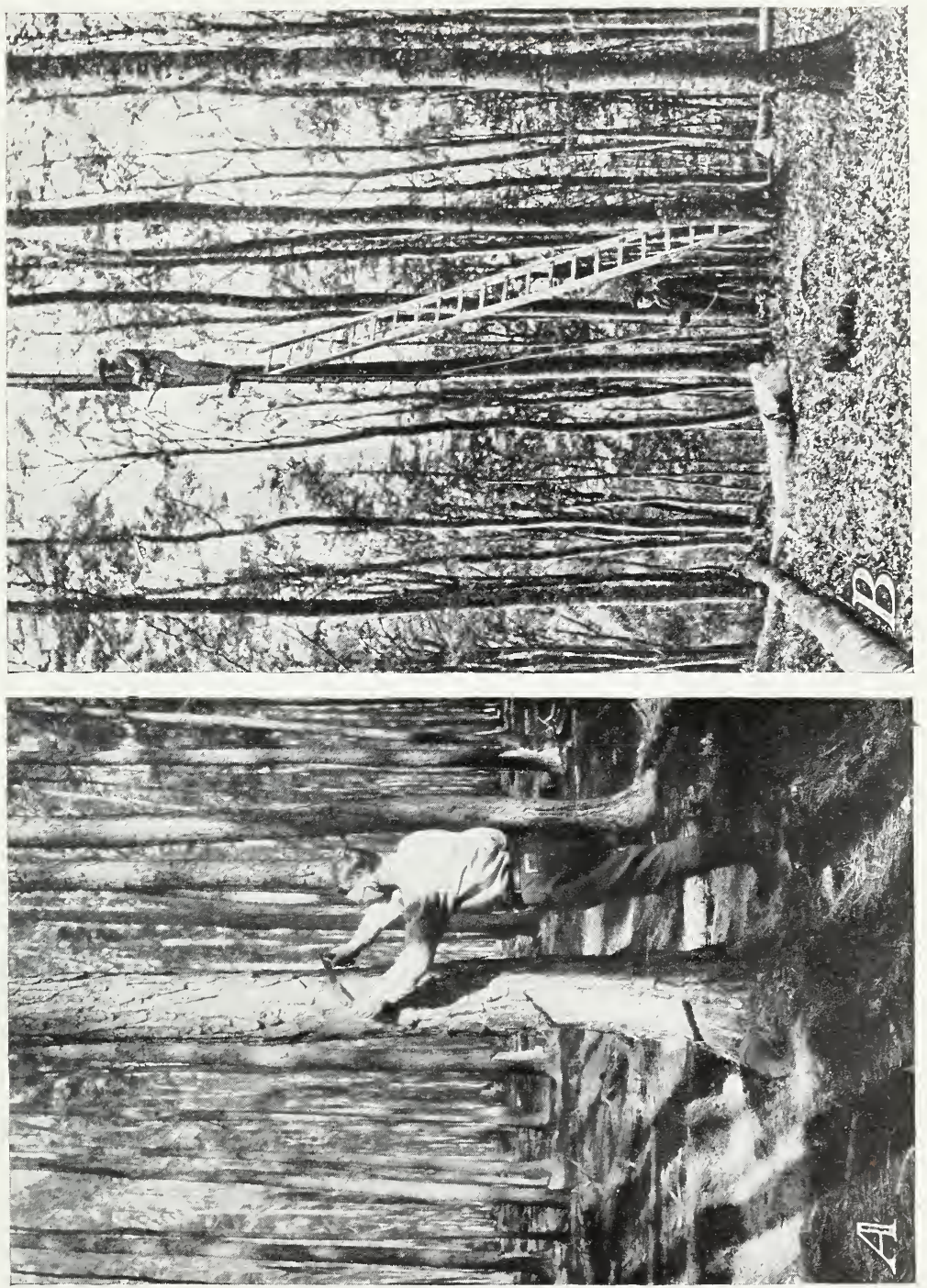

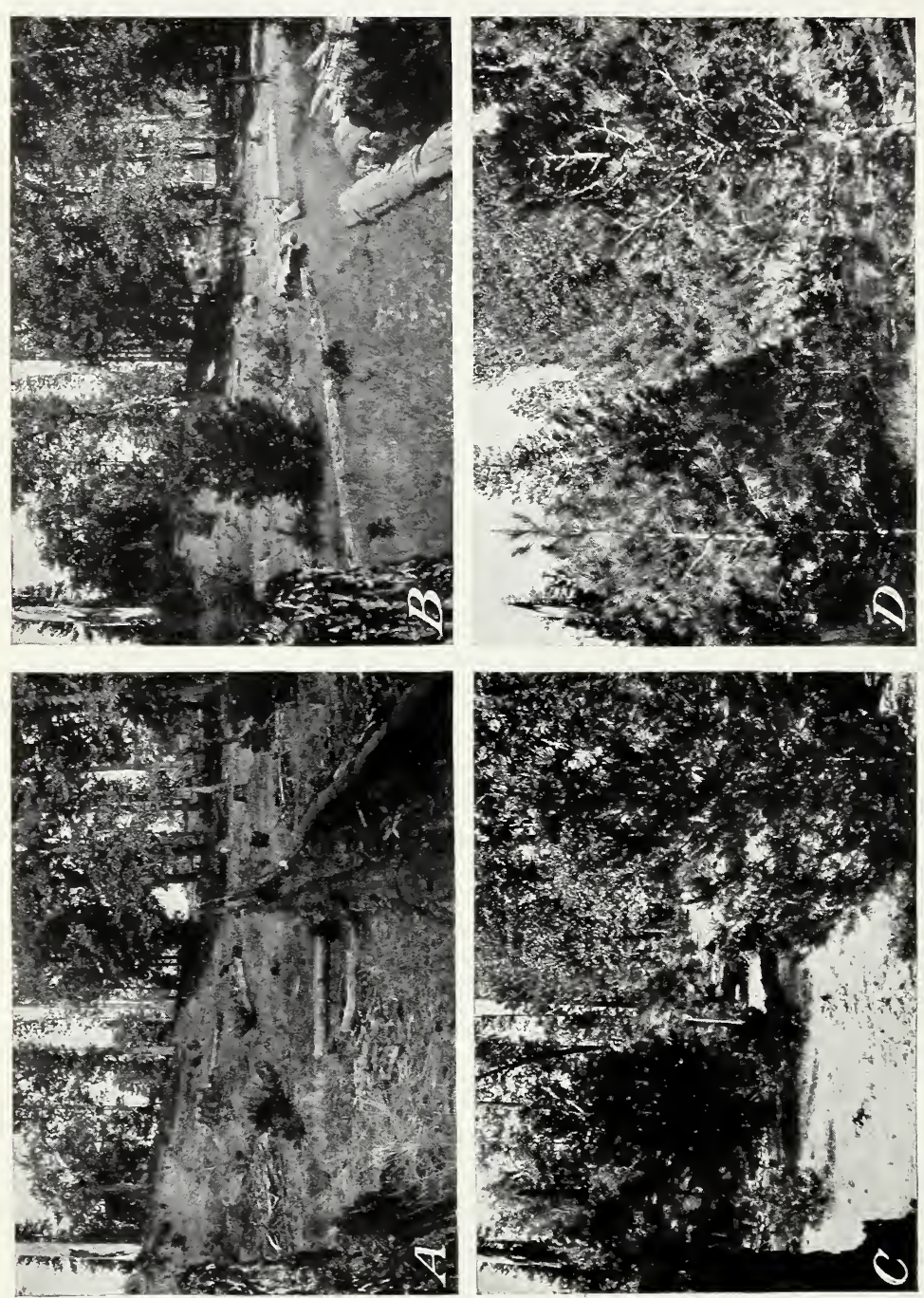
calls for studies to determine the time of active growth as a basis for choosing both time of treatment and time of measurement.

In general, treated plots should be subjected to the same treatment accorded the stand of which they are samples. However, while there is bound to be more or less accidental injury to the reserved stand in felling and logging, sufficient care should be taken on the plot not to cause damage that will vitiate the purpose of the study.

Cultural measures should be carried out in such fashion as to do the least possible injury to the remaining trees or to other vegetation on the plot. Large trees remored should be so cut as not to rake the boles or break the tops or branches of reserved trees. Trees lodged in the tops of their neighbors should be remored if at all possible. In machine logging or skidding, reserved trees should be cushioned by encasing the lower end of the bole with a stockade of stout poles firmly tied to the tree.

Cutting on sample plots should be done as neatly as conditions permit. On larger trees the saw should be used in preference to the ax. In stands of rery small trees cutting should be done with a machete or pruning shears, which make a clean. sharp cut. In pruning operations cuts should be made close to the stem, so that they will heal over promptly and without injury to the stem. Neat cutting calls not only for good workmanship but for sharp tools.

Locations for skid roads and trails should, if possible, be selected before cutting is begun, and felling should be so conducted that skidding will cause the least possible injury to reproduction or to subordinate regetation. If skidding is to be done in the winter, areas that are to be specially protected from damage should be designated in adrance of snowfall. If erosion is likely to derelop as a result of skidding operations, the areas dragged bare should be corered with a heary layer of litter unless the project includes study of conditions on areas bared by skidding.

The trunks and hearier branches of trees cut on a plot and its isolation strip should, if possible, be remored from the plot area. If not utilized they should be burned, or so treated as not to invite insect attack. Such material should not be placed in piles.

Slash resulting from any cultural work constitutes a menace to plot safety if left untreated. In most instances slash should be burned, if this can be done without damage to the reserve stand. If slash must be burned on the plot, the safest method is to burn it in a few small piles as cutting proceeds. Care should be taken to prevent a fire on a plot from spreading, and to avoid placing so much material on the fire at any one time as to cause scorching of crowns or heat-killing of buds or leares. Care should be taken, also, not to place piles so close to reserved trees that the heat from their burning will kill the cambium through the bark; such injury causes the formation of hidden fire scars and distorts diameter growth. If possible, a supply of water should be kept at hand to prevent the spread of fire, to cool down fires that become too intense, and to control fires that escape. In regions of heavy snowfall, slash can be piled and burned with minimum damage to the reserved stand while the ground is corered with snow.

$87471^{\circ}-35-3$ 


\section{COLLECTION OF PLOT DATA}

\section{FIELD NOTES AND FORMS}

Field notes demand special care. Measurements should be recorded in an orderly way, on forms devised specially for the study or on forms in general use for similar work. All data required by the project should be recorded at the time the work is done. If columns are used for data of a character different from that indicated by the form headings, or if data are entered in columns that in the printed forms were left without headings, the changes and insertions should be carefully made in the field. A standard set of abbreviations of species names should be used in every study. 'Technical and common names of trees as given in the Check List ( $/ 1)$ and of other plants as given in Standardized Plant Names (2) should invariably be followed.

All notes should be completed in the field, and before the plot is left the notes should be checked for completeness. All notes, forms, and maps should be initialed and dated. Nothing should be left to memory.

All records must be legible and permanent. Printing is usually more legible than script. Special care should be taken to make all figures so distinct that they cannot be misread. Good-quality paper should be used, and permanent ink or a pencil soft enough to make reading easy but not so soft as to smear. Carbon duplicates of field notes may sometimes be needed for field-station files, and serve as an insurance against loss of valuable data. Each sheet or form for field notes should bear a serial number. All forms should be made up on sheets of uniform sizes, i.e., single sheets should be of such size that they can readily be filed without folding or rolling, and can be bound in standard covers. Use of miscellaneous odd-sized forms or, particularly, of small-sized forms should be discouraged..$^{16}$

Some typical forms, used by the Forest Service, for the collection of data from sample plots, and abbreviations and a numerical code for use in recording such data, are given in the appendix (pp. 66 and 73$)$.

\section{TREE MEASUREMENTS ${ }^{17}$}

\section{BREAST-HEIGHT DIAMETER 18}

The standard point for measuring breast-height diameter (d.b.h.) is $41 / 2$ feet above the average ground level. This point should be determined exactly for each tree with a measuring stick and should be permanently marked on trees that are to be measured repeatedly. On slopes the average ground level is a point vertically half-way between the ground levels immediately above and below the tree. Con-

16 Standardization of the sizes of all forms used in forest research has much to commend it. It facilitates filing and binding, makes for uniformity in the records, and tends to reduce the number of forms needed. The standard unit should be ordinary letter size ( 8 by $101 / 2$ inches). Smaller or larger forms should be of some standard fraction or even multiple of this size.

${ }_{17}$ The appendix contains a list of the instruments, tools, etc., needed in measuring trees (p. 72 ) and a discussion of methods of preparing volume and yield tables (p. 79 ).

is The arest trees is more significant than their diameter, and could as easily be measured directly if the proper graduations were put on tapes and calipers. At present the fact that basal area is not readily measured or calculated, and that "square feet per acre" is an unfamiliar conception, prevents its general adoption. Its use should, however, be encouraged in every way. 
venience often dictates, however, that the point of measurement be established $4 \frac{1}{2}$ feet above the ground on the uphill side of the tree.

In some unusual cases, e.g., a tree growing on a boulder or a log with its base high above the ground, the point of diameter measurement may be $4 \frac{1}{2}$ feet above the root collar. On leaning trees the breast-height measurement should be taken $41 / 2$ feet from the arerage ground level as measured along the bole.

If abnormal swellings or depressions occur at breast height, the diameter measurement should be taken at the nearest point above or below it where the trunk is normal, if such a point exists between the heights of $21 / 2$ and 6 feet above the ground. If no such point exists within that height range, measurement should be made at breast height regardless of abnormality. In such cases, if the abnormality has materially increased the diameter, it is desirable to estimate what the normal diameter would be and to use this estimated diameter in all calculations. At times of remeasurement, the periodic diameter growth of a tree the diameter of which has been thus estimated should be assumed to have matched the plot average for: trees of its original estimated diameter and of its crown class. The point at which measurement is taken should always be definitely recorded. Usually the contents of trees measured below or above breast height because of abnormality can be derived from volume tables in the same way as if the diameters had been measured at breast height, without causing serious error in the plot total. A sounder practice for applying volume tables is to measure the diameter at two points equidistant from breast height where no abnormality is present and average them. Measurement at a single point is believed to be preferable in most cases, because it creates less confusion and less chance of error in computations. If the plot is small and a considerable proportion of the trees cannot be measured at breast height, volume determination may require a special study.

Under some conditions it is impractical to use breast height as the standard for diameter measurement. Diameter is customarily measured 9 feet above the ground on pines that are to be worked for turpentine, and approximately at the high-water line on hardwoods or cypress subjected to frequent and long-continued inundation. Aside from such special cases, before any departure is taken from the standard practice of measuring diameter at breast height the effect should be considered most carefully; sooner or later, such a departure is likely to cause confusion in comparisons of growth.

In general, vines and moss should be removed from a tree trunk before the diameter is measured. Some vines, such as species of Rhus, so unite with the bark that they cannot be removed from softbarked trees without considerable loss of bark or even exposure of the cambium. Under such conditions it is usually preferable not to remove firmly established vines preparatory to diameter measurement. In recording diameter measurements no allowance should be made for distortion due to such vines, but their presence and their approximate diameter should be noted. If the vines are very large, it is desirable to remove them, so far as is practical, at the point at which the tree is to be measured, by careful use of a light hand ax, unless the study contemplates their continuance. 
In measuring the diameters of trees with scaly bark, such as shortleaf pine, great care should be taken to avoid undue removal of bark. Removal of very loose bark is permissible at the time of the first measurement, but not at times of remeasurement, as this would affect the records of diameter growth. An estimate as to quantity of bark removed at the time of plot establishment should be recorded for each tree so treated. In the case of species having bark plates that curl out and away from the tree, such as shagbark hickory, the portion of each plate that interferes with the breast-height diameter measurement may be cut or broken away at the time of first measurement; at subsequent measurements no bark should be removed, but the tape should pass under and not over any such protruding bark scales.

Measurements of bark thickness near the breast-height point are desirable in some investigations as a means of checking up on diameter growth-especially in fire studies, in the course of which part of the bark may be burned away. These may be made without injury to the tree by the use of the Swedish bark punch, shown in plate $3, B$. How many bark measurements should be made on each tree depends largely upon the purpose of the study. Enough should be made to obtain a reliable sample.

Unless it is necessary to maintain ecological conditions with the least possible disturbance, dead branches near the breast-height point should be remored in order to permit easier and more accurate diameter measurement. These branches should be cut clean, close to the trunk.

If a tree forks below breast height, the diameter at breast height on each fork should be measured and recorded as that of an individual tree.

The diameter tape ${ }^{19}$ is standard for the measurement of diameters of standing trees on permanent sample plots. The tape gives consistent results, and is easy to carry. It should be used in all cases except in remeasuring plots on which calipers were used in earlier measurements. If calipers are used two diameter measurements should be taken, at right angles to each other. Calipers have fallen into disfavor in American silvicultural research because they are hard to keep in adjustment and because they fail to give consistent results when used on tree boles of irregular shape. They are bulky, and their use, since it involves two measurements and the recording of two figures for each tree, consumes an undue length of time. The use of calipers is sometimes justified where the luxuriance of vines, or the presence of highly toxic vines, makes it difficult to obtain diameters with a tape. It is sometimes justified also on trees that are heavily buttressed, such as southern cypress or western red cedar.

Diameter tapes and calipers are shown in plate $3, B$.

Under no circumstances should diameters on permanent sample plots be taken with a Biltmore stick or with any other device the standard error of which cannot be accurately determined.

Diameter at breast height should ordinarily be recorded to the nearest one-tenth inch.

\footnotetext{
${ }^{19}$ For discussions of tape versus calipers in taking diameter measurements, see the following references in Literature Cited, p. 62: 9, 42, $5,48,63,6 \%$.
} 
Considerable care is required to get a true measurement by the use of the diameter tape, especially if the diameters exceed 18 inches. In that case the tape should be fastened at the breast-height point and carried around the tree in such fashion that it remains in a true horizontal plane. The practice of throwing the end of the tape about large trees often leads to a considerable plus error because the tape sags or becomes hooked over an obstruction.

On most sample plots, the man taking the diameter measurements should call the data to the recorder in the following order: Tree number, species, diameter, condition of bole as to injuries, and any other pertinent information that is to be noted.

After the diameter has been measured the tag should be marked with a piece of crayon, or the bark scratched in a distinctive manner at a point where the scratch will not interfere with any later diameter measurement. This may save much footwork on the part of the man taking the measurements.

Remeasurements should always be made at the same season of year as the original measurements in order not to complicate growth calculations. This is much more important in regions of rapid growth, particularly in regions where growth is practically continuous during all but a very small part of the year.

Measurements made in early spring should be timed not in accordance with the calendar but in accordance with actual stages of vegetative development. It is preferable to avoid making any measurements during the period of most active growth.

Both moisture and temperature affect tree diameters; consequently remeasurements should preferably be made under the same general weather conditions as the original measurements. The French forest experiment station recommends (5\%) that a check measurement of all diameters be made a few weeks after the original measurement. This would of course serve the purpose of detecting mistakes in measurements as well as differences due to weather.

\section{HEIGHT}

The total height of a standing tree is usually defined as the rertical distance from a horizontal plane drawn through the arerage ground level at its base to a horizontal plane drawn through its tip.

The relative advantages of various hypsometers for measuring tree heights have been studied repeatedly $(18,21,23,31,40,41,46$, $51,55,58,66)$. The general conclusion has been (5) that the Abney level and the Forest Service hypsometer give more reliable results that any other instruments requiring the minimum of time and care in manipulation. (Hypsometers and the Abney level are shown in plate $3, A$.) The type of Abney that is used on a tripod is more accurate than the hand type. The Klaussner probably exceeds both instruments in accuracy and in freedom from mathematical errors. It is less rugged in construction, however. With this instrument a Jacob's staff should always be used.

Jacob's staffs can be made on the ground, from almost any suitable material. A Jacob's staff superior to any on the market can be made from a long-handled hoe. The blade of the hoe is remored, and the shank straightened and sharpened. The handle is cut to about $51 / 2$ feet including the spike. The top is fashioned to take the 
ball-and-socket attachment of a compass. A notch is then cut around the top of the handle, about an inch from the socket seat, to permit tying the ball and socket or the hypsometer to the staff with a stout cord. The spike, with its thimble, should be removable. Properly fitting the thimble, or using a screw to hold the thimble firmly in place, makes it possible to remove the spike for convenience in packing. If a step or foot-rest attachment is fixed to the handle about 2 or 3 inches from the thimble of the spike, it is possible to force the staff firmly into the ground by foot-pressure. The staff then makes a very firm rest.

Hypsometers should be kept clean and should be maintained in good working order at all times. Before being used, a hypsometer should always be thoroughly tested to make sure that it is in perfect adjustment. It should be tested each day it is used.

Height measurements should be taken in the same general direction on a plot, and the field notes should clearly indicate this direction. On sloping ground, measurements should consistently be taken from the uphill side. Under this practice some of the inaccuracies due to lean are eliminated, as the lean of each tree is in the same general direction with reference to the observer.

The hypsometer should in general be used at a distance from the tree that is greater than the tree's height; in taking heights down a slope, it may be used at an appreciably shorter distance. In dense stands of uniform height, or in any stands of hardwoods during the leafy season, it is often exceedingly difficult to use a hypsometer with any great degree of reliability. Height measurements of hardwoods should invariably be made when the leaves are off the trees.

Where trees more than 125 feet tall, and only a few trees, are to be measured periodically, the use of the transit may be justified. In such cases, permanent hubs should be set up and the same trees should be measured from these each time. This system tends to save time and expense, and to eliminate errors. ${ }^{20}$ If a transit is used, the reading for the tip of the tree and that for its base should both be recorded, so that errors in calculating height may be checked. Care should be taken to give each reading the proper sign (plus or minus). As the base of the tree frequently is an indeterminate point or is hard to distinguish through an instrument or in brushy stands, the top of a measuring stick held against the tree may be used as the base and the length of the stick added to the calculated height of the tree, or the breast-height point may be used as the base.

The distance from the point of observation to the tree may be measured with a tape, with a range finder, or with a telescopic alidade and stadia rod. The tape is the most accurate, but in some stands it may be impossible to make successful use of any instrument other than the range finder (61). On sloping ground, the use of a slope

\footnotetext{
20 The Revised Instructions for the Establishment of Permanent Sample Plots of the Canadian Forest Service (mimeographed, Ottawa, April 1929) suggest that the height of each tree be measured from the base of some other tree on the plot, and a note "from tree no. — " recorded with each height. These instructions proceed: "Where a map has been made, the distance from the instrument or base tree to the various trees measured may either be scaled on the map or measured by tape. As the former method assumes that the map is accurate, a small check should be made to determine if the map distances between trees coincide with the actual distances on the plot. Errors in this check should be less than one foot."
} 
or topographic tape with an Abney makes for rapid work. With an improved Abney, slope distance can be converted into horizontal distance with practically no effort $(66)$.

Distances should be measured from the rear sight of the hypsometer to the center of the bole at average ground level, or to the breastheight point. Measurements to the breast-height point tend to be more consistent. The man holding the tape at the tree can indicate the breast-height point when it is not clearly seen by the instrument man. In measuring leaning trees an effort should be made to determine the exact vertical projection of the tip, and the distance from the hypsometer to this point should be taken as the distance to the tree.

If the top of a tree is hard to see, or if the top is round and the tip indistinct, it may be necessary to make 2 or 3 height readings with the hypsometer from different directions in order to get a reliable figure.

For height measurements made with the hypsometer in connection with studies in which height growth is to be followed with care, the following standards of accuracy are suggested: For trees less than 60 feet tall, height should be determined within one-half foot, except in the case of trees (such as round-topped hardwoods or flat-topped conifers) the tips of which cannot be accurately determined; for trees between 60 and 125 feet tall, height should be read within the nearest foot; for trees more than 125 feet tall, height should usually be read within 2 feet, except in dense stands In the majority of stands, such accuracy may be impossible.

For trees less than 18 or 20 feet high, a measuring rod may be used. This may be an extension rule designed like a leveling or stadia rod, such as is shown in Figure $2(69,80)$, or a rod on which colored bands represent different linear units. Extension rods with a pulley arrangement have been developed for measuring trees as tall as 35 feet. These work less well, however, at heights of more than 30 feet.

In most studies, only normally shaped trees of the crown class concerned should be measured for height. Where it is possible to make a choice, leaning trees should not be measured. Occasionally it is necessary to measure an abnormal tree for height; when this is done, an accurate description of the tree should be recorded.

For how many trees height measurements should be made on an even-aged plot depends on the use that is to be made of the measurements. In some cases, as in studies of height growth and volume production, the heights of all the trees may be needed. If the height data are to be used in determining plot volume alone, only enough measurements for a smooth diameter-height curve are needed; but this curve should be well substantiated by a series of strong points. In this latter case a summary of the diameter measurements on the plot will show what height measurements are needed, or heights may be plotted over diameters as they are taken in the field until there are enough points to give a good curve. If heights of individual trees are to be followed throughout the life of a plot, more should be taken than are needed at first, so as to allow for the cutting or death of some of the trees. The general 
tendency is to take too few height measurements rather than too many, largely because height measurement is tedious and consumes much time.

In some growth investigations in young even-aged stands, as in yield or thinning studies, it may be appropriate to record heights
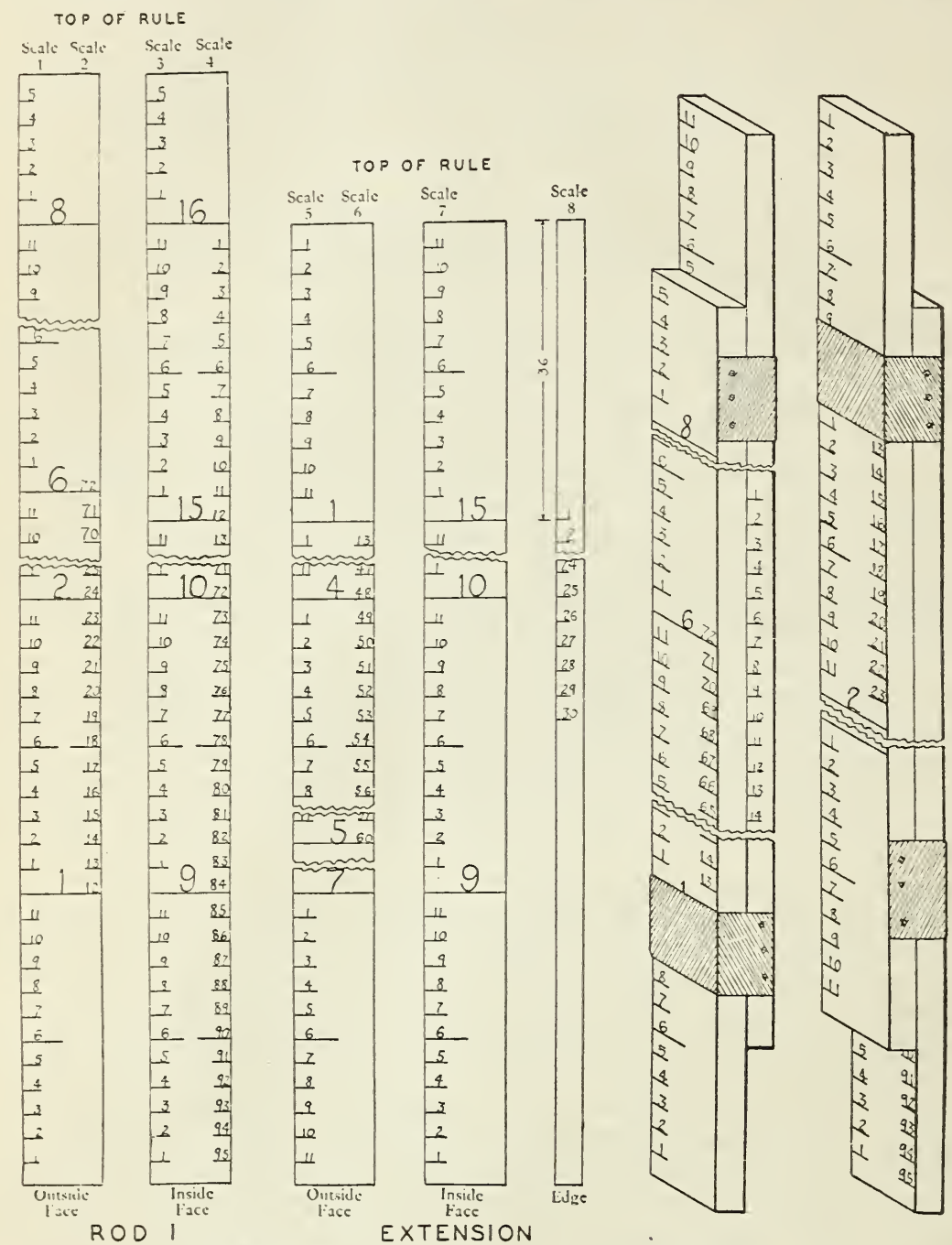

Figcre 2.-A sliding scale for height measurements.

for only a sample of the stand on each plot. Thus data on heights might be taken. at each measurement period, only on a sufficient number of individuals to give a strong diameter-height curve. In such cases a separate curve should be prepared for each species on the plot, representing all crown classes present. On plots with understocked or irregularly spaced stands groups of trees should be sampled, also, so as to obtain data on the effect of spacing. 
In uneven-aged stands or in culled forests, height measurements must be made on practically every tree at each remeasurement.

Since the limit of "merchantable height" is variable and may be due to either branching, defect, or excessive taper, and since standards of merchantability change with economic conditions and utilization practices, no measurement on a merchantability basis should be made without adequate definition. (For a discussion of the measurement of upper diameters of standing trees, see the section on "Taper".)

"Height to base of crown" $(H t-B C)$ may be recorded if it is significant and can be determined with reasonable accuracy. The base of the crown is usually defined as the place where the lowest branch leading into the crown proper emerges from the trunk. The definition varies among studies, depending, for instance, on whether the value to be determined is clear length of bole or crown length. ${ }^{21}$ In cases in which base of crown is a questionable point, definite notation should be made as to what point is considered the base.

\section{TAPER}

In studies in which current information on change in tree form is needed, it is necessary to measure the diameters and bark thickness of individual trees at various heights from the ground. This is done by climbing the tree or by using a dendrometer.

The climber measures diameter with a tape, and bark thickness with the Swedish bark measurer. If data on age and rate of growth are needed, he also bores the stems at the measuring points. Usually he determines the distance from each measuring point to the ground by means of a tape attached to his belt. This operation is illustrated in plate $7, B$.

The measurements may be taken at irregular height intervals, because of the difficulty of relocating an exact point of measurement. Usually the intervals between measurements made by a climber are very irregular, depending largely as they do upon the availability of resting places. In most studies this makes little difference if the data are plotted to produce a tree diagram. ${ }^{22}$

Since studies of form are based on averages, it is often unnecessary that remeasurement for changes in form be made on the same trees as the former measurements. Where it is desirable to record form changes of individual trees, remeasurements of each tree should be made at the same heights as the original measurements, and for this reason the heights should be definitely marked. Tags may be hung or a band may be painted at each point of height measurement.

To climb standing trees by sheer muscular effort is often difficult, especially if the trees are large and tall and if they possess few branches or other projections on which the climber may rest. On sample plots it is inadvisable, however, to use climbing irons such as are used by telephone linemen, because the irons wound the trees. Wounds thus made may attract insects or sapsuckers; admit disease or mistletoe infection; result in pitch flow, pitch soaking of

${ }^{21}$ In some foreign studies (64), one-half the distance between the lowest branch and the first definite whorl of branches has been taken as the base of the crown.

$\because 2$ For the purpose of drawing a form curve, all the data for each indiridual tree can be entered on a graph form, such as Forest Service form 55sa, on which the ordinates represent area in square feet and the abscissas represent height in feet $(60)$. 
the wood, or callousing that distorts diameter growth; or in other ways affect tree derelopment adrersely. The use of climbing irons is dangerous for the climber, also, because bark does not always hold and because occasionally something goes wrong with the supporting apparatus. If climbing irons are used they should have spurs sufficiently long and stout to gire a good purchase and should be adapted to use on the tree species involved.

In dense stands of pole-wood size it is sometimes possible for a climber to go up one tree and, by crossing orer in the branches, come down another, making measurements of both.

Where many trees are to be measured and the lower branches of the trees are within easy reach, a ladder may be used. The use of a light ladder. with or without an extension derice, sares much time. Eren for fairly tall trees, a 10- or 12-foot sectional ladder such as is often used by painters in scaffolding work is a means of obtaining measurements quickly and safely. When a ladder of the latter type is used, each separate section should in turn be lashed to the bole. More than two sections of this ladder cannot be used safely unless the ladder is in an almost rertical position.

Standing trees up to 22 inches in diameter and 85 feet in height are measured by the Central States Forest Experiment Station by the use of special equipment, consisting of a 14-foot extension ladder, 150 feet of 1/2-inch hemp rope, a swing board, shown in figure 3 , an 8-foot bamboo pole marked in 1-foot lengths, and a telephone climber's safety belt and strap. The climber uses the ladder to a height of 24 feet and then climbs to the highest dependable crotch. carrying with him one end of the rope and one end of a 100-foot steel tape. The rope is fed through the crotch, hand orer hand, until it comes within reach of men on the ground, who then draw the swing board up to the climber. The height of the tree above the highest crotch reached by the climber is determined with the pole, and that below with the tape. After taking all needed measurements above the crotch the climber lowers himself, by means of a special slipknot, to definite points at which he measures diameters and bark thicknesses. Distances are measured directly along the stem of the tree. This scheme is feasible only with trees that hare sturdy forks near the tops, and so cannot be used with some conifers.

Various dendrometers hare been dereloped by means of which upper diameters of a tree can be measured from the ground. Of those used in this country the Liljenström ${ }^{23}$ has so far been judged to be the most accurate. The Liljenström dendrometer is best suited for measuring straight-boled trees, and is better adapted to conifers than to hardwoods ( 79$)$.

In using any dendrometer, howerer satisfactory and reliable it may be. the limitations of its accuracy for the work at hand must be carefully observed. It should be remembered, also, that a special study of bark thickness at various heights is necessary before the data obtained with a dendrometer can be used in rolume-table construction.

${ }^{23} \mathrm{~J}$. A. Amiln (3) describes this instrument in detail and gives the results of a study of its accuracy. See also $(35)$. 


\section{AGE}

Tree ages are determined by counting annual rings on incrementborer cores or on stumps. Borings for the purpose of determining age and diameter growth are usually made at breast height (8).

The increment borer, with extractor, and a device for measuring increment cores are shown in plate $3, B$.

If the total age of a tree is sought, account must be taken of the time required by the tree to reach the height at which the rings are counted. The length of this period may be determined from stem analyses of reproduction of the same species growing under the same conditions. In order to hold this correction to the minimum, incre-

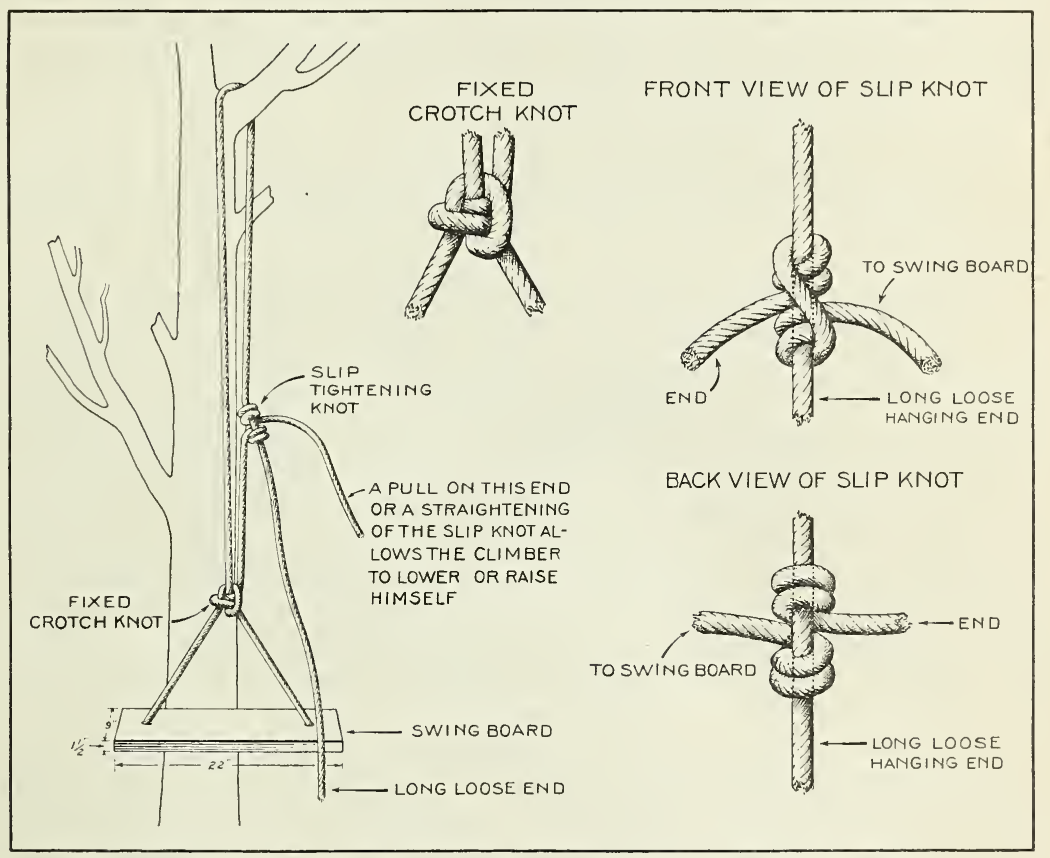

Figure 3.- Swing for taking measurements on standing trees.

ment borings for the determination of total age should be made as near the ground line as possible. On hillsides borings may sometimes be made on the downhill side of the tree at the root collar, and total age thus determined directly. For some species, true age cannot be ascertained dependably even by this method; e.g., seedlings of longleaf pine ( $P$. palustris) remain in the "grass stage" for a period that may exceed 20 years, and that cannot be exactly ascertained in a given case by any method now known. Badly suppressed small seedlings of tolerant species, also, may make so little diameter growth over a period of many years that their growth rings cannot be counted except with the use of a low-power microscope.

It should be borne in mind that eccentricities of growth may make a single boring in a tree unreliable as an indicator of the diameter 
growth of that tree, but that when one boring per tree is obtained from a large number of trees eccentricities of diameter growth are usually ironed out. In collecting growth data by one boring per tree, special care should be taken to aroid bias.

Considerable difficulty is sometimes encountered in measuring precisely the growth made during individual years or during groups of jears. Various derices hare been developed to aid in making such ineasurements $(19.24,59)$.

Occasionally data are needed on growth during the last few years. Increment borers are seldom sharp enough, and the hand holding them is seldom steady enough, to make a clean cut without crushing or distorting the outer 2 or 3 annual growth rings, except in a relatively small number of species. To obtain such data, a chip about three-fourths of an inch square should be cut from the tree with a sharp wood-chisel. The cut should be sufficiently deep not to cause clearage between annual rings.

In the case of plantations the period since planting should be recorded as the age of the stand, no matter how old the trees were when planted. Records should be kept, howerer, of the age of the stock used.

In even-aged stands, age is considered by 10 -vear periods the first of which dates from the time of the stand's origin. Thus the 20rear age class is composed of trees aged from 20 to 29 years, inclusire, and the 30 -rear age class of trees aged from 30 to 39 years, inclusive. In studies of uneren-aged stands, especially those involving old-growth timber, trees beyond the sapling stage may be considered in four major groupings-young, thrifty mature, mature, and overmature. The spread of ages included in any one group is not fixed. but varies with species and site. In long-lived species such as ponderosa pine (Pinus ponderosa), maturity may be taken as between 150 and 250 vears. In shorter-lived species such as shortleaf pine $(P$. echinat $\dot{a})$, maturity may be taken as between 75 and 100 vears.

Taking borings at an angle often has the result that small bits of wood break off in the borer and clog it, particularly in pitch-soaked or punky heartwood. Clogging is less likely to occur if the barrel is frequently swabbed with kerosene or. preferably, with high-grade machine oil: this, howerer, does not entirely prevent clogging or aid greatly in remoring the compacted material. Material that cannot be removed with the extractor sometimes can be remored with the aid of a stiff wire. It can be remored quickly with a $\frac{5}{32}$-inch wood and steel drill welded on $a_{16} \frac{3}{16}$-inch steel rod the top of which is bent so as to form a handle $(56)$.

Growth by 5-year interrals should be measured on the freshly extracted core. before any distortion can have been caused by shrinkage. A growth record of this kind made in the field is particularly raluable, because of the fragility of cores and the unerenness with which they shrink. If lengths representing 5 years' growth each are marked off on the core they can readily be narked off also on a field form that will become a part of the permanent record. If the boring misses the center of the tree, a diagram of the first few years' growth as inferred from the core should be drawn on the form so that future workers will have information as to the interpretation made. 
An indelible pencil is most convenient for marking cores, as it makes a permanent mark on moist wood.

Recently, the use of phloroglucin has been advocated as an aid in counting annual rings on increment cores $(\%)$. Phloroglucin stains the lignin. As the lignin is more dense in the late summer wood, the stain causes the annual rings to stand out. Phloroglucin is used in an approximately 5-percent aqueous solution. The stain is intensified if hydrochloric acid also is used, in a solution containing 2 parts of water to 1 part of concentrated acid. The two fluids may be mixed and used together; better results are obtained, however, by immersing the cores for a short time in a test tube of phloroglucin and then placing them in a tube of acid. Drying the cores in advance does not interfere with this practice. Cores that have been dried do absorb more of the stain, unless they are slightly moistened with water before being stained. Phloroglucin is equally efficacious on stumps, if poured or lightly brushed into a groove cut along the radius on which it is proposed to count the rings.

So far as is possible, increment cores should be preserved. In excellent means of carrying cores in the field and of filing them is to place them lengthwise in the folds of corrugated paper. Increment cores taken in the general forest survey in Sweden were preserved by inserting each core in a paper tube, one end of which was closed by flattening and stapling, The tubes were made of several turns, or layers, of paper and so were stiff enough to endure ordinary handling without becoming bent. A printed form on each tube permitted the entry of a record identifying the core. Pencil boxes are satisfactory for small cores that are not subject to warping. Test tubes that can be corked are sometimes used.

The use of the increment borer, like the use of nails and the scraping of bark, on some species of pine may cause pitch soaking of the wood or start a flow of resin that will attract insects. Full information as to how increment borings ultimately affect trees, although badly needed, is not yet available. On a permanent plot the fewest possible borings should be made. If there appears to be danger of damage to the tree, the hole may be filled with a $1 / 4$-inch wooden dowel that fits it exactly. The dowel should be driven into the hole until the outer end is flush with the cambium. It is believed that within a short time after this treatment the opening will be closed by a callus. A record should be kept of the trees that are bored for any purpose.

The increment borer should be kept sharp at all times. In the field, minor nicks and slight dullness can be corrected by careful use of a small rat-tail file. Such sharpening should not, however, be depended upon entirely. After about 100 or 200 borings, according to the character of the wood on which it is used, the borer should be sent to a competent machinist for sharpening (62).

\section{STUMP DIAMETER}

It is sometimes necessary to estimate the diameters of felled trees from stump measurements. A study of butt taper of similar trees in a similar situation will show the relationship between the diameter at breast height and the diameter at any stump height. Such a study should be made in all cases in which ordinary accuracy is required. It should be remembered, however, that stump measure- 
ments are not very reliable, because of weathering of the bark, insect action, fire damage, checking, etc. Unless the cutting was comparatively recent, allowance should be made for errors approximately as follows: Stumps less than 6 inches in diameter, one-half inch; stumps from 6 to 18 inches in diameter, about an inch; and stumps more than 18 inches in diameter, about 2 inches. Because of variation among species, systematic and reliable observations on this subject are needed.

\section{TREE DESCRIPTION AND CLASSIFICATION}

Sometimes need arises for sample-plot data of other kinds than those ordinarily collected. Consideration should aways be given to the desirability of collecting from plots not only data that are useful from the standpoint of the current study but other data that may amplify our knowledge of the growth characteristics of trees and the reactions of trees to site factors.

Such supplemental data include those classifying trees according to width, length, fullness, density, and shape of crown; color of foliage; type and degree of injury; abnormalities of form; seed production; and sprouting capacity. The width, length, and density of a tree's crown, and the color of its foliage, may indicate its vigor and rate of growth. Records on such characteristics may be valuable as a means of relating appearance of crown to growth characteristics and behavior of the individual tree. Since stem diameter is closely correlated with crown width, data on crown width may contribute toward development of a method of estimating timber on the basis of aerial photographs.

In many cases it is desirable to develop a herbarium for a plot or plot series, particularly if cover conditions are to be changed in the course of the experiment. (A herbarium is of course an essential part of the record of each experimental forest.) Phenological observations, particularly on flowering and fruiting, are an important feature of many plot records. At research centers. such as experimental forests, phenological observations should be considered an important and necessary activity.

General terms should be avoided. and for each study complete definitions of the various terms needed should be adopted at the time of plot establishment. This is especially important in connection with describing the condition and appearance of individual trees, for the reason that in later years other workers may remeasure the plot and without adequate definitions may not be able to record data in a comparable manner, to reconstruct the stand, or to interpret the recorded data properly.

Many of the descriptive data can be recorded in the field by appropriate symbols or abbreviations. In many cases, especially when it is possible that data will be put on punch cards for machine tabulation and analysis, there is much to recommend the usa of a numerical code, such as that given in the appendix (p. 73), instead of symbols or abbreviations.

\section{TREE CLASSIFICATION}

The position that the crown of a tree occupies in the forest canopy has an important bearing on the tree's growth and development and 
its future value in the stand. This position may be classified according to the following definitions $(25, p .7 / 4)$ adopted by the Society of American Foresters:

Dominant. Trees with crowns extending above the general level of the forest canopy and receiving full light from above and partly from the side; larger than the arerage trees in the stand, and with crowns well-developed but possibly somewhat crowded on the sides.

co-dominant. Trees with crowns forming the general level of the forest canopy and receiving full light from above but comparatively little from the sides; usually with medium-sized crowns more or less crowded on the sides.

Intermediate. Trees with crowns below, but still extending into, the general level of the forest canopy, receiving a little direct light from above but none from the sides; usually with small crowns considerably crowded on the sides.

Overtopped. Trees with crowns entirely below the general forest canopy and receiving no direct light either from above or from the sides. These may be further divided into oppressed usually with small, poorly dereloped crowns, still alive, and possibly able to recover; and suppressed or dying and dead.

In practice almost no attempt is made to distinguish between the oppressed and the suppressed class, the term "suppressed" being used to cover both classes. As both of these terms have a physiological significance, their general use to denote crown position is erroneous. The term "suppressed" is in much more general use than "oppressed."

This standard classification, widely used in North America, can be applied without modification only to pure and fairly well stocked even-aged stands. Several other tree classifications have been proposed, one of the best of which is that used for conifers by the Swedish Forest Experiment Station, given in the appendix (p. 78); but all these apply (with more or less success) only to even-aged stands. Many of the stands, particularly of the coniferous stands, that have developed under conditions typical of the United States are uneven aged, understocked, and ragged. In many cases raggedness has been complicated by mixture of species varying in tolerance. A system is needed for classifying trees in uneven-aged stands according to growth capacity or thrift, as the standard classification indirectly describes trees in the even-aged stand.

The one such tree classification thus far proposed in North America is that developed by Dunning (20) for the ponderosa pine forests of California. This classification, which is given in the appendix (p. 76), has been applied successfully to similar ponderosa pine forests in other regions, and recent indications are that with modifications it can be applied also to stands of other species.

\section{INJURIES AND ABNORMALITIES}

All perceptible injury, either past or present, suffered by a tagged or numbered tree should be recorded. The record should show explicitly the location and extent of the injury and its apparent cause.

Abnormalities of form usually should be recorded as carefully as injury. Abnormalities include burl, crook, heavy fork or unusual branching, misshapen top, heavy butt or root swell, elliptical or irregular cross section of bole, etc. In some studies these have little bearing on the result sought; but since the sample plot is rightly considered a source of data on all growth characteristics of both species and individuals, on reaction to all the factors of site, and on form, such information is logically a part of the record. 
Record should be made of any injurious insects or diseases present, and they should be identified if possible. The recording of secondary pests is optional; but since they are sometimes destructive or lead to further stand losses in later years, good practice dictates that the presence of all such pests be made a matter of record. Nectria, the locust borer, or Buprestids may be a primary cause of windbreak, mistletoe of stem swellings, etc.

\section{REPRODUCTION MEASUREMENTS}

Reproduction as considered here includes (1) young trees below the minimum size given an individual number on the plot, or, in a stand consisting entirely of young trees, and (2) indiriduals less than 3.6 inches in breast-height diameter. The second classification includes all the tree classes below the pole-wood stage as defined by Leffelman and Hawley (43, pp. 10-11) in the following:

1. A sprout is a tree which has grown from a stump over two inches in diameter at the ground line. ***

2 . A seedling is a tree grown from a seed. * * *

3. A single seedling sprout is a tree with a single stem which has grown from a stump two inches or less than two inches in diameter at the ground line. ***

4. A multiple seedling sprout is a tree with more than one stem, which has grown from a stump two inches or less than two inches in diamcter at the ground line. ***

5. A root sucker is a sprout from a root. ***

Decision as to which of the small trees on a plot are to be measured depends very largely upon the purpose of the study. When trees of appreciable volume are to be dealt with, trees below sapling size often are disregarded unless they occur on subplots. Sometimes, however, study is concentrated on the growth and derelopment of the jurenile stand itself. and sometimes it is desirable to establish in stands of young growth fairly large plots that will be used in later studies. In such cases, particularly if the stands of young growth are dense and are subject to heary mortality because of suppression, it is often unnecessary to measure each tree, sprout, or sprout clump. Instead it may be desirable merely to run a narrow strip through the plot, mark each tree on this strip with a dab of paint, and record the number of such trees. If the stand is not too dense, a wider strip may be run or trees may be recorded on small subplots. The trees may be recorded by height class alone until the stand has changed sufficiently to warrant more detailed measurements, sufficient data being taken to define clearly the height-age curre. Such a method should be used only with full realization of how the data will be analyzed later.

For reproduction stands a veraging more than 3 feet in height, if growth and derelopment of the stand is the major subject of investigation a simple record of the total number of stems, by height classes, per unit of area is usually adequate. In such cases it is sufficient to record this information for a random strip that samples the stand. without establishing a plot for remeasurement. If a plot is needed the boundary should be liberally marked by painting trees inside the plot only. The boundary of the plot and of its divisions can be marked temporarily with string.

Studies in which young stands are treated require plots and a record of development. The data recorded for some plots may cover 
merely the aggregate number of trees in height classes, such as the 6 -inch, 12 -inch, or 24-inch height groups. Height may be determined within 6 inches by placing a graduated stick against the tree. Data based on exact measurement of individual trees are much more valuable, however.

When individual stems are tagged, actual heights are recorded. Measurements should be taken from the ground line, with the exception that the heights of stump sprouts should usually be taken from the point of sprouting. Each sprout should be considered as an individual, unless the sprout clump is considered as a unit. Even then it is often desirable to record the number and development of individual sprouts, by clumps.

In very small growth, when the effects of individual growth factors are under observation actual height measurement should be taken along the stem. Obviously, very careful measurements are not necessary in the case of rapidly growing species or sprouts, and in many cases will not be required after the tree has reached smallsapling size. Where confusion is likely to occur otherwise, field data should show how the measurements were taken.

If the smaller trees on a treated plot are individually tagged, measured, and recorded, this does not make it necessary that the trees on the control plot be treated in the same manner. For the control plot, data need be taken only on a certain number of trees representative of the various height classes present. The purpose of the study, the species, and the method of treatment will usually determine which trees and how many shall be taken.

Diameter measurements on very young stands are usually valueless; until the tree has reached at least the 2-inch class an expression of volume growth has little meaning. In some instances, however, it may be desirable to take these measurements in order to extend the diameter-height curves to their origin. When a diameter record for very small trees is necessary the measurement should be made at a point about 6 to 8 inches from the base to avoid root swell, which is sometimes pronounced, particularly in coppice growth. Calipers can be used. It is rarely necessary to mark the point at which the measurements are taken.

To determine the age of a young stand, some of the stems should be cross-sectioned at the ground line. This method will probably be adequate for every species except longleaf pine. The age recorded for planted stands is the number of years (growing seasons) since planting. (Records for such stands should show, however, how old the trees were when planted.)

A crown classification is usually meaningless as applied to reproduction. In describing reproduction it may be highly important, however, to indicate the relative thriftiness or vigor of the seedling, sprout, or sprout clump. No xalid classification of thrift or vigor has yet been advanced. Among those suggested are relative vigor in the stand, as indicated by quantity of foliage (as related to age or size of plant) and freedom from suppressive shade or other competition (as indicated by fullness of crown); character of foliage, including density, general appearance, and color, and perhaps dry weight of representative leaves; comparative height growth; and thrift as judged on the standard of the average thrift of a plant of 
the same age and species grown under favorable conditions. Since a definite standard is lacking, classification as to thrift or vigor is often open to question, particularly if made by different workers at different reexaminations.

\section{STEM AND CROWN MAPS}

A map locating all trees on a sample plot is called a stem map. Such a map may make it unnecessary that all trees be individually tagged or numbered in the field. In addition to presenting a picture of tree distribution and providing an index to the tree numbers on the plot, it facilitates analytical study; division, for statistical study, of a plot on which all tree data were originally lumped; and elimination of any parts of the plot that develop abnormalities. One or another of these uses will in a great many instances justify making a stem map. As an index to tree numbers, alone, the stem map may save many hours of work, which in its absence would be consumed in relocating irregularly placed numbers and identifying trees that have lost their numbers. It should be remembered, however, that the preparation of a stem map is itself a time-consuming task. The decision to prepare one in connection with a given study should be based on a careful consideration of use and need.

The field work involved in mapping tree locations is simplified by dividing the plot into squares with string (p. 16). The coordinates of each tree in each square can quickly be read with a measuring stick ${ }^{24}$ and plotted on cross-section paper. If a chain is stretched through the middle of each square the distance along it may be read directly, and the distance to the right or left of it measured with the stick. It is essential in such work that the chain be kept taut, that allowance be made for slope, and that the measuring stick be held at right angles to the chain. In open stands, distances within a given strip may readily be determined by the use of a range finder. Tree locations may be mapped with a traverse board or with a plane table and an alidade. Under some circumstances, when the plot is carefully sectionized, plane table and alidade may be dispensed with and a piece of cross-section paper mounted on any fairly smooth, hard surface can be used with a high degree of accuracy. The distances may be measured with a chain, with a range finder, or with a telescopic alidade and stadia rod. If much brush or undergrowth is present, it is impracticable to use the range finder or stadia rod.

Tree locations can be determined also by the use of the angle mirror (65). Tapes are stretched along the plot subdivisions (right angles are necessary). One man plots the trees while each of two other men walks along a tape holding an angle mirror from which is suspended a plumb bob. As soon as the proper tree is located the coordinates are called to the mapper, who plots the tree's position. Where there is much undergrowth such use of the angle mirror is impracticable, as the plumb-bob lines are frequently caught. Else-

$24 \mathrm{~A}$ measuring stick used in dense brush by the Forest Service is a rod marked off in feet and painted in bright colors like a surveyor's sight rod but with the difference that 5 instead of only 2 colors are used, each 5 feet of rod displaying the same sequence of white, orange, blue, yellow, and red. When this measuring stick is used, instead of having to look for numbers or letters to identify the foot distance the cartographer has only to distinguish the identifying color of the foot in question, and this he can do if only an inch of the color shows through the tangle of vegetation. 
where, the angle mirror is perhaps as rapid and efficient an instrument as can be obtained.

The scale of the map should be chosen with regard to the quantity of detail required and the density of the stand. A scale of 2 to 4 inches to the chain is usually sufficiently large for plots of one-fourth acre or more. A convenient scale that is readily divisible expedites the work and lessens the danger of mistakes. Measurements can be plotted easily and accurately when an engineer's scale rule is used.

Trees may be shown on the map by dots or by special symbols that distinguish trees to be cut and trees to be left, crown classes, species, sprouts, and seedlings, etc. Or abbreviations placed near the tree position may be used to indicate any one of these.

When the trees bear numbers, the numbers should always be shown on the map, preferably just below the tree positions. 'These numbers on the map should be checked against those on the tree-record sheets to make sure that none has been omitted. Diameters may be written in or may be shown by the relative sizes of the symbols used. To enter much detail on the map may cause confusion and lessen the map's usefulness. The map legend should fully explain each symbol used.

A crown map, in addition to showing the positions of the boles, shows the rertical projection of the tree crowns, thus presenting graphically the shade conditions on the plot. Crown maps are of more value for several-storied than for single-storied stands. Comparison of crown maps made before and immediately after treatment shows the effect of treatment on crown density, and comparison of the latter with subsequent maps shows the derelopment of the crowns of the trees left. Because of the length of time required to prepare a crown map, such a map should be prepared only if its value is clearly demonstrable.

Tree crowns may be mapped by plotting 3 or 4 points at the edge of each crown and then sketching in its shape. These points are located most easily if an assistant to the mapper stands directly under the edge of the crown and the mapper determines the distance and direction from the assistant's position to the tree bole. In stands with irregular crowns, 1 or 2 assistants can locate points and measure distances while the mapper is sketching.

The crown map should represent the stand as seen from above. The highest crowns should be outlined with solid lines; the crowns of the second level may be outlined with broken lines, those of the third level with lines of crosses, etc. An arrow should be drawn from the position of the bole to the position of the crown edge wherever the relationship is not clearly evident on the map.

Since the crowns of trees on the isolation strip surrounding the plot affect those of trees on the plot, a fringe of the former should be included in every crown map.

In many studies it may be desirable to indicate on a plot map the locations of bare areas, piles of slash, logs, skid trails, etc. The purpose of the study will largely govern the extent to which these details should be shown.

As the value of the map depends upon its accuracy, care in plotting is essential.

Reproduction quadrats may be mapped by essentially the same method that has been outlined for plots. The quadrat may be 
sectioned off with string or, preferably, with a standard wooden frame.

Reproduction on quadrats can often be mapped by coordinates $(4,36,49,50,73,78) .{ }^{25}$ This eliminates tagging and sometimes makes field mapping unnecessary. A number of research agencies have found the coordinate system so satisfactory that they have discarded the tagging method entirely. They report that seedlings can be located by this method within half an inch on milacre quadrats. If reproduction is mapped by coordinates, great care is necessary to aroid erroneous location of stems. Where a standard wooden frame is used, mapping by coordinates requires about the same time as tagging. It sares a great deal of time in reexaminations, however, by obviating the necessity of hunting for tags. some of which may have been damaged by animals or covered with debris.

When detailed mapping of quadrats is necessary, slope areas rather than horizontal areas should be used and the results should be converted to a horizontal-area basis.

If plant succession is to be studied by repeated mapping of reproduction quadrats it is well to make the second and subsequent maps on transparent orerlays, so that changes can be brought out without the confusion resulting from marking changes on the original maps. ${ }^{26}$ Except in instances in which the composition or density of the regetation changes rapidly from one season to the next, many quadrats need not be recharted more often than every 2 or 3 years. Colors may be used to indicate year of origin of the reproduction or area occupied by various plants. Symbols or abbreviations may be used for species, and heights may be written in.

Maps of surface conditions, such as the depth, character, and density of litter, the exposure of mineral soil or rock, or the color of the soil after fire, are often of sufficient value to justify preparing them.

Symbols used in sample-plot mapping are shown in the appendix (p. T6).

Every map should be initialed and dated in the field.

\section{PLOT DESCRIPTION}

When the trees and reproduction on a sample plot have been measured the plot itself remains to be described. The plot description should be carefully written in the field and not left to be prepared weeks or months later from hurriedly written field notes. Many facts easily obtained but often overlooked in the field are of inestimable value in working with the data away from the plot, especially to those not familiar with the plot itself. The success of the whole experiment may depend on the completeness of this description.

The quantity and kind of detail needed and methods to be used vary according to the permanence of the plot and the duration of the study $(\%, 15,16,54.72)$. A long-time study should have a more complete record than a short one. But since short-time studies often merge into long-time ones, in initiating a short-time study it is desir-

\footnotetext{
25 TocMer, J. W. See footnote 7 .

26 A phytograph for recording abundance, frequency, size classes, and basal area per acre by species is described by Lutz $(4)$.
} 
able to take more data than are actually called for by existing plans. Quantitative data derived from field measurement, whenever they can be had, are preferable to qualitative descriptions. Items that should in all cases be covered are the following:

1. Designation and location.

2. Date of establishment.

3. Dimensions and area.

4. Name of person making the description, and date of description.

5. Description.

(a) Forest type: Name, composition, etc. (Standard classifications of the Forest Service or the Society of American Foresters should be used if applicable.)

(b) Density of stand and distribution of stems. Density of canopy, both principal and subordinate. Method of determination.

(c) Age of stand. Method of determination.

(d) Site quality or site index. Method and basis of determination. (If more than one species are found in the stand, site should be given for each of the important species.)

(e) Climatic conditions.

( $f$ ) Altitude, absolute and relative.

(g) Slope and aspect. Drainage. Other topographic features.

(h) Soil : Type, origin, drainage, depth, mechanical analysis, $\mathrm{pH}$, etc

(i.) Rock: Underlying, outcropping, kind, quantity, distribution, etc.

(j) Litter and humus: Kind, depth, condition, distribution, etc.

(k) Ground corer: Species, ${ }^{27}$ density, height, distribution, location of significant, etc.

(l) Underbrush: Species, ${ }^{2 \pi}$ density, height, distribution, location of significant, etc.

(m) Reproduction: Origin, species, density, distribution, etc.

6. History of stand.

(a) Origin and development.

(b) Fire. Nature of eridence.

(c) Cutting and other disturbances caused by man.

(d) Disturbances caused by other agencies such as livestock, game, insects, fungi, wind.

7. General summary of silvicultural conditions and growth.

Descriptions of individual divisions of a large plot in an irregularly distributed stand may be very useful in explaining differences in results on different parts of the plot. Brief descriptions of subplots are needed in the case of subplots that are laid out for the purpose of studying special conditions on the plot, and may be useful in other cases.

\section{PHOTOGRAPHS}

Good photographs are an almost indispensable part of a plot record. They illustrate conditions on the plot better than word description, and when repeated after a lapse of time show clearly the changes in these conditions. (A series of repeat photographs is shown in pl. 8.) In later years, the early photographic record may be even more important than the early written record. Because they are so valuable a part of the plot record, photographs should be taken as carefully and with as much attention to details as plot measurements.

The choice of views is important. The photographs for any one plot should together give as accurate an impression of plot conditions as possible. To make them do this may necessitate including a few unusual features, in addition to typical features. The possi-

${ }^{27}$ Here again, a herbarium for the plot may be very useful. 
bility of a repeat picture should be borne in mind in photographing every scene; features that are likely to change in a significant way should be sought, and views that are likely to be hidden later by brush or reproduction should be avoided.

In photographing seedling stands, the usual tendency is to set up the camera so that the picture is longer horizontally than vertically. In later years this set-up becomes undesirable, because the narrow vertical section is inadequate to register height growth. If a seedling stand has features that can be made to stand out only by horizontal photographs, then two photographs are necessary, the horizontal to show the stand as it appears at the moment and the vertical one to be used in connection with later repeat work.

Individual seedlings should be photographed against a contrasting background, as in plate $2, B$.

In the early history of a plot many more photographs should be taken than are needed immediately. As time passes the value of photographs will change, and some of them may retain no significance except as records of original conditions. For example, some repeat photographs may not show clearly the changes that have taken place on the plot, and in others the view of significant features may be completely obstructed by brush. An especially generous number of pictures should be taken on a plot that is to be treated, so that those having little record value after the treatment may be discarded.

In order that repeat pictures may be made from the identical points from which the original ones were made, the "camera points" for all pictures to be repeated should be permanently marked (p. 17), given distinctive numbers, and referenced to permanent plot-boundary stations or numbered trees. It is recommended that at least 4 such camera points be established on each plot up to three-fourths of an acre in size, 6 on each plot of from threefourths to 1 acre, 8 or more on each plot larger than an acre, and at least 1 for each 3 chains of line transect. Plot and subplot corners often make excellent camera points.

When possible, photographs should be developed while the party is still in the field. This practice permits "retakes" of any photographs that are not clear or sharp. When such prompt developing is impossible, it is often advantageous to take more than one photograph from a given camera point to allow for possible failures. The duplicate photographs should be made with different timing or different aperture from the first exposure, as a check on the first effort. They can be distinguished from it and from each other by changing the position of some identifying object in the view between exposures and making a note of the change.

A camera to be used for sample-plot work should preferably take pictures at least 5 by 7 inches in size and have a ground glass on which the view can be focused. ${ }^{28}$ Only, in rare instances should a

\footnotetext{
${ }^{28}$ Many arguments have been adranced in favor of small cameras, but these break down when the photographs are examined. Almost invariably repeat photographs fail to coincide and the number of successful. worth-while prints is low. The use of small cameras leads to hasty and ill-considered work and to the making of numerous snap-shots rather than careful photographs. Although low expense is an argument often advanced, the average cost of a successful photograph is often as great for a small camera as for a larger one. Small cameras are decidedly easier to carry; but in relation to permanent plots, which usually are readily accessible, the difference in ease of transportation is not important.
} 
research agency support cameras that do not take photographs larger than 19 square inches. A tripod should always be used. To get an identical view in a repeat picture, it is necessary to use a camera of the same size and with the same focal length as the one previously used and to orient the photograph by a print of the one preceding it.

Photographs in the woods are best taken on cloudy, windless days, when the contrast between light and shadow is not great and there is no movement to blur long-time exposures. For a picture of a stand, since depth of focus is desirable, small stops with correspondingly long exposures should be the rule. A photometer aids greatly in properly timing pictures. For the best results, color-sensitive films and color screens should be used. Where the sky shows through the crowns, the use of a graduated sky filter is recommended. Precautions should be taken in handling and developing special films to avoid fogging.

Overexposure is preferable to underexposure. An overexposed negative can often be saved by reduction, but no treatment can intensify details that are not present in the negative.

A record should be made of each picture when it is taken. This record should show photograph number, date and hour, stop and exposure used, light conditions, position of camera, direction of view, kind and focal length of lens, kind of filter, and type of film, and should include a description of the camera. (It is suggested that the lens number be noted.) These items should be followed by a complete description of the view, and an explanation of its choice.

A view can be permanently identified as to location by including in it the plot number and station designation. For this purpose, use may be made of a series of large loose-leaf numbers and letters that can be combined in any desired way.

Some object that will give an idea of relative dimensions should be included in each photograph.

Repeat pictures should be taken at all the permanent camera stations at the time of remeasurement, even if no readily apparent change has taken place in the view. Lack of change may be highly significant in some cases, and something significant may be brought to attention by the photograph or may show up at the time of the next visit. If a picture is not repeated, the reason should be noted. Even if one photograph has been a failure, the fact that plots are presumably to be under observation for a long time justifies making a photograph from the same point at each later visit.

Retakes offer a better opportunity for comparison if always taken at approximately the same time of year and of day. Otherwise, minor vegetation of importance from the project standpoint and visible in one photograph may be obscured by snow in a later one. In the case of hardwoods, the whole aspect may be changed by the presence or absence of foliage. Uniformity as to time of day results in similarity of light and shadow effects. 


\section{REMEASUREMENTS}

The proper interval between remeasurements cannot be exactly decided upon at the time of plot establishment. for it depends on the rate of change on the plot. Obviously, the more rapidly a stand grows the more often it should be remeasured.

The nature of the experiment determines how closely growth and other changes should be followed. Since significant changes take place rapidly during the reproduction stage, in methods-ofcutting studies it is common practice to examine reproduction subplots annually, at least for the first few rears. Intensive studies of reproduction sometimes call for examining the subplots each week or every few days.

For stands beyond the reproduction stage, a 5-year interval between remeasurements is generally satisfactory. If growth is extremely slow, as on poor sites and in very old stands, the interval may be lengthened to as much as 10 years. Where growth is exceedingly rapid, a 3-year remeasurement interval may be appropriate.

Diameters are measured at each remeasurement period.

Heights, except in thriftily growing stands, usually need be measured only at alternate remeasurement periods.

Tree-description data, such as data on size, shape, and conformation of crown, are ordinarily taken not oftener than every 10 rears, and on mature trees may be taken at eren longer intervals; in some studies in which changes occur rapidly, as in young thrifty stands and in stands of fast-growing species, it is necessary to take these data more often.

On plots that are known to be liable to disturbance, measurements should be made at shorter intervals.

Mortality is of course recorded, and trees that have died since the last preceding measurement should be permanently blazed, at each remeasurement.

When height data are taken on a height-diameter-curve basis, in remeasurement it is well to run strips through the plot in such a manner as to include a part of the strip on which height measurements were previously made. This helps to keep the distribution of height measurements well balanced and truly representative of the stand. In order to determine whether changes in mechantable height and in clear length are such as to call for a complete remeasurement, remeasurements should be made on representative trees.

Remeasurements should be made at the same time of year that the original data were taken. Uniformity in this regard has a particularly important bearing on the significance of records of seedling survival. If remeasurements cannot be made at the same time of year as the original measurements, they should preferably be taken during the period of regetative rest.

The first duty of those remeasuring plots is to become familiar with the work previously done on the plots and with the technic used. They should carefully review the records and study the plan so as to appreciate fully the intent behind the experiment and fully understand the method of procedure.

The methods used in the original measurement should be followed in all remeasurements. and so far as possible the same instruments or types of instruments should be used. Remeasurements 
usually call for the same degree of precision as that originally sought; if a decision has been reached that increases or decreases the demand for accuracy, the new procedure and the reasons for it should be carefully described in the plot records. Over-refinement is preferable to under-refinement. The notes should be kept by the same system used previously.

The man recording the measurements as they are called to him should constantly check them against the data from previous measurements. In this way current mistakes will be prevented and errors in a previous measurement will be caught when it is easiest to rectify them. A change made in an earlier measurement should be written above the original, and the reasons for it should be noted in the field. Such changes should be initialed and dated. At the time of the first remeasurement a special watch should be kept for trees overlooked at the time of plot establishment. Original diameters can be calculated from increment cores. The original heights of any missed conifers, if needed, can be estimated from the height-growth data.

At every remeasurement, all the plot corners and other permanent stations should be inspected and any needed replacements or repairs made. Any painted numbers, diameter-measurement marks, or boundary lines that have become illegible, weathered, or dull should be renewed. If original numbers cannot be freshened satisfactorily, the numbers should be painted anew. Nails holding tags should be pulled ${ }^{29}$ so that they again protrude from the tree by from one-half to three-fourths of their length. Trees that have grown into the measurable size class since the previous measurements should be numbered (p. 27) and measured. Trees from which tags are missing should be identified by means of the stem map, if any, and their original numbers replaced.

Stem maps should be revised at each remeasurement by plotting the positions of any new trees and indicating any trees that have died. For a plot for which a crown map has been made, if the density of the crown cover has changed significantly a new crown map should be prepared. Transparent overlays facilitate copying usable portions of old maps in the field, and when placed over a translucent table top in the office make possible rapid detection of crown changes.

The description of the plot should be brought up to date, particular note being made of changes evidently due to treatment. After each remeasurement a report should be prepared summarizing all the work done on the plot in connection with the remeasurement.

\section{REPORTS AND OFFICE RECORDS ${ }^{30}$}

\section{REPORT ON PLOT ESTABLISHMENT}

When all the field work of plot establishment has been finished, a complete but concise report should be prepared, bringing together for

20 For this work a mechanic's claw hammer with straight chisel prongs is preferable to a carpenter's hammer, which has curved claws. The chisel edges of the mechanic's hammer make it easier to get the claws under imbedded nails. and thus make pulling a much easier and simpler task.

30 In the appendix a re given abbreviations and a numerical code for use in sampleplot work (p. 73 ), a list of stationery, etc., needed in such work (p. 72), and specimen forms for summarizing plot uata (p. 66). 
ready reference all the information on the plot or series of plots that would be necessary to enable a forester unfamiliar with the plot or plots to carry on the work. It should include maps and survey notes, directions for reaching the plot, and such summaries of data collected as the conduct of the experiment may demand. The instruments and methods used in each step of the work should be noted with special care. In fact, it would be a good plan for the writer of the establishment report to run through this manual and whererer a choice of methods is presented explain which method he chose and why.

The establishment report should cover each heading in the following outline that applies to the work done, explaining in detail the methods used and giving all the descriptions called for in sufficient detail to prevent misinterpretation:

General aspects and purposes of project.

Plot location.

Reconnaissance.

General reasons for selection.

Forest and area (description).

Description, including full directions for reaching plot.

History of plot.

Plot establishment.

Surrey: Methods, instruments, error of closure.

Demarcation of plot: Methods, symbols, kind and quality of paint used (if any), mapping.

Numbering of individual trees: Series of numbers used, location of firstand last-numbered trees, method of painting "numbers or of tagging, kind and quality of paint used (if anr).

Collection of data before treatment: Number of trees, by diameter, height, and crown or other classification; range of diameters; basal area; rolume.

Tree-measurement methods and instruments.

Tree-description terms, and definitions.

Reproduction measurements, and methods.

Soil, litter, ground cover, and other conditions, stem and crown mapping.

Soil type, depth, profile, acidity, etc.

Photographs.

Forms used.

Treatment.

Purpose of plot in detail. (Relation of present work to future program.)

Definitions of qualitative expressions.

Work done, and methods.

Form of utilization, and disposal of debris.

Number of trees treated or removed, by diameter, height, and crown or other classification.

Basal area and rolume of trees remored, by classification.

Damage to stand, cause.

Photographs of plot undergoing treatment.

Collection of data after treatment.

Number of trees.

Tree measurements.

Tree descriptions.

Reproduction measurements.

Soil conditions.

Stem and crown maps.

Photographs.

Comparison of plot conditions before and after treatment.

Stand: Distribution, health, thrift, diameter, crown classes, etc.

Reproduction.

Ground cover and other minor regetation.

Soil and litter conditions.

Personnel of field party and dates of work. 
Recommendations for future work. Discussion of future treatments as to kind, degree, and time. This should carry the work for from 10 to 20 or more years into the future.

Appendix: Maps, survey notes, field and explanatory notes, volume tables, photographs, etc.

Usually it is unwise to make an elaborate analysis of plot data at the time when the establishment report is written. Remeasurements are likely to show that some other approach would be more profitable than the one chosen at the time of establishment. However, in anticipation of changes in personnel and in view of the difficulty of fully appreciating at a later time what was in the mind of the man who established the plot, it is well for the establishment report to make rather definite recommendations as to procedure in analysis. These serve as a guide to those who make reexaminations and write progress reports; also, preparing such recommendations in conjunction with the original plan tends to assure that the information taken at establishment will cover all points needed in a future analysis. The recommendations as to procedure need not be adhered to, of course, if some more profitable approach develops.

\section{PROGRESS REPORTS}

At every remeasurement a report should be prepared describing conditions found on the plot and any treatment given it (with reasons therefor), summarizing the data, and presenting the principal findings from preliminary analysis. Each such report should discuss further treatment needed by or planned for the stand. These reports should be supplemented with progress reports made after every additional visit to the plot. The latter may be exceedingly brief, but should mention anything out of the ordinary that the visits bring out. Information currently recorded on such matters as presence of insects, wind damage, recent death of numbered trees, excessive numbers of rodents, disturbance of plot corners, and missing tags is very helpful at later remeasurements.

Before the progress report is prepared the author should consult the working plan, establishment, and previous progress reports so that he will have clearly in mind the purpose of the study and the previous findings. Such a review will assist him in carrying out the essential aims of the investigation.

\section{FIELD RECORD}

In order that the sequence and usefulness of the plot records may be better understood, a continuous diary should be kept of all the operations on the plot. This diary should include the following points :

(1) Date of each visit.

(2) Personnel of visiting party.

(3) Work done, and methods of work.

(4) Instruments used, and persons using them.

(5) Weather.

(6) Other pertinent matters.

An analysis of the time and number of men needed for each step of plot establishment and treatment is useful in subsequent planning for similar work. 


\section{PLOT INDEX}

An office index to plot establishment and remeasurements should be kept up to date. A file of cards about 5 by 8 inches in size with spaces provided for the required information will be useful, since the cards for individual plots may be grouped at will according to projects, localities, or years when remeasurements are needed. The information for each plot should include:

Project designation.

Plot designation.

Date of establishment.

Treatment and date.

Area and dimensions.

Number of reproduction quadrats.

Date of each remeasurement.

Date next reexamination is required.

The card for a new plot should be filled out and filed as soon as the field work of establishment is complete.

An alternative device is a plot calendar, recording the same information as the index cards but taking the form of a large chart on which each line represents an individual plot. Such a calendar has advantages over a card index in that the records of all the plots of a given locality or series can be seen at a glance and direct comparisons can be made immediately.

\section{PRESERVATION AND FILING OF FIELD RECORDS}

Original field notes, since they are irreplaceable, should be very carefully protected against loss. Field data should be kept in a fireproof safe. In many cases, as an insurance against loss, field notes should be duplicated, particularly those that will be needed in the field for extended periods during remeasurements. One copy should be kept always in a safe place, while the other may be taken into the field at the time of remeasurement. In the field. all records should be kept under lock and key when not in use, and should be checked daily to make sure that none is lost. The duplicates may be made with carbon paper when the original notes are written. If they are not made then, to avoid errors that might occur in copying they may be photostated. To reduce the cost of such reproduction, several sheets of plot records can be photostated at one time.

The records of each plot should be filed separately. Data applying to a group of plots should have a separate folder and be filed ahead of the records of the individual plots in the group. If maps and photographs are filed separately from the measurements and plot descriptions, a notice of their location should be placed in the plot folder.

\section{PLOT ABANDONMENT}

Changes in silvicultural practice sometimes appear to destroy the value of plots previously established to meet a specific condition. Thus certain plots established to show damage due to horse logging became valueless so far as their original purpose was concerned because of adoption of machine logging. Plots established on a diameter-limit basis may be rendered obsolete by a lowering of the limit in practice. Plots for study of a farored species may lose much of their accumulated research value when the associated species form- 
erly regarded as inferior suddenly becomes raluable. Maintenance of such plots requires time; compilation of the records probably requires more. The question arises as to whether plots affected by such changes should be dropped and forgotten or whether collection and compilation of data from them should continue.

Occasionally, also, an investigator is confronted by the fact that certain plots established many years previously are too small, were not comparable, or were abnormal in composition, age, site, or stand. In such cases there may be some doubt as to whether the plots should be continued and, if so, for how long.

Despite precautions, accidents happen to sample plots rather frequently. An electric transmission line may be put through one corner of a plot; a band of sheep may be bedded down in an enclosed plot area; woodcutters may make a hole in the stand; a storm may break or uproot a large percentage of the stand; fire may destroy part of the reproduction; insects may suddenly become epidemic; or disease may break out.

No hard and fast rule can be given as to whether, in such circumstances, plots should be abandoned or retained. Obviously, more than temporary considerations should be taken into account and no plot should be abandoned unless it is so far awry that further effort is certain to fail of a reasonable return. When plots are found to be too small, otherwise inadequate, or noncomparable, little can be done to remedy the situation. Such plots should be dropped unless they have some intrinsic merit that will make them valuable in the future. In many instances, however, when the value of plots has been destroyed so far as their original purpose was concerned the plots have retained value from other points of view, sometimes because of developments unforeseen at the time when they were established.

Foremost of the considerations to be taken into account is the fact that all plots increase in value as they grow older, regardless of what they show, because thus far we have in North America no authentic data on forest growth and mortality over long periods. Such data are needed in growth predictions. Even if the original purpose must be abandoned or if the plots are not as they should be to meet a specific need, often the value of prospective data is sufficient to warrant further work.

Second, plot records systematically built up over many years can be expected to tell us much about the reactions of trees to their environment. Reliable data on such reactions are now nonexistent for most of our forest tree species. Such information is essential to putting American silviculture on a sound basis.

When the applicability of plot data is changed through changes in utilization practices, instead of abandoning the existing plots it may be desirable to establish supplemental plots. For this reason it is well at the initiation of a plot series to lay out a larger number of plots than that the need of which is foreseen.

When the value of a plot is in question it may be advisable to continue plot measurements on a reduced scale only. Measurements may be made at intervals longer than the period originally prescribed, or irregularly rather than regularly. Tags can go longer without pulling, or paint can weather still more before being freshened. 
Intervals between repeat photographs may be lengthened. Corner markers that fall over may not need to be replaced. Subplots may be forgotten. Records may go uncompiled, if they are properly preserved. With such handling many plots, abandonment of which is considered, can be continued, possibly to surprise the investigator in later years with their value.

\section{LITERATURE CITED}

(1) Alien, F. E., and Wishart, J.

1930. A METHOD OF ESTIMATING THE YIELD OF A MISSINg PLOT IN FIELD EXPERIMExtal Work. Jour. Agr. Sci. [England] 20: 398-406.

(2) Ayerican Jonvt Committee on Horticultural Nomexclature. 1923. Standardized plant rasies. Prepared by F. L. Olmsted, F. V. Corille, and H. P. Kelsey. 546 pp. Salem, Mass.

(3) Ayitur, J. A.

1925. LILJexström's Dendrometer. Pulp and Paper Mag. 22: 835-836.

(4) Baldwix, H. I.

1927. A USEFUl QUADRAT TAKER AND REPRODUCTION COUNTER. Ecology 8: $385-387$, illus.

(5) BARRETT, L. I.

1929. ACCURACY OF FOREST SERIICE STANDARD HYPSOMETER. Jour. Forestry 27: $587-588$.

(6) and Righter, F. I.

1929. WORKING PLAN FOR EXPERIMENTAL THINNINGS IN SHORTLEAF AND LOBLOLLY PINES. Jour. Forestry 27: 782-803, illus.

(7) Bates, C. G., and ZoN, R.

1922. RESEARCH METHODS IN THE STLDY OF FOREST ENIIRONMENT. U.S. Dept. Agr. Bull. 1059, 209 pp., illus.

(8) BAUER, H. A.

1924. STUDYiNg GRowth With AN INCREMENT BoRER. Jour. Forestry 22: 298-301.

(9) Behre, C. E.

1926. COMPARISON OF DIAMETER TAPE AND CALIPER MEASUREMENTS IN SECOND-GROWTH SPRUCE. Jour. Forestry 24: 178-182.

(10) Berg, B.

1929. AN IMPROIED METHOD FOR NUMBERING TREES OX PERMANENT SAMPLE PLOTS. Jour. Forestry 27: 750-751.

(11) Bouroucos, G. J.

1930. A COMPARISON OF THE HYDROMETER METHOD AND THE PIPETTE METHOD FOR MIAKING MECHANICAL ANALYSIS OF SOILS, WITH NEW DIREctions. Jour. Amer. Soc. Agron. 23: 747-751.

(12) Bowley, A. L.

1920. elements of statistics. Ed. 4, 459 pp., illus. London.

(13) BRUCE, D.

1925. SOME POSSIBLE ERRoRS In the Use of CuRves. Jour. Agr. Research 31: 923-928, illus.

(14) and ReINeke, L. H.

1931. CORRELATION ALINENENT CHARTS IN FOREST RESEARCH: A METHOD OF SOLVING PROBLEMS IN CURVILINEAR MULTIPLE CORRELATION. U.S. Dept. Agr. Tech. Bull. 210, 88 pp., illus.

(15) Clements, F. E.

1905. ReSearch methods in Ecology. 334 pp., illus. Lincoln, Nebr.

(16) - and Goldsmith, G. W.

1924. THE PHYTOMETER MIETHOD IN ECOLOGY; THE PLANT AND COMMUNITY As INSTRUMENTs. 106 pp., illus. Washington, D.C. (Carnegie Inst. Wash. Pub. 3ä6.)

(17) Davis, R. O. E., and Bennett, H. H.

1927. GROUPING OF SOILS ON THE BASIS OF MECHANICAL ANALYSIS. U.S. Dept. Agr. Circ. 419, 15 pp., illus.

(18) Detwiler, S. B.

1915. SAVING LABOR IN MEASURING HEIGHTS; A NEW PRINCIPLE APPLIED TO THE HYPSOMETER. Forestry Quart. 13: 442-444, illus. 
(19) Dunning, D.

1925. AN INSTRUMENT FOR MEASURING INCREMENT CORES. Jour. Forestry $23:$ 183-184, illus.

(20)

1928. A TREE CLASSIFICATION FOR THE SELECTION FORESTS OF THE SIERRA NEVADA. Jour. Agr. Research 36: 755-771, illus.

(21) Erickson, M. L.

1914. THE USE OF THE ABNEY HAND Level. Forestry Quart. 12: [370]375.

(22) EzeKiEL, M.

1930. METHODS OF CORRELATION ANALYSEs. 427 pp., illus. New York and London.

(23) Falconer, J. G.

1931. A METHOD OF ACCURATE HETGHT MEASUREMENT FOR FOREST TREES. Jour. Forestry 29: 742-746.

(24) Fenska, R. R.

1925. DEVICE FOR MEASURING INCREMENT BORINGS. (Note) Jour. Forestry 23 : 540-542, illus.

(25) Fernow, B. E., chairman.

1917. FOREST TERMINOLOGY. REPORT OF COMMITTEE. Jour. Forestry 15: 68-101.

(26) FisHer, R. A.

1926. the ARrangement of Field experiments. Jour. Min. Agr. [Gt. Brit.] 33: 503-513.

(27)

1932. STATISTICAT METHODS FOR RESEARCH WORKERs. Ed. 4, rev. and enl., 307 pp., illus. Edinburgh and London.

(28) - and WishaRT, J.

1930. THE ARRANGEMENT OF FIELD EXPERIMENTS AND THE STATISTICAL REDuction of the results. Imp. Bur. Soil Sci. Tech. Commun. 10, 24 pp.

(29) Goulden, C. H.

1931. MODERN methods of Field Experimentation. Sci. Agr. 11 : 681701.

(30) 1932. APPLICATION OF THE VARIANCE ANALYSIS TO EXPERIMENTS IN CEREAL CHemistry. Cereal Chem. 9: 239-260.

(31) HAIG, I. T.

1925. SHORT CUTS IN MEASURING TREE HEIGHTS. Jour. Forestry 23 : 941-944, illus.

(32) 1929. ACCURACY OF QUADRAT SAMPLING IN STUDYING FOREST REPRODUCTION oN CUT-OVER AREAS. Ecology 10:374-381, illus.

(33) 1931. THE STOCKED-QUADRAT METHOD OF SAMPLING REPRODUCTION STANDS. Jour. Forestry 29 : 747-749.

(34) Hanzlik, E. J.

1924. TREE CLASSIFICATION IN SWEDEN. Jour. Forestry 22 : 175-177, illus.

(35) HEJLL, G.

1926. EIN NEUES DENDROMErER. Tharandter Forstl. Jahrb. 77 : 338-343, illus.

(36) Hit., R. R.

1920. CHARTING QUAdRATS With a PLANTograph. Ecology 1: 270-273, illus.

(37) IMMER, F. R.

1932. A STUDY of SAMPLING TECHNiC WITH SUgAR BeEts. Jour. Agr. Research $44: 633-647$.

$(38)$

1932. SIZE AND SHAPE OF PLOT IN RELATION TO FIELD EXPERIMENTS IVITH SUGAR BEETs. Jour. Agr. Research 44: 649-668, illus.

(39) Kittredge, J., JR.

1924. USE OF STATISTICAL METHOdS IN FOREST RESEARCH, Jour. Forestry 22 : $306-314$, 
(40) Kratch, H.

1918. SOME NEW ASPECTS REGARDING THE USE OF THE FOREST SERTICE STANDARD (GRADIMETER) HYPSOMETER. Jour. Forestry 16: 772776 , illus.

(41)

1922. A NEW METHOD OF MEASURING TREE HEIGHTS ON SAMPLE PLOTS. Jour. Forestry 20: 220-222.

1924. COMPARISOX OF TAPE AND CALIPER MEASUREMENTs. Jour. Forestry 22: $537-538$.

(43) Leffelman, L. J., and Hawley, R. C.

1925. STLDIES OF CONNECTICUT HARDWOODS: THE TREATMENT OF ADVANCE GROWTH ARISING AS A RESULT OF THINNINGS AND SHELTERWOOD cuttings. Yale Univ. School Forestry Bull. 15, 68 pp., illus.

(44) Lutz, H. J.

1930. THE VEgETATION OF HEART'S CONTENT, A VIRGIN FOREST IN NORTHWestern PENxsylvania. Ecology 11: 1-29, illus.

(45) McArdle, R. E.

1928. RELATIVE ACCURACY OF CALTPERS AND DIAMETER TAPE IN MEASURING DOUGLAS FIR TREES. Jour. Forestry 26:338-342.

(46) and ChapMan, R. A.

1927. MEAStRING TREE HEIGHTS ON SLOPES. Jour. Forestry 25: 843-847, illus.

(47) - and Meyer, W, H.

1930. THE yield OF DOCgLAS Fir IN the PaCific NoRthinest. U.S. Dept. Agr. Tech. Bull. 201, 64 pp., illus.

(48) McCarthy, E. F.

1924. COMMAEN ON TAPES AND CALIPERS. Jour. Forestry 22: 539.

(49) McGinnies, W. G.

1930. THE QUADRAT. Jour. Forestry 2S: 23-27.

(50) Moore, E. B.

1931. A METHOD OF MAPPING DETAIL ON SAMPLE PLOTS UNDER HEAVY BRUSH COVER. Jour. Forestry 29: 1075-1076.

(51) MIOREY, H. F.

1931. A test OF HYPSOMEters ox short treEs. Jour. Forestry 29: 233-237.

(52) 1931. TAGS AND PAINTEd Numbers oN TREeS IN PERMANENT SAMPLE PLOTS.

(53) Morgan, M. F. Jour. Forestry 29: 821-822.

1932. microchemical sorl tests. Conn. Agr. Expt. Sta. Bull. 333.

(54) Nichols, G. E. pp. [111]-132, illus.

(55) NOYES, D. K.

1916. COMPARATIVE TEST OF THE KLAUSSNER AND FOREST SERIICE STANDARD HYPsometers. Soc. Amer. Foresters Proc. 11: 417-424.

(56) Olsen, C. F.

1932. A CORE-EXTRACTING DRILL FOR CLOGGED INCREMENT BORERS. Jour. Forestry 30: 228-229, illus.

(57) Oudis, A.

VUES D'ENSEMIBLE STR L'ORGANISATION EN FRANCE DES RECHERCHES DE SYLVICULTURE ET D'ÉCONOMIE FORESTIÈRE: LES MÉTHODES. Ann. École Nat. Eaux et Forêts et Sta. Recherches et Expériences Forestières 3 (fasc. 2) : [229]-266. (Summary in English, pp. [263]-264; in German, pp. [265]-266.)

(58) PAETH, W. J.

1914. OBTAINING VERTICAL CONTROL OF PRACTICAL VALUE WITH THE ABNEY HAND LEVEL. Forestry Quart. 12: [347]-369.

(59) Patterson, J. E.

1926. MICROMETER SLIDE ADAPTED TO CORE MEASURING. Jour. Forestry $24: 691-693$, illus.

(60) Reineke, L. H.

1926. THE DETERMINATioN OF tree VoluMe By PLANIMETER. Jour. Forestry 24: 183-189, illus. 
(61) REINEKe, L. H.

1928. A new forest instrument. U.S. Dept. Agr. Forest Worker 4 (2) : 13.

(62) Richards, E. C. M.

1931. A METHOD FOR SHARPENING INCREMENT BORERS. Jour. Forestry 29 : 133.

(63) Robertson, W. M.

1928. REVIEW OF THE CASE OF DIAMETER TAPE VS. CALIPERS. Jour. Forestry $26: 343-346$.

(64) Robinson, Sir R.

1933. SIGNIFICANCE OF CROWN LENGTH IN LARCH PLANTATIONS. Forestry [London] $7(1):[9]-15$, illus.

(65) Sammi, J. C.

1932. THE ANGLE MIRROR IN SAMPLE PLOT WORK. Jour. Forestry 30 : $753-754$.

(66)

1933. THE LATEST IN ABNEY Levels. Jour. Forestry 31: 852-853, illus.

(67) SCHERER, N. W.

1914. Relative ACCURACY of CALIPERS AND Steel TAPE. Soc. Amer. Foresters Proc. 9: 102-106.

(68) Schumacher, F. X., and Bull, H.

1932. DETERMINATION OF THE ERRORS OF ESTIMATE OF A FOREST SURVEY, WITH SPECIAL REFERENCE TO THE BOTTOM-LAND HARDWOOD FOREST REGION. Jour. Agr. Research 45: 741-756, illus.

(69) Stevens, R. D.

1929. A SLIDING SCALE FOR HEIGHT MeAsuREMENTS. Jour. Forestry 27: $550-553$, illus.

(70) Stewart, G.

1930. PHLOROGLUCIN AS A STAIN TO AID IN DETERMINING GROWTH RATEI OF TREES. Jour. Forestry 28: 402-403.

(71) SUDWORTH, G. B.

1927. CHECK LIST OF THE FOREST TREES OF THE UNITED STATES: THEIR Names and Ranges. U.S. Dept. Agr. Misc. Circ. 92, 295 pp.

(72) Tansley, A. G.

1923. PRACTICAL PLANT ECOLOGY; A GUTDE FOR BEGINNERS IN FIELD STUDY of PLANT COMmUNities. $215 \mathrm{pp}$, illus. New York.

(73) and CHIPP, T. F.

1926. AIMS AND METHODS IN THE STUdy OF VEgETATION. 383 pp., illus. London.

(74) Thrupp, A. C.

1926. A NEW METHOD IOR LAYING OFF RECTANGULAR SAMPLE PLOTS. Jour. Forestry 24: $30-62$, illus.

(75) TtPpetT, L. H. C.

1931. THE METHODS OIN STATISTICS; AN INTRODUCTION MAINLY FOR WORKERS IN THE BIOLOGICAL SCIENCES. 222 pp., illus. London.

(76) TRUOG, E,

1930. THE DETERMINATION OF READILY AVAILABLE PHOSPHORUS OF SOILS. Jour. Amer. Soc. Agron. 22: 874-882.

(77) Wallace, H. A., and SNedecor, G. IV.

1931. CoRrelation and machine calculation. Revised by G. W. Snedecor. Iowa Agr. Col. Off. Pub. v. 30, no. 4, 71 pp.

(78) Weaver, J. E., and Clements, F. E.

1929. Plant ECology. 520 pp., illus. New York.

(79) Winters, R. K.

1930. SUITABILITY OF THE LILJENSTROM DENDROMETER FOR READING DIAMETERS OF TREES IN BLACK WALNUT PLANTATIONS. Jour. Forestry 28: $511-514$

(80) Wright, W. G., Robertson, W. M., and Mulloy, G. A.

1925. Forest RESEARCH MANUAL. Canada Dept. Int., Forestry Branch.

(81) YATES, F. 93 pp., illus.

1933. THE PRINCIPLES OF ORTHOGONALITY AND CONFOUNDING IN REPLICATED

(82) YULE, G. U. EXPERIMENTs. Jour. Agr. Sci. [England] 23: 107-145.

1927. an introduction to the theory of statistics, Ed. 8, rev., 422 pp. London.

$87471^{\circ}-35-5$ 


\section{APPENDIX}

\section{TYPICAL FIELD FORMS USED IN SAMPLE-PLOT WORK BY THE UNITED STATES FOREST SERVICE}

(All forms are letter size ( $S$ by $10 \frac{1}{2}$ inches) unless otherwise stated)

561 Tree description. Prorides for original measurement and four remeasurements of a single tree. In addition to basic data like breast-height diameter and height, provides for description of bole, crown, vigor, etc. Notebook size.

561B Tree descriptions. Has same headings as 561, but provides for orig. inal measurement and four remeasurements of $\&$ trees, or single measurement of 40 trees.

$11 t$ Permanent sample plots-Enumeration sheet. Like 561B except that the only printed headings are species, breast-height diameter, height, and crown class.

279 Physical surres. Prorides for detailed description of a plot or observation point under these headings: Topographic features, forest environment, soil character, and moisture supply. Space on reverse for sketch map and additional notes. 


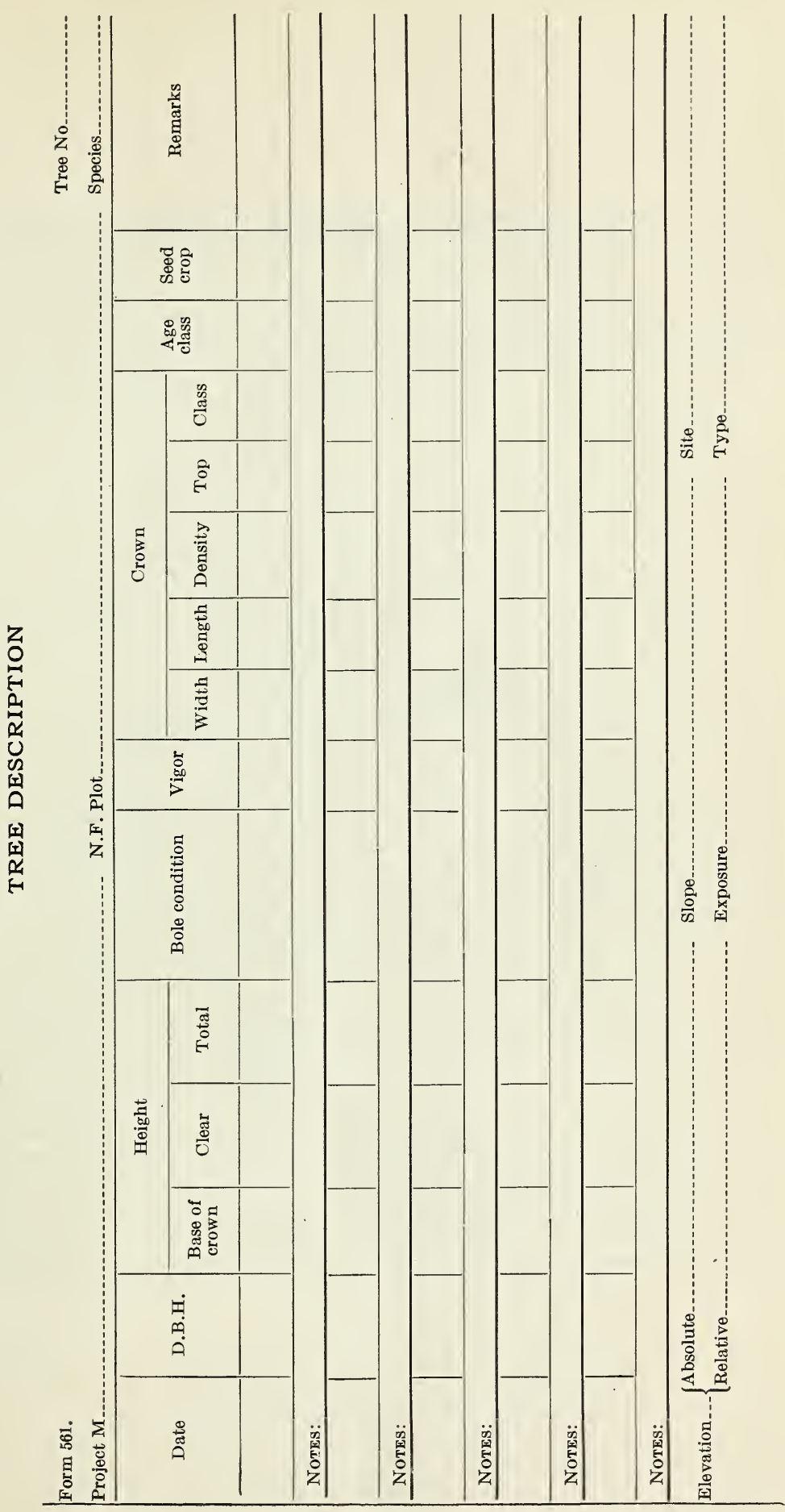




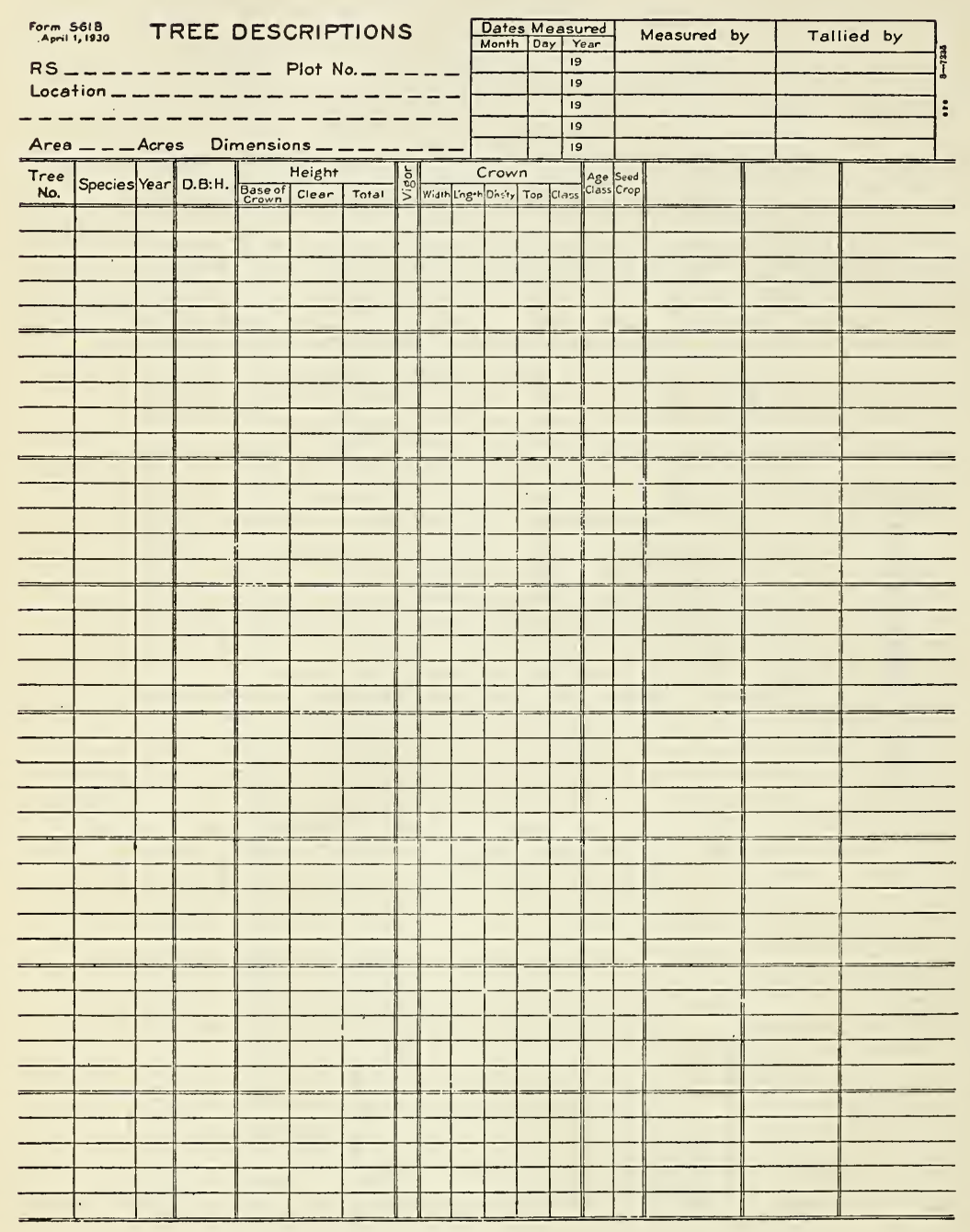


PERMANENT SAMPLE PLOTS-ENUMERATION SHEET

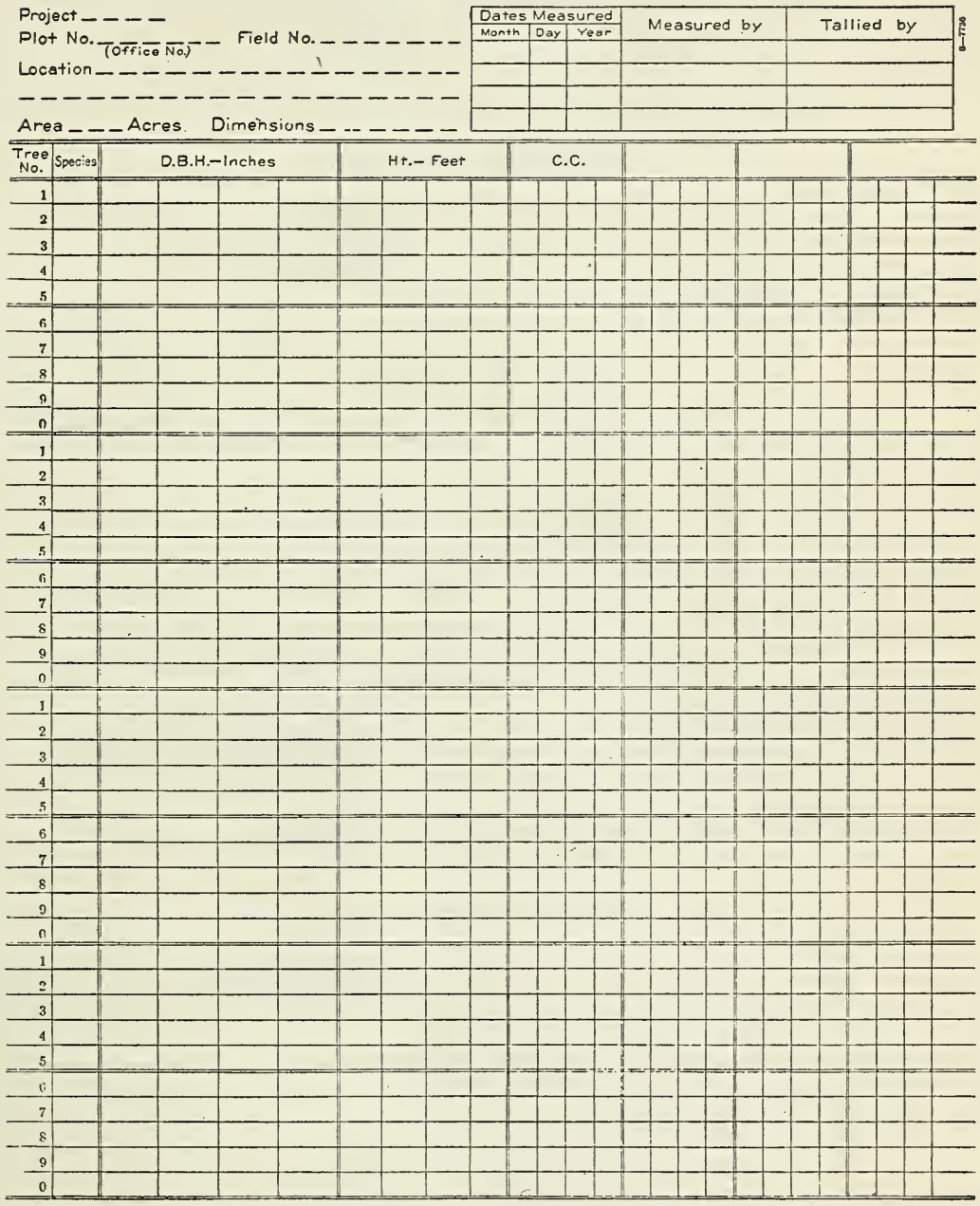


RS

DESCRIPTION OF : Observation Point $\square$, Limited Area $\square$, Tree Environment $\square$.

Purpose of plot

Station No_-

Forest type

Permanent sample plot No

Forest

County

Legal Loc.

State

\section{TOPOGRAPHIC FEATURES}

Gen. char

Aspect.

Distance from ridge.

Elevation above water

Air drainage conditions

Area involved.

Absolute elevation

Block No

Nearest P.O

Drainage

Exact Loc $^{1}$

Eleration of horizon to east

\section{FOREST ENVIRONMENT}

History

Distance of nearest trees to north

Age of trees ${ }^{2}$

Height ${ }^{2}$

Diameter ${ }^{2}$

Trees per acre ${ }^{2}$

Stand. ft. B.M. ${ }^{3}$

Stand. cu. $\mathrm{ft}_{-}$

Basal area, sq. ft_-_-_-_-_-

Growth rate in height, diam., or cu. ft. per A.

Shading, amount

Site quality

Light at the ground, percent

Summary of conditions affecting reproduction, ${ }^{4}$ not elsewhere mentioned:

Size, growth, vigor, and reproductive capacity, injuries, etc. ${ }^{5}$

\section{SOIL CHARACTER AND MOISTURE SUPPLY}

Depth of litter

Character

Depth of humus

Surface moisture

Penetration of humus in mineral soil as shown by color, inches

Char. subsoil, distinguished from soil

Total depth of soil permeable to roots, inches

Amount and kind of rock fragments in soil

Char. impermeable substratum

Origin (in situ, colluvial, alluvial, or eolian, and from what rocks)

Composition and class (after analysis)

Drainage

Present moisture

\section{Observer}

Date-

\footnotetext{
1 Sketch on back of sheet.

2 Describe separately for each species or crown class, or both.

3 Give also volume table or scale used, and top diameter utilization.
}

${ }^{4}$ Give complete list of vegetation on back of sheet.

${ }^{5}$ Description of special tree only. 
[Form 279, reverse]

UNITED STATES

DEPARTMENT OF AGRICULTURE FOREST SERVICE

Further Notes and Remarks:

Sketch: Details of site, exact location and detailed instructions for reaching area.

References :

Maps:

Reports :

Photograph Nos

Stem analyses :

Environmental conditions measured

Moisture samples:

Samples for analysis:--

Soil analyses filed:

Other :

Plot vegetaticn: 


\section{INSTRUMENTS, ACCESSORIES, TOOLS, AND STATIONERY USED IN SAMPLE-PLOT WORK}

\section{INSTRUMENTS}

Alidade, 30-inch scale.

Aneroid barometer.

Auger, soil.

Bark measurer, Swedish.

Bark scratcher.

Calipers.

Camera, with carrying case, color screens, films, ground glass, special lenses, photometer, set of numbers, sky filter, and tripod.

Chain, surveyor's.

Compass.

Containers, increment-core.

Drafting boards.

Drafting instruments.

Geotome.

Hypsometer, Forest Service standard and Klaussner.

Increment borer (preferably two sizes), with extra bits.

Lenses, hand.

Level, Abney.

Microscope, field, low-power.
Mirror, angle.

Pins, surveyor's.

Plane tables, large and small, with tripod.

Plumb bobs.

Potentiometer, soil-acidity.

Quadrat frames.

Range finder, Fardi.

Register, tally.

Rods, measuring.

Rods, stadia.

Rules, 12-inch; steel, with $\frac{1}{10}$-inch divisions; wood, with $1 / 8$-inch divisions.

Scales, engineer's 12-inch boxwood.

Slide r'ule.

Staff, Jacob's.

T-square, drafting.

Tapes, diameter, 10-foot, 20-foot, and 50-foot.

Tapes, surveyor's, 50-foot, 100-foot, 1chain, 2-chain.

Transit, with tripod.

\section{ACCESSORIES}

Brushes, paint, several sizes, and stiff wire.

Canteen.

Carrying case, hand, canvas.

Chalk, crayon and precipitated.

Cheesecloth (or cheap muslin).

Climbers, tree.

Crayons, artist's, in lifferent colors; keel (red, blue, black).

Iron, angle (for corners).

Knapsack.

Ladder, sectional.

Maps, county, forest, road, State.

Nails, assorted copper (sixpenny, eightpenny, twelvepenny, finishing).

Numbering machine and tape.

Paint.

Phloroglucin.

Pins, wire (for reproduction).

Pipe, iron (for corners).

Posts, concrete (for hubs or permanent corners).

Press, plant, with blotter's and papers.

Protractors, metal and xylonite.

Pepair outfit, tape, complete.

Axes, hand and single-bit.

Brush cutters (pruner's).

Chisel, cold and carpenter's 1-inch.

Connectors, wire.

Cutters, wire.

Dies, set of.

Draw-shave.

Files, flat, rat-tail, and triangular.

Hammer's, carpenter's special claw, machinist's, and light sledge.

Hatchet.
Rope, clothesline and manila (or hemp), 3/4-inch.

Sacks, burlap, chalk, seed, soil.

Safety belt, lineman's.

Scales, postal, 25-pound capacity.

Screws, assorted sizes.

Scribe, timber.

Signs, tin, enamel, wood (for location survey, boundary, information, etc.). Sling seat (for climbing trees).

Soil cans.

Spray gun, paint.

Stamps, rubber (tree-numbering).

Staples, fence.

Stencils (for signs).

Tacks, carpet and thumb.

Tags, tree.

Tatum holder.

T'riangles, xylonite.

Trunk (for instruments and records). Twine.

Wire, copper, noninsulated and insulated; hay, store, and telephone no. 12.

\section{TOOLS}

Knives, bolo, butcher, hand, and machete.

Mattock.

Pliers.

Rasp.

Saws, carpenter's hand, and crosscut.

Screw-drivers (large and small).

Shovel, long-handled.

Spade.

Whetstone. 
STATIONERY, ETC.

Clips, paper.

Envelops, assorted.

Erasers, art gum and pencil.

Forms.

Glue.

Ink, drafting and writing.

Labels (paper and cloth).

Notebooks.

Paper, carbon, coordinate (several sizes and scales), notebook, scratch, tabulating, tracing, transparent (overlay), and writing.
Paste.

Pens, drafting and writing.

Pencils, colored (set), and drawing (2H, 4H, 6H)

Photographs (original and repeats).

Reports, establishment, etc.

Rubber bands.

Working plan.

\section{ABBREVIATIONS AND NUMERICAL CODE FOR USE IN SAMPLE- PLOT WORK}

Age classes:

Uneven-aged stands:

Young

Thrifty mature

Mature

Even-aged stands:

0 to 9 years

10 to 19 years

20 to 29 jears

Etc. (If data are for 20-year age classes-e.g., $0-1 \overline{9}$ years, 20-39 years-use odd numerals only, as i, 3,5 .)

Bark thickness

Basal area (square feet)

Base of crown

Bearing tree (witness tree)

Bench mark (witness marker)

Board feet

Brush (cf. Slash.) Area occupied by brush (or chaparral) Species may be plotted and a letter or coded numeral adopted to meet local conditions.

Camera point

Cords

Cordwood

Crown class

Dominant

Codominant

Intermediate

Suppressed

Open grown

Crown length

Long - -

Medium

Short

Crown shape

Pointed

Round

Flat.

One-sided

Two-sided

Spike top (dead top)

Bayonet top

Crown width

Wide

Medium

Narrow

Cubic feet

\begin{tabular}{cr}
\multicolumn{2}{c}{$\begin{array}{c}\text { Abbrevi- } \\
\text { ation }\end{array}$} \\
Yumerical \\
code
\end{tabular}
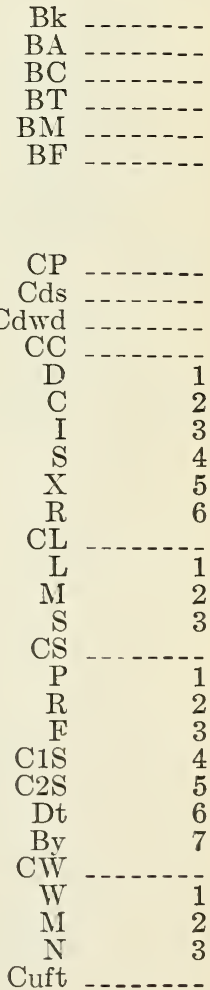
Density of stand: This usually refers to light conditions, being in effect a measure of the tolerance of the ground cover. It may be expressed in terms of the percentage of light reaching the ground. This is recorded in tenths, by the use of numerals 1 to 9 . Complete density (10) is expressed by 0 .

Very dense shade: complete canopy of tolerant species (e.g., dense spruce, hemlock, or beech)

Dense shade: canopy with some holes, tolerant species not forming complete canopy

Medium shade, such as is formed by complete canopy of intolerant species

Half shade

Open stand (less than half shade)

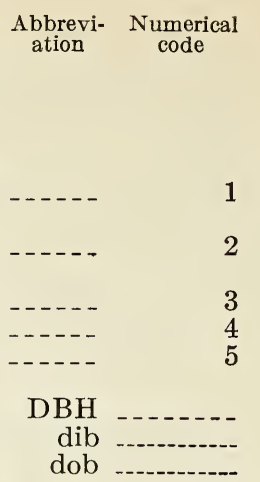

Erosion:

Breast height_...

Inside bark

Outside bark

Sheet:

Slight

Severe

Shoestring:

Slight

Moderate

Severe

Gullying:

\section{Slight}

Moderate

Excessive

Exposure:

Flat.

North - -

Northeast

East

Southeast.

South

Southwest

West.

Northwest.

Form:

Class

Factor

Point -

Quotient.

Ground cover (may be recorded separately for grass, weeds, or brush, or for individual species of each):

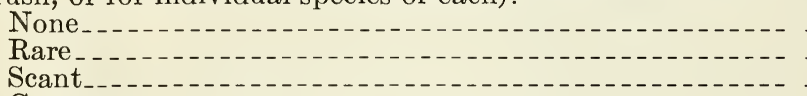

Scant-1-1-20

Abundant

Very abundant

Height:

Base crown

Merchantable

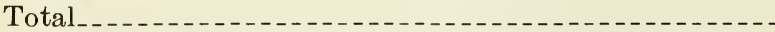

Increment boring -

Two borings on tree Injury:

Three borings on tree

Disease-abbreviations for specific names of diseases or numerical code.

Fire:

Basal scar

Crown scorched

(Express degree in percentage and use 1 to 10 under the Hollerith code.)

Heat killed

Fs

BC

Mch

$\mathrm{Ht}$

Bo

$2 \mathrm{Bo}$

1

2

3

4

5

6

8

Ft

NE

SE

SW

W

Fc

Ff

Fp

q

3Bo

Fcs

Fx 
Injury-Continued.

Fungus - as for Disease.

Insects-abbreviations for specific names of insects or numerical code.

Logging

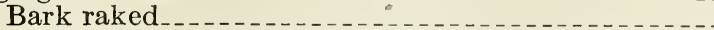

Basal scar

Girdled . . . . .

Limbs broken

Top broken out

Tree bent over

Tree uprooted

Abbrevi- Numerical ation code

Light, see Density of stand.

\section{Litter:}

None

Scant, but uniform cover

Scant, irregularly distributed

Complete:

Less than $1 / 2$ inch deep

$1 / 2$ to 1 inch deep

1 to $1 \frac{1}{2}$ inches deep 2 inches deep.

2 to 4 inches deep.

4 to 12 inches deep.

More than 12 inches deep

Seed crop:

None

Scanty

Good

$\begin{array}{rr}\text { L } & \\ \text { Lbk } & 1 \\ \mathrm{Ls} & 2 \\ \mathrm{Lg} & 3 \\ \mathrm{Lb} & 4 \\ \mathrm{Ltp} & 5 \\ \mathrm{Lo} & 6 \\ \mathrm{Lx} & 7\end{array}$

Slash:

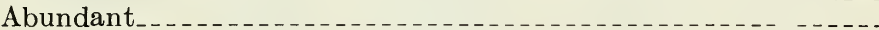

Absent

Scattered

Light, uniformly distributed

Light, unevenly distributed.

Medium, uniformly distributed

Medium, unevenly distributed

Heavy, uniformly distributed

Heavy, unevenly distributed

Very heavy, uniformly distributed

Piled

Very heavy, unevenly distributed

Compact piles:

Unburned

Burned.

Windrows:

Unburned

Burned

Lopped and scattered

Swamper burned Slope-express in percentage. Record as numeral 1 to 10 .

Species. Use symbol (as \#, ॰, †), letter, or coded numeral.

On a map diameters are shown following the symbol, as \#7.3.

In most regions, it may be necessary to code all tree species found. Separate lists should be made up for tree species, brush species, and herbaceous cover.

Thrift

Vigorous

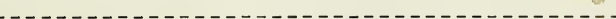

Medium

Poor

Very poor

Volume

Board feet

Cords

Cubic feet.

Table

$\begin{aligned} \text { SI } & 00 \\ \text { Slo } & 10 \\ \text { Sll } & 11 \\ \text { Sld } & 12 \\ \text { Slm } & 13 \\ \text { Slmd } & 14 \\ \text { Slh } & 15 \\ \text { Slhd } & 16 \\ \text { Slk } & 17 \\ \text { Slkd } & 18 \\ \text { Slp } & 20 \\ \text { Slp } & 21 \\ \text { Slpb } & 22 \\ \text { Slw } & 23 \\ \text { Slwb } & 24 \\ \text { Sc } & 25 \\ \text { Swb } & 26\end{aligned}$

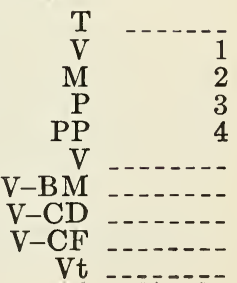




\section{SYMBOLS USED IN \\ SAMPLE PLOT MAPPING}

\begin{tabular}{|c|c|}
\hline-9 & Plot corner \\
\hline 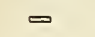 & Boundary post \\
\hline$-\phi-$ & Tree on line \\
\hline$\rightarrow$ & Subplot corner \\
\hline 可 & Quadrat \\
\hline$\triangle$ & Transit station or hypsometer hub \\
\hline$*_{\mathrm{L} 3}$ & Litter station \\
\hline$\tau_{s_{3}}$ & Soil station \\
\hline & Bench mark \\
\hline$\star \mathrm{CP}_{3}$ & Camera point (arrow shows direction of view) \\
\hline$\circ_{324}$ & Tree number \\
\hline$\Delta$ & Triangulation station \\
\hline & Road \\
\hline$===$ & Woods or logging road \\
\hline----- & Trail \\
\hline$=:>-$ & Skid trail \\
\hline$===$ & Chute \\
\hline$\Longrightarrow=$ & Skid trail with chute \\
\hline$\longrightarrow \longrightarrow$ & Flume - V-shaped \\
\hline$\longrightarrow$ & Flume-box-shaped \\
\hline$=\Rightarrow$ & Ditch (uphill side dashed) \\
\hline म中 & Railroad \\
\hline$\longleftrightarrow$ « & Fence - barbed or smooth wire \\
\hline xhan & Fence-mesh wire \\
\hline ת...... & Telephone line \\
\hline 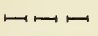 & Pipe line \\
\hline$=\frac{4}{3}$ & Bridge \\
\hline 6 & Tool shed or cache \\
\hline$\curlywedge$ & Shelter \\
\hline II & Cabin \\
\hline
\end{tabular}

Sine location
Stream-living
Stream-intermittent
Stream bed-dry wash

\section{DESCRIPTION OF PONDEROSA PINE TREE CLASSES ${ }^{30}$ AS DEVELOPED BY DUNNING}

Seven tree classes are recognized, as follows (fig. 4) :

Class 1: Age class, young or thrifty mature; position, isolated or dominant (rarely codominant); crown length, 65 percent or more of the total height; crown width, average or wider; form of top, pointed; vigor, good.

Trees of this class are rarely orer 30 inches in diameter even on good sites. The bark is dark brown and roughly fissured into ridges or small plates. The foliage is rich green in color and dense, owing to retention of the needles of 3 to 5 seasons or more, except at the base of the crown. The needles are often long and coarse, especially near the top. Terminal buds are large. The top is pointed, owing to the rapid elongation of the terminal. Thrifty opengrown young trees belonging to this class are, howerer, sometimes roundtopped because of excessive lateral growth of branches near the top. On the other hand, slow-growing trees sometimes hare pointed tops, due to weak derelopment of laterals. The annual whorls of branches and internodes are still

${ }^{30}$ Dunning's conclusions (20) have as a basis 20,000 individually numbered trees, on 25 permanent sample plots in uneven-aged stands, which were followed over a period of 15 years, 
distinct, except in the lower crown. Branches are horizontal or upward curving, except at the base of the crown where suppression is taking place. Numerous stubs of dead branches are likely to be present below the crown.

Class 2: Age class, young or thrifty mature; position, usually codominant (rarely isolated or dominant); crown length, less than 65 percent of the total height; crown width, average or narrower; form of top, pointed; vigor, good or moderate.

Such trees are usually less than 24 inches in diameter. They are commonly the inside codominant trees of groups. The crowns are smaller and less dense than in trees of the first type. Otherwise they are similar to those of class 1.

Class 3: Age class, mature; position, isolated or dominant (rarely codominant); crown length, 65 percent or more of total height; crown width, average or wider; form of top, round; vigor, moderate.

These trees are ordinarily between 18 and 40 inches in diameter, depending on site quality. The bark is light brown or yellow, with moderately large smooth plates. The foliage is less dense than in class 1 trees. The top is

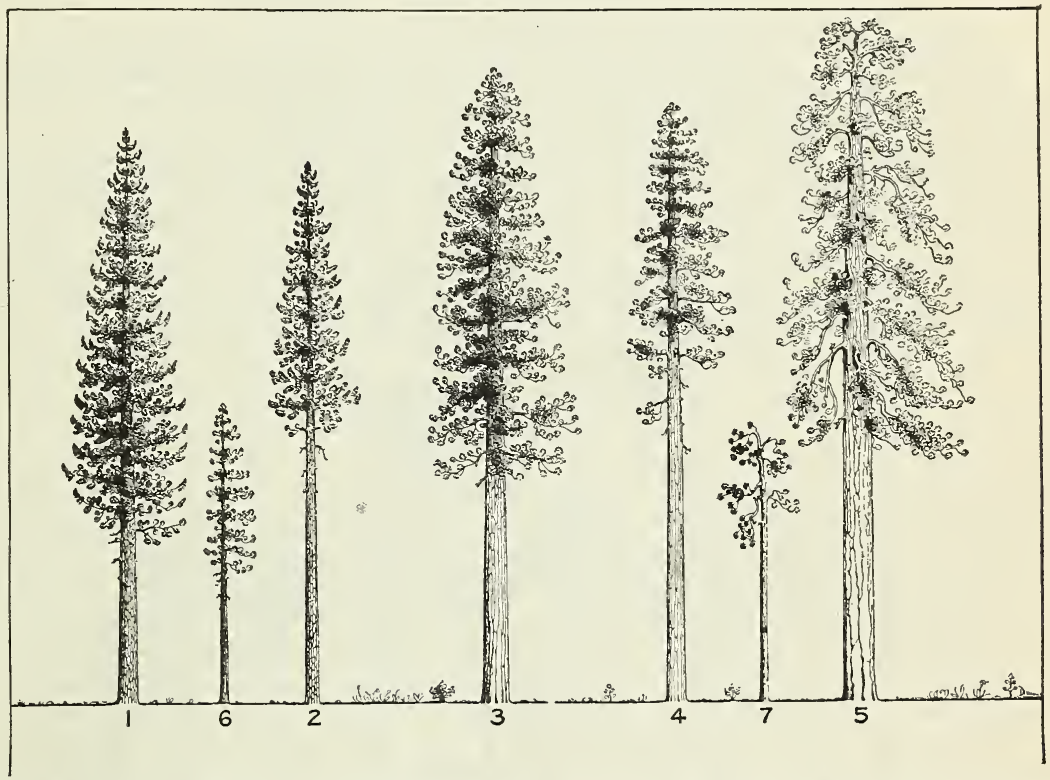

Figure 4.-Tree classes in uneven-aged stands of ponderosa pine, as defined by Dunning.

round, because of slow height growth. The nodes are indistinct, because of incomplete whorls of branches. The branches are nearly all horizontal or drooping.

Class 4: Age class, mature; position, usually codominant (rarely isolated or dominant); crown length, less than 65 percent of the total height; crown width, average or narrower; form of top, round; vigor, moderate or poor.

These are commonly the inside or codominant trees of this age class. Except for their small, poorly developed crowns and smaller size, they are similar to class 3 trees.

Class 5: Age class, overmature; position, isolated or dominant (rarely codominant) ; crown of any size; form of top, flat; vigor, poor.

These are usually the largest trees in the stand. The bark is light yellow in color, the plates often very wide, long, and smooth, especially near the base. The bark may be thin, having weathered more rapidly than it has grown. The foliage is usually rather pale green and very thin. The needles are fairly short, appearing as tufts on the ends of the twigs. The needles of 2 or 3 seasons only may be retained, even near the top. The top is flat, the terminal rarely discernible. There is no appreciable elongation of the main axis. 
Scarcely any nodes are distinguishable. Nearly all the branches are drooping, gnarled, and crooked.

Class 6: Age class, young or thrifty mature; position, intermediate or suppressed; crown of any size, usually small; form of top, round or pointed; vigor, moderate or poor.

These are understory trees, rarely over 12 or 14 inches in diameter. The bark is dark and rough. The top is round or pointed, showing that some height growth is taking place. Whorls of branches are evident, though the internodes are short.

Class 7: Age class, mature or overmature; position, intermediate or suppressed; crown of any size, usually small; form of top, flat; vigor, poor.

These understory trees are rarely over 18 inches in diameter. The bark is light in color, thin, and smooth. The top is flat, the terminal rarely distinguishable. The foliage is excessively thin. The few branches present are gnarled and drooping.

\section{SWEDISH TREE CLASSIFICATION (34)}

1. Dominants-Trees of dominant class, i.e., the tallest trees in the stand.

2. Codominants-Trees of somewhat less height and thinner crowns and generally more slender boles than class 1 trees. The heights run from about twothirds to five-sixths of the heights of the dominant trees.

3. Suppressed-Trees the height of which ranges from one-half to two-thirds of the height of class 1 trees. The leaders are usually short. In even-aged stands this class includes the slower-growing trees of the predominating age class.

4. Understory-Trees the height of which does not come up to half that of class 1 trees. This class includes the smaller suppressed trees (of younger age classes in uneven-aged stands, or advance reproduction of sapling size).

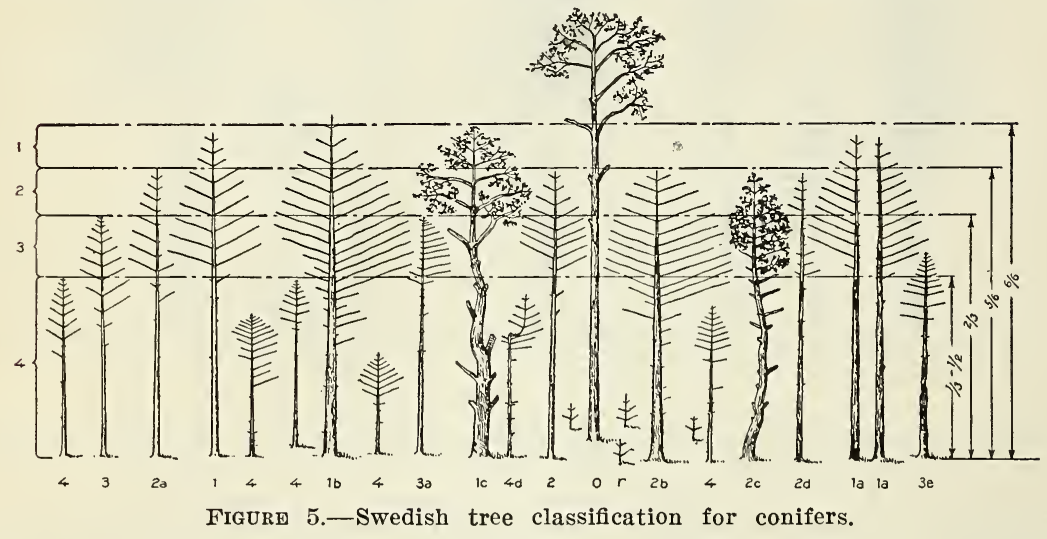

In addition, the following symbols are used: $r$, reproduction of less than sapling size; $\mathrm{O}$, overstandards. Overstandards are trees of an older age class (usually 30 or 40 years older than the main stand), usually considerably taller and of greater diameter than the other trees in the stand.

A tree with a well-formed crown and with a good bole is entered without any notation other than the number of the tree class. Other trees in each of the crown classes are further classified, with reference to the character of the crown and the form of the bole, by letters, as follows:

a. Trees with one-sided crowns.

b. "Wolf" trees of better quality, with large, low-hanging branches.

c. Crooked or twisted trees, forked trees, poor-quality "wolf" trees.

d. Trees with crowns suppressed or damaged owing to influence of adjacent trees.

e. Trees in a sickly condition owing to damage by insect, fungus, fire, or other agency.

f. Dead, broken, or heavily snow-damaged trees. 
Examples of the use of the symbols given are illustrated in figure 5, as follows: 1. A dominant tree normal as to crown and bole.

1a. A dominant tree with one-sided crown.

1b. A fast-grown tree with large limbs, a better wolf tree, in the dominant class.

1c. A decidedly crooked or limby tree of poor quality in the dominant class.

2. A codominant tree with normal crown and bole.

2d. A codominant tree with crown suppressed or damaged owing to influence of adjacent trees.

3d. A suppressed tree with damaged crown.

4d. An understory tree with crown damaged through influence of adjacent tree.

4f. A dead tree in the understory.

\section{METHODS OF PREPARING VOLUME AND YIELD TABLES}

\section{VOLUME TABLES}

(Report of a committee on standardization of volume and yield tables)

The Forest Service has had in mind for several years a series of manuals covering methods used in silvical forest research. At a meeting of forest experiment station men held at the Forest Products Laboratory, Madison, Wis., in March 1924, the need of such a series was clearly shown, and it was proposed to establish certain definite standards for silvicultural and mensurational research. Because of the growing demand for growth and yield studies, and because no uniform methods were being followed, it was felt that these should receive precedence. To insure that the field would be adequately covered and the forestry profession fully represented, a committee of 9 was formed. Three members were appointed from the Forest Service, 3 from the Society of American Foresters, and 3 from the Association of State Foresters. The committee immediately began studying different methods in use and proposed, and decided to present those measures which it felt would result in accurate and consistent volume and yield tables. It was not the purpose of the committee so to standardize the preparation of these tables that further research in mensurational fields would be precluded, but to present the best practice now in fairly common use so that any agency preparing volume and yield tables could proceed in confidence that its work would measure up to a high standard of accuracy and completeness. In following these methods, that agency would also have the benefit of previous mistakes and avoid many of the pitfalls that beset the unwary. It is hoped that the committee's labors will result in improved volume and yield tables, and that the outline here presented will be followed by all forest agencies undertaking their preparation.

The members of the committee have devoted considerable time to this task and have cooperated heartily in a work which has developed numerous discussions. In addition to the suggestions offered by the committee members, advice and comment were obtained from the various forest experiment stations, several of which now have growth studies under way, and from foresters not formally represented on the committee. Much of the burden of preparing this material has been carried by Donald Bruce rather than by the chairman.

COMMITTEE MEMBERS

\section{Forest Service}

Edward C. Behre

Donald Bruce

E. N. Munns, chairman

\section{Society of American Foresters}

H. H. Chapman

T. S. Hansen

D. T. Mason
Association of State

Foresters

J. S. Illick

M. B. Pratt

E. O. Siecke

\section{FIELD MEASUREMENTS}

1. Diameter breast high should be measured $4 \frac{1}{2}$ feet above arerage ground level.

2. The measurements should be taken with calipers, when possible, two diameters at right angles being averaged.

3. The diameter should be measured to the nearest one-tenth inch.

4. Bark thickness should be recorded at b.h. 
5. If the diameter tape is used in place of the calipers a special investigation should be made to determine the arerage difference between the measurements by the two instruments for the species in question.

6. Total height should be measured from the arerage ground lerel to the tip of the leader.

i. Height should be recorded to the nearest one-half foot.

8. If possible, height should be measured by tape or measuring stick before the tree is dirided into sections. If not, it should be obtained by summing the lengths of the indiridual logs plus those of the stump and the tip.

9. Height should be measured with tape or measuring stick.

10. Merchantable height should be taken to a fixed diameter limit; 5 inches if the International rule is to be used, and either 6 or 8 inches, according to local standards of utilization, if the Scribner rule is to be used.

11. Age should be determined by stump counts on 10 to 25 percent of the trees, selecting trees of raried sizes.

12. Diameters should be measured at regular intervals up the tree as follows :

(a) At 8.15-foot intervals where maximum height of timber does not exceed five logs;

(b) At 16.3-foot intervals for taller timber.

13. The height of stump should be 1 foot in the case of second-growth and $11 / 2$ feet in the case of rirgin timber.

14. The following intermediate taper measurements should be taken near the butt of the tree:

1 foot abore stump.

2 feet above stump.

6 feet above stump.

8.15 feet abore stump.

12 feet above stump.

(Except in the case of trees which are irregular in form at these points on account of fire scars, turpentining, etc.)

15. Diameters up the tree should be taken at lengths which are measured from the standard stump height (see no. 13) instead of from the actual stump height.

16. All diameter measurements should be taken by means of calipers, and should be the arerage of two measurements at right angles, to the nearest one-tenth inch. If diameter tape is used, an investigation should be made of the arerage difference between measurements by the two instruments.

17. The arerage bark thickness should be obtained at each point of diameter measurement to the nearest five one-hundredths of an inch by areraging two measurements made at points diametrically opposite each other.

18. The standard instrument for obtaining bark thickness is the Swedish bark-measuring instrument.

19. The following characteristics should be considered as making a tree too abnormal for use in rolume tables: Forked tops, broken tops, a heary lean, and turpentining or fire scars which distort the d.b.h. measurement. Tops repeatedly broken back by whipping should not disqualify trees of species for which this is a normal condition.

\section{OFFICE COMPUTATION}

20. In computing cubic-foot rolume the stump should be considered a crlinder, with a basal area corresponding to the diameter at stump height.

21. Logs should be cubed by the Smalian formula, using short sections as indicated br no. 13 for butt log and 8.15- or 16.3 -foot sections, as indicated in $12(a$ and $b)$, for the remaining logs.

22. The tip should be cubed as a paraboloid.

23. The computations may be performed by using multiple basal-area tables, alinement charts, or the basal-area slide rule.

24. In cubing, three significant figures should be retained.

25. The ralues for the fundamental table should include stump and tip but no bark, while subordinate tables may be prepared for merchantable volume, exclusive of stump or tip and inclusire or exclusire of bark (no. 35).

26. In computing rolume board measure the standard log rule for second growth is the International $1 / 8$-inch kerf. In addition, where the timber is already merchantable the local rule may in some instances be used. 
27. For virgin timber, both the International (1/8-inch kerf) and the local rule should be used; preference among local rules should be given to the Scribner decimal $\mathrm{C}$ rule.

28. The tree should be scaled in 16-foot $\operatorname{logs}$ (as in 12) plus a short top section (to the top cutting limit) which is scaled as a fraction of the next length.

29. No deductions should be made for defect.

30. No individual tree computations of volume in cords and other units of minor importance should be made, since tables based on these are more readily obtained by conversions of the final table (no. 35).

31. In place of computations of volume, the percentage of d.i.b. at 10-percent height intervals over d.b.h. may be used where taper tables are to be prepared.

\section{PREPARATION OF TABLES}

32. Separate tables should be prepared for second growth and for mature timber, the line being drawn at the most probable rotation age.

33. The possibility of separate tables for different sites should be carefully considered.

34. The cubic-foot table should be prepared as follows:

(a) The trees should be grouped in the following height and diameter classes: Diameter, 1-inch classes for species not exceeding 36 inches or 2 inches for species larger than this.

Height, 5-foot classes for species not exceeding 100 feet and 10-foot classes for species taller than this.

(b) For each height-diameter class the average d.b.h., average height, average volume, volume of cylinder corresponding to these average dimensions, and average form factor should be computed.

(c) These form factors should be curved over height and diameter.

(d) The final table should be prepared by multiplying the volumes of cylinders computed for the various height-diameter classes by the curved form factors.

35. The board-measure table should be prepared in the following manner:

(a) The grouping into height-diameter classes should be as follows:

Diameter, 1-inch classes for trees not exceeding 36 inches, and 2-inch classes for larger timber.

Height, 8-foot classes for trees not exceeding five $\log _{\mathrm{s}}$ in height and 16foot classes for taller timber.

(b) For each group the average d.b.h., average height, average volume, and average frustum-form factor (based on the frustum corresponding to these average dimensions) should be computed. This computation is facilitated by the use of an alinement chart which permits ready interpolation.

(c) The frustum-form factor should be curved over d.b.h. only.

$(d)$ The final table should be prepared by multiplying the frustum-form factor values by values taken from the alinement chart for the various height and diameter classes.

36 . Whatever subordinate tables are required, they should be derived from the basic tables by conversion factors based on diameter and height. For example :

$$
\text { Table }
$$

Conversion factor

Cords Cubic feet per cord.

Merchantable volume to 3 inches_-_-_-_-_. Percentage of total volume which is merchantable.

Volume including bark Percentage of bark.

Volume board measure based on total height.L.ength of top above the merchantable limit.

37. The following checks should be made on all tables:

(a) The aggregate difference between the actual volumes of the trees and those corresponding thereto taken from the tables should be computed. Satisfactory limits of error are one-half percent for more important tables and 1 percent for less.

(b) The average deviation of the individual-tree volumes from the table should be computed. In this computation the volumes read from the tables should be interpolated to the nearest one-tenth inch of diameter and the nearest foot of height. This may be done readily by putting the table in graphic form.

$$
87471^{\circ}-35-6
$$


(c) Where two or more tables have been independently prepared from the same data they should be checked against each other, as, for example, by computing the board foot-cubic foot ratio or the percentage difference between the volumes by the Scribner and International rules.

38. The following information should be published with every volume table:

(a) Species (common and scientific names).

(b) Region or locality.

(c) Author and date.

(d) Unit of measure ( $\log$ rule).

(e) Portion of tree measured.

( $f$ ) Basic data: Number in each d.b.h. class, number in each height class, location of data by heavy lines.

(g) Method of computation.

(h) Method of measurement (instrument and length of sections).

(i) Average deviation.

(k) Aggregate difference.

(l) Age.

( $m$ ) Site, if yield tables exist; if not, physiographic location of material.

39. It is premature to standardize methods of preparing taper tables. The Jonson and Behre formulas are the most promising, but demand a further study of the factors of bark thickness and root swelling and of the method of field determination of form classes. The conventional methods are of doubtful accuracy.

40. The number of trees required for a satisfactory table depends on two factors:

(a) The arerage deriation.

(b) The number of entries in the final table. The number of trees measured should be directly proportional with each of these factors, but it is probably premature to set fixed limits. Perhaps 300 or 400 could tentatively be accepted as satisfactory where neither of these factors is abnormally high.

41. In checking the applicability of volume tables a relatively small number of trees may be used. If their aggregate difference and average deviation from the table are calculated, the test for satisfactory accuracy is an average deviation of the same order of magnitude as that for the basic data on which the table was prepared and an aggregate difference which does not exceed two times this average deviation divided by the square root of the number of trees used in the test. In cases of exceptional importance a check of this sort should be made separately on the smaller and the larger sizes.

\section{NORMAL YIELD TABLES FOR PURE EVEN-AGED STANDS}

\section{FIELD DATA}

42. The basic data for the preparation of an adequate yield table should consist of from 100 to 300 plots for each major type involved, well distributed throughout the range of site classes and ages involved.

43. The plots should be well distributed over the region to be studied so as to include all characteristics of the type's range.

44. All plots should be essentially even-aged, the definition of "even-aged" depending on the reproduction period of the species studied. By "reproduction period" is meant the average time required to obtain sufficient young growth on the ground to insure a fully stocked stand at maturity.

45. The size of the plots should be such that they will include from 100 to 300 trees each.

46. The shape of the plots need not be rectangular, but there should be at least four sides, and all angles should be greater than $60^{\circ}$.

47. Each plot should be surrounded by an isolation strip of similar timber wherever possible, and where not, as large a proportion as possible of the perimeter of the plot should be thus protected and the boundary on exposed sides should be laid out with exceptional care to include the whole area occupied by the border trees.

48. The survey should be made by staff compass and tape or other means of equal accuracy.

49. Plot areas should be computed on the basis of horizontal distances.

50. Wherever practicable one semipermanent corner on each plot should be set and tied to some easily identified landmark. A sketch map of the region showing location of plots should also be prepared. 
51. All plots should be normal rather than empirical. By strict definition a normal stand is that producing the maximum volume in cubic feet for a giren age and site (thinnings usually being disregarded) ; practically, howerer, this definition must be applied with sufficient flexibility to permit finding plots at a reasonable expense. Obviously, then, the leeway necessary will depend on the character of the species and the region studied.

52. Understocked stands may be identified by such criteria as presence of holes in the crown corer (except for intolerant species), presence of excessive undergrowth or reproduction, abnormally low number of trees per acre, and abnormally high diameters for the age class in question.

53. Orerdense stands are uncommon and often hard to identify. They should usually be measured whenever encountered unless there is no uncertainty as to their identification. They may have such characteristics as an abnormally high percentage of suppressed trees or very slow diameter and height growth even on dominants.

54. Stands with pronounced variations in stem density should be aroided where possible.

(a) Age will usually be determined by means of increment borings, approximately average dominants being chosen. Abnormally large trees should be tested to see if they are older than the main stand and occasional small trees bored to ascertain whether the stand is essentially even aged.

(b) Increment cores should be numbered to permit identification and preserved for later detailed analysis.

55. The length of time required for seedlings to reach the point at which the age was determined must be ascertained by measurements of seedlings on similar sites. Open-grown seedlings should be selected which will obviously derelop into average dominants at the ages of greatest importance in the yield study.

56. The d.b.h. of each tree on the plot should be measured with diameter tape or calipers, depending on which instrument was emploved in preparing the corresponding volume table; if a different instrument is used average discrepancies should be determined.

57. These measurements should be to the nearest inch.

58. All living trees orer one-half inch d.b.h. should be tallied.

59. The diameter-class limit should be from 0.6 to the following 0.5 inch, as from 9.6 to 10.5 inches.

60. Measurements should be taken at $4 \frac{1}{2} 2$ feet from the arerage ground level.

61. All measurements should be tallied by species and by crown classes.

62. The use of three crown classes is sufficient unless perhaps work in the same or adjacent similar regions has been based on four classes.

63. All species, eren those of subordinate importance, whether softwood or hardwood, should be recorded, the word "miscellaneous" being avoided. There is, however, no objection to grouping in a miscellaneous column a number of subordinate species, providing that the tally identifies the species of each tree for which record is made.

64. The height and d.b.h. of a sufficient number of sample trees should be measured to permit the drawing of a curve of height over diameter for each plot.

65. The complete range of d.b.h.'s present should be covered by these samples.

66. The number of sample trees required is not a fixed percentage of the total number on the plot but is determined by the number needed to yield a satisfactory height curve.

67. Height should be measured with any standard instrument, such as the Forest Service or Faustman hypsometer or the Abney, distances being taped.

68. Trees measured should be sufficiently normal to be acceptable for rolumetable work, forked and broken tops, for example, being avoided.

69. Separate curves are needed for any subordinate species present unless so unimportant proportionately as to make it practicable to use the height curve of the principal species.

70. The height of 5 to 10 mature dominant trees adjacent to the plot should be measured where possible as an aid to site classification.

71. The height of 10 to 15 dominants growing in obriously open or overdense stands adjacent to the plot, on similar sites and of the same age, should be measured wherever such stands are found to permit a study of the effect of density on height.

72. The plot description should include the following headings: Crown density; Normality; Percentage of boundary in open; Type; Distribution; Slope 
and aspect; Altitude (total and relative) ; Soil and rock; Soil cover (underbrush, advance reproduction, litter, humus); History (origin, date of fires, date of cuttings, present condition); Tie-survey notes and sketch map.

73. The form of tally sheet may vary with the species and type studied, although the Forest Service form 547 is capable of wide application. It should, however, not omit any of the following items: Date; locality; survey notes; name of party chief; plot number; ages of sample trees; average age; area; species; site class (entered in office) ; diameter, tallied by crown class; height measurements of sample trees; plot description (see last paragraph). Wherever possible, provision should be made for complete computation on the original sheet of basal area, volume, etc., as filing is much simplified thereby.

74. Since site determination of the plots in the field and $\mathrm{by}^{\mathrm{inspection}}$ has been found difficult, inaccurate, and of little value, but since there is need of some current means of determining whether the plots found are satisfactorily distributed through the various site classes, a tentative series of height-age curres should be prepared on the basis of the first 15 or 20 plots on which measurements are taken, and subsequent plots allocated tentatively to site classes thereby.

75. A two-man party is adequate for the collection of these data. Of these men only one need be experienced. Where more than one party are working on a single study, it is of the greatest importance to coordinate their methods. It is desirable to start with a single party of two experienced men, later to split this party in two by giving each an assistant, and so on. If this is impracticable, at least the man in charge of the project should train each crew when it is starting work, so that he may impress his conception of normality, etc., upon each. It is also essential that one man have direct charge and responsibility of both field and office work.

76. If volume tables are not already available, data should be collected for their preparation. The plan of felling and measuring 1 or 2 average dominants on each plot has been found inadequate because the range of diameters and heights will not be properly covered. See preceding section on volume-table preparation.

OFFICE WORK

77. For each plot a curve of height over d.b.h. should be prepared for each important species.

78. For each plot the basal area should be computed to three significant figures and totaled by species and crown class.

79. For each plot the number of trees should be totaled by species and crown class.

80. For each plot the volume should be calculated and totaled by species and crown class. Volume should be interpolated to the nearest foot of height. This may be done with sufficient accuracy by putting the volume table in graphic form or in the form of an alinement chart.

81. The fundamental volume figure is that in cubic feet including the entire wood of the stem. Subordinate figures should be obtained in board measure by means of the International (1/8-inch) log rule. The local rule should also be used in cases where the material involved is now merchantable, preference being given to the Scribner.

82. For each plot the arerage d.b.h. is calculated by dividing the sum of the basal areas by the number of trees.

83. For each plot the arerage height is read from the height-diameter curve corresponding to this arerage d.b.h.

84. For each plot the actual total age is determined by adding the seedling allowance to the average of the determined ages.

85. For determining the site index a series of curves showing the relation between the arerage height of the dominant trees and their ages should be prepared. The basis should be the average height of dominants (or of dominants and codominants) at 50 or 100 vears, depending on the probable rotation age. The curres should be at 10 -foot intervals at the selected age. The height of individual trees, if used at all, should be merely a guide to the location of the curres. The curres should, of course, be applicable to the principal species being studied.

86. The site index of each plot should be read to the nearest foot. By site index is meant the arerage height of dominants which the plot has attained or will attain at the age chosen for classification. 
87. In cases where the ultimate height is used for site-classification purposes, ultimate-height values should be correlated with the height at the classification age, and the site-index number obtained thereby. In other cases this should be done wherever practicable, as an aid to application of the tables.

88. A summary should be prepared for each plot for all species, showing the basal area, number of trees, volumes in cubic feet and board feet. The foregoing should be for all trees on the plot. The same information should be summarized for the dominants, and, in addition, the a verage basal area per tree and the arerage height corresponding thereto.

89. Compute the number of trees, and the average basal area and corresponding average height for the trees above the diameter limit fixed by the board-foot volume table which is to be used.

90. Compute the plot area and express all summarized figures on a per acre basis.

91. The rejection of plots should be based primarily on deriations in basal area from the tentative curves of basal area over age and site.

92. For this purpose preliminary curves should be prepared of basal area on age by site-index classes, and the deviation of each plot from these curres computed. interpolating to the nearest year of age and nearest foot of site index. The standard deviation should then be computed (using the approximation formula $1.25 A D=S D$ ) and all plots deviating by more than two standard deviations should be rejected.

93. The remaining plots should be sorted by age and site-index classes. The classes should be 5,10 , or 20 years in age, depending on the range of ages, and 5,10 , or 20 feet of site index, depending upon the range of site indexes.

94. For each class the following totals should be computed: Number of trees per acre, and volume per acre in board feet and in cubic feet. The arerage basal area per tree should then be obtained by dividing the total basal area per acre by the total number of trees per acre. The average height should be obtained by giving each plot equal weight. The foregoing figures should be obtained for the entire stand, for the dominant stand, and for that abore the diameter limit fixed by the board-foot rolume table used.

95. In preparing these figures the plots should be given equal weight by using the per acre figures.

96. Harmonized curves should be prepared by site-index classes orer age for each element mentioned in paragraph 94. Many of these curres may profitably be developed by means of anamorphosis.

97. Curves of average basal area per tree should be substituted for those of arerage d.b.h., the final results being translated into terms of diameter for entry in the tables.

98. The following checks should be used: (1) The number of trees per acre times the average basal area per acre should equal the total basal area per acre; (2) the number of trees per acre times the rolume from the volume table corresponding to the arerage diameter and height should equal the arerage volume per acre. Both these checks should be applied to the entire stand and to the dominant stand. Check no. 2 should be applied to both the boardfoot and the cubic-foot curres. In addition, the board foot-cubic foot ratio when plotted over d.b.h. should produce a single curve of normal shape for all site-index classes. Furthermore, the percentage ratio between the totalstand and dominant-stand values for all factors when plotted over the average d.b.h. of the entire stand should produce a well-defined curve of reasonable shape. Lastly, for all factors, the aggregate difference between the actual measurements and those indicated by the curres should not exceed 1 percent.

99. Average deviations of the individual plots from the curves should be computed for the following factors: Basal area per acre, number of trees per acre, volume board measure per acre, and volume in cubic feet per acre.

100. The frequency distribution of the diameter classes should be investigated and if the normal distribution is found, the standard deriation should be curved over average d.b.h. This will permit the preparation of stand tables for any age and site.

101. Eren if this frequency distribution is not normal, the existence of any characteristic type will permit the preparation of subordinate tables (such as trees above 4 inches d.b.h.), by curving the ratios between the factors for the stand above such a limit to those for the entire stand over the average d.b.h. 
102. Subordinate tables such as those in cords. those for trees abore $t$ inches in diameter, and those for rolumes below a 3-inch top, should be deduced from the primars tables br converting factors instead of by direct preparation.

103. The following information should be included in the final tables:

(a) Species, common and scientific name.

(b) Forest type.

(c) Region.

(d) Author and date.

- (e) Basic data-number of plots used and their distribution through the site and age classes.

(f) Definition of site index used.

(g) Collectors of field data.

(h) Arerage deriations of individual plots from the rield-table ralues for factors mentioned in no. 98 .

104. All tables should contain information on the following factors:

(a) Arerage total height of dominants.

(b) For entire stand, the

(1) D.b.h.

(2) Total height.

(3) Number of trees per acre.

(4) Basal area per acre.

(5) Yield in cubic feet, entire stem. Without bark.

(6) Yield in board feet. International (1/8-inch) log rule.

In addition, tables giving similar information for the dominant stand, for the stand abore one or more diameter limits, and for yields in other units or to other limits of merchantability should be included as needed.

\section{FOREST SERVICE POLICY REGARDING EXPERIMENTAL FORESTS, NATURAL AREAS, AND PRIMITIVE AREAS}

The following regulation was approved by the Secretary of Agriculture on dugust 7,1930 , as National Forest Regulation L-20:

The Forester shall determine, define, and permanently record a series of areas of national-forest land to be known as experimental forests, sufficient in number and extent adequately to provide for the experimental work necessary as a basis for forest production or forest and range production in each forest l'egion, these areas to be dedicated to and used for research; also where necessary a supplemental series of areas for range investigations to be known as experimental ranges; and a series to be known as natural areas sufficient in number and extent adequately to illustrate or typif 5 virgin conditions of forest or range gromth in each forest or range region, to be retained in a virgin or unmodified condition for purposes of science, research. and education; and a series of areas to be known as primitive areas and within which will be maintained primitire conditions of environment, transportation, habitation, and subsistence, with a view to conserving the value of such areas for purposes of public education and recreation. Within any areas so designated, except for permanent improrements needed in experimental forests and ranges, no occupancy under special-use permit shall be allowed, or the construction of permanent improvements by any public agency be permitted, except as authorized by the Forester or the Secretary.

These instructions relating to experimental forests, natural areas, and primitire areas were approved by the Secretary.

\section{EXPERIMENTAL FORESTS}

\section{PURPOSE}

The purpose of experimental forests is to make permanently arailable for silvicultural, range, products, and other related forest research carefully selected areas as fully representative as possible of conditions in important parts of forest regions and large enough to meet present and foreseeable future needs. In essence these areas are field laboratories for intensire investigative work. In the interest of results of the greatest breadth and reliability, of protection, of efficiency, and of the best working conditions for the investigative staff, the work of forest experiment stations will be concentrated as fully as possible on them. 
A secondary and incidental but hardly less important purpose is to provide for the demonstration of results, favorable and otherwise, of widely varying silvicultural and other forest practices.

Assured provision for the best possible field laboratories for research is so vital to sound national-forest administration and to the development of private forestry that the selection of necessary areas is made a part of Forest Service policy and procedure under mandatory instructions from the Secretary of Agriculture.

\section{NUMBER, CHARACTER, AND EXTENT}

The McSweeney-McNary Forest Research Act specifies 12 or 13 forest regions in the United States proper, in each of which a forest experiment station is to be established. So far as can now be foreseen, from 5 to 10 experimental forests will ultimately be required in each region, with an average of about eight. The area of each of these forests should range from about 1,500 acres as a minimum to about 5,000 as a maximum, and average about 3,500 acres, exclusive of natural areas. They should be large enough to provide adequately for present and foreseeable future work. They should be small enough to aroid all unnecessary burden of administration. Size should be governed primarily by the complexity of the type and the growth rate of tree species. The simpler the type and the higher the growth rate the smaller the area that will be required.

Each experimental forest should be as fully representative as possible of the conditions in important subregions. More specifically, this means adequate representation of forest types and sites, of the conditions which underlie types and sites, such as soils, climatic variations, altitudinal range, etc., and of the older age classes particularly. Accessibility is an important consideration, for the marketing of forest products to permit intensive silvicultural experimentation, and for ease of access to visitors and to the investigative staff.

Accessibility may require both satisfactory automobile roads, and railroads or drivable streams. Assurance of protection against fire may also be a factor of importance in location because the cumulative investment of large numbers of investigative projects will soon far exceed the intrinsic value of the timber stand itself.

Where it is not possible to find a satisfactory representation of conditions in 1 area it may be advisable to select 2 or eren 3 areas within easy working distance of an experimental forest headquarters.

Each experimental forest should, whererer possible in the interest of greatest representation of conditions for scientific work, include in addition to the area already specified a natural area of the character provided for below.

\section{OTHER CONSIDERATIONS}

The selection of experimental forests should be carried forward rapidly enough so that the ralue for research of the most suitable areas will not be seriously reduced, or destroyed for many jears, by timber cutting. It will be far better to select, designate, and hold such forests orer a long period of years without any work in them than to lose them altogether for research or to have their value greatly impaired. While the investigative work of the Forest Service is being built up as rapidly as funds and competent men can be obtained, it will probably be a good many jears before the resources will be large enough to carry out a large-scale program on the number of experimental forests for each region indicated. Immediate or even future returns to the Treasury in the cutting of timber for profit is not a valid reason for excluding from experimental forests areas needed for that purpose. The use of such areas for research should establish a sound scientific basis for future national-forest practice and that on private lands, and hence greatly increase the returns on all forest lands. Similarly, sustained yield should be incidental. The primary purpose in the handling of experimental forests should be to install and maintain the series of inrestigative projects which seem most necessary as a foundation for good silviculture, etc.

Where suitable areas for experimental forests cannot be found on existing national forests, consideration should be given to the acquisition of suitable areas by gift under the provisions of section 5 of the act of March 3, 1925 (43 Stat. 1132), by exchange, or, as a last resort, by purchase. 


\section{JURISDICTION AND ADMINISTRATION}

Although experimental forests will be set apart and dedicated to research, they will remain an essential part of the national forests in which they are located. They will have something of the same status as areas for which special uses are granted and special activities authorized. Receipts will be credited to the national forests in which they are situated and reported with those of the national forests.

The responsibility for protection against fire should rest primarily upon the administrative staff of the national forests in which they are situated. Since the investigative work will represent a rapidly increasing investment, especially intensive plans for protection should, as soon as possible, be worked out in cooperation by the administrative force and the staff of the experiment station concerned and put into effect. In this protective scheme the custodial staff of the experimental forest should be made an essential part.

The permanent improvement plan should also be worked out by the administrative and research staffs in cooperation. Ordinarily, where investigative work on any scale is under way the plan will need to be more intensive than that on the surrounding forest. Supervision of the construction of the improvement projects agreed upon should be worked out by mutual agreement in accordance with the most effective plan under existing conditions.

The director of the experiment station should be held responsible for timber cutting and range or other use of the experimental forest, solely to insure the conduct of the work in the manner required for the investigative purpose in view, and to establish clear-cut responsibility. This involves such questions as the making and supervision of timber sales, grazing permits, etc., which will ordinarily be small. In some cases it may be desirable to work out arrangements where members of the administrative force will scale timber, etc. Where there is joint range use of national and experimental forest areas the plans of joint use, including the issuance of permits, will be worked out cooperatively by the supervisor and director.

Since the primary purpose of experimental forests and experimental ranges is research and an important incidental use is the demonstration of investigative results, general or promiscuous public use should be restricted as far as practicable, and if this is impossible, should be carefully regulated.

\section{NATURAL AREAS}

PURPOSE

Permanently to preserve in an unmodified condition areas representative of the virgin growth of each forest or range type within each forest region so far as they are represented within the national forests, to the end that its characteristic plant and animal life and soil conditions, the factors influencing its biological complex, shall continue to be available for purposes of science, research, and education.

\section{NUMBER AND EXTENT OF NATURAI. FOREST AREAS}

A sufficient number of natural areas should be established to insure the preserration of virgin areas typical of important forest conditions in the United States and permitting continuity of study to climax types. Probably a dozen such areas will be required in each forest region. If, howerer, a forest type is adequately represented in some other permanent form of reservation such as a national park, duplication in a national forest may be unnecessary.

Since undue conflict with industrial or economic needs would threaten the permanence or stability of the natural area, they should, where practicable, be located where there is least probability of such conflict and be confined to the minimum area within which their full purpose can be realized; but they should not be so restricted as to minimize their scientific value. The area essential to the maintenance of virgin conditions for any material length of time will vary with the type of forest involved or possibly with climatic and topographic conditions, but under average conditions 1,000 acres would be about the minimum.

Wherever possible a natural area should be established in connection with each experimental forest and in addition to the area required for the latter. 
Where this is not possible and no natural area is available, it may be highly desirable to add to the experimental forest an area in which the timber is not yet mature, to be maintained without use so that in time it will develop into a natural area. Where suitable natural areas are not already included in national forests, acquisition by other means suggested under Experimental Forests should be considered.

UTILIZATION OF NATURAL AREAS

Within natural areas scientific and educational use will be exclusive. The cutting of timber, and as soon as possible grazing use also, should be prohibited. General or promiscuous public use will be incompatible with the scientific use of the area, and should be restricted as far as practicable; and if this is impossible, carefully regulated. The present laws are inadequate to permit the total exclusion of the public or prevent the location of mining claims or the establishment of easements under public-land laws.

\section{SCIENTIFIO VALUE DEPENDENT UFON PERMANENCY AND STABILITY}

The highest value of natural areas can be maintained only by the total exclusion of all forms of use. Consequently no utilization shall be authorized or changes made in boundaries without the prior approval of the Forester, which will not be granted unless there is certainty that the change will not react adversely upon the plans of the Forest Service or of any related research agency.

\section{AVAILABILITY OF NATURAL AREAS TO OTHER RESEARCH AGENCIES}

While natural areas will be established primarily to meet the needs of the Forest Service, their use by other research or educational agencies for purposes which do not conflict with Forest Serrice projects shall be allowed under appropriate cooperative agreements approved by the Forester.

\section{SPECIMEN AGREEMENT PROVIDING FOR EXPERIMENTAL USE OF PRIVATE AREA}

\section{COOPERATIVE AGREEMENT BETWEEN THE
FOREST EXPERIMENT STATION OF THE CO. AND THE}

THIS AGREEMENT, dated this _-_- day of _-___-_, A.D. $19_{--}$, by and between the -...... CO., a Corporation organized and existing under and by virtue of the laws of the State of _.........-, hereinafter referred to as the "Company", and the _._._. FOREST EXPERIMENT STATION OF THE _-_._-_, hereinafter referred to as the "Station,"

WITNESSETH, That in consideration of the mutual advantages hereinafter provided for and of the respective services to be rendered in connection therewith, the parties hereto mutually agree as follows:

That the "Company" shall:

FIRST: Place at the disposal of the "Station" for experimentation and demonstration in timber growing a certain tract of land owned by the "Com-

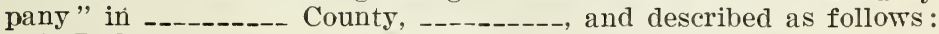

ALL that tract of land situated in the Township of _......--, in the County and State aforesaid, having an area of approximately --.----- (_---) acres, now owned or in the process of acquisition by the "Company," excepting such lands as are now owned by the "Company" and about to be conveyed to

Corporation, and also excepting the following land, as shown on a map of the Estate of _.....-.-. made by

(Detailed description of tract follows.)

This experimentation and demonstration is specifically understood to include the cutting of mature or defective timber and the thinning of young timber.

SECOND: Protect the said tract from fire at all times to the full extent of its power, and to take all reasonable precautions against the use of fire on the tract.

THIRD: Permit access to the tract by such visitors as the "Station" may designate, under the guidance of the "Station." This shall not be interpreted by the "Station" to include the general public except under such conditions 
and at such times as shall be satisfactory to the "Company" and agreed to in writing by it.

FOURTH: Permit the erection by the "Station" of structures, including fences, necessary for office and laboratory use, together with living quarters necessary to the "Station's" staff, at such points on the tract as may be satisfactory to the "Company," and the removal thereof within -..--.---- days after any termination of this agreement.

That the "Station" shall:

FIRST: Undertake such experiments and demonstrations in timber growing on the tract as are in its judgment best calculated to bring the tract to the highest degree of forest productivity, including experiments in obtaining natural reproduction of the forest after cutting, in thinning to stimulate growth, in artificial forestation where deemed necessary, and any other experiments of a similar nature.

SECOND: Direct and supervise under contracts to be let by it all cutting and removal of forest products designated for cutting on the tract except that at its option the "Company" itself may cut and remove the products, or may enter into contract with a third party for such cutting and removal, but in every case the cutting and removal shall be under the direction and supervision of the "Station" and all proceeds shall be paid to the "Company."

THIRD : Cooperate in protecting the tract against fire and assist in suppressing fires that may occur thereon to the extent that its men are present at the time of the fire.

It is mutually agreed that:

FIRST: Nothing in this agreement shall prevent the use of the tract by the "Company" either for__._-_._- purposes or for the erection of any building or buildings which in the judgment of the "Company" are necessary for carrying on its work; but it is agreed that the use of no plot or plots (to wit, small areas within said large tract) set apart by the "Station" for experimental purposes shall be interfered with by the "Company" in such or other uses unless found to be absolutely necessary for the conduct of "Company's" work; and it is further agreed that should such use of plots in the judgment of the "Station" seriously interfere with its work, the "Station" may, on one year's notice in writing to the "Company", terminate this agreement.

SECOND: In cutting and removal of forest products from the tract the needs of the "Company" for fuel, lumber, and other forest products shall be given first consideration.

THIRD: This agreement shall continue in effect for a period of --_-_- (--) years unless sooner terminated by mutual consent, provided that nothing in this agreement shall bind the "Station" to the expenditure of funds beyond appropriations made available by ------- for the purposes thereof, and provided further, that should the "Company" during the term of this agreement sell the tract and abandon its use for the purposes to which it is now devoted, this agreement shall thereupon terminate.

IN WITNESS WHEREOF, the "Company" has caused these presents to be signed by its President, its Corporate seal affixed, and the doing thereof attested by its Secretary, and the "Station" has caused these presents to be signed by the ........, on the day of the date hereof.

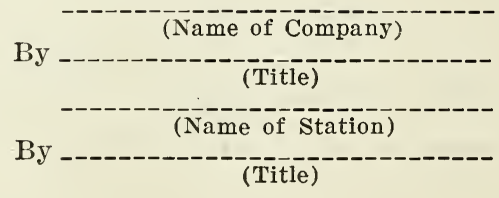




\title{
ORGANIZATION OF THE UNITED STATES DEPARTMENT OF AGRICULTURE WHEN THIS PUBLICATION WAS LAST PRINTED
}

\author{
Secretary of Agriculture \\ Henry A. Wallace. \\ Under Secretary \\ REXFORD G. TUGWELL. \\ Assistant Secretary \\ M. L. Wrison. \\ Director of Extension Work \\ C. W. WARBURTON. \\ Director of Personnel \\ W. W. STOCKBERGER. \\ Director of Information \\ M. S. EISENHOWER. \\ Director of Finance \\ W. A. JUMP. \\ Solicitor \\ Seth Thоmas. \\ Agricultural Adjustment Administration \\ CHester C. DAvis, Administrator. \\ Bureau of Agricultural Economics \\ NIIs A. Olsen, Chief. \\ Bureau of Agricultural Engineering \\ S. H. McCrory, Chief. \\ Bureau of Animal Industry \\ JоHN R. MOHLER, Chief. \\ Bureau of Biological Survey \\ J. N. Darling, Chief. \\ Bureau of Chemistry and Soils \\ H. G. KNIGHT, Chief. \\ Office of Cooperative Extension Work \\ C. B. Sмrth, Chief. \\ O. E. REED, Chief. \\ Bureau of Dairy Industry \\ Lee A. Strong, Chief. \\ Bureau of Entomology and Plant Quarantine_ \\ Office of Experiment Stations. \\ James T. Jardine, Chief. \\ Food and Drug Administration \\ Walter G. Campbeld, Chief. \\ Forest Service \\ Grain Futures Administration \\ Ferdinand A. Silcox, Chief. \\ J. W. T. Duvel, Chief. \\ Bureau of Home Economics \\ Louise Stanley, Chief. \\ Library \\ Clartbel R. Barnett, Librarian. \\ Bureau of Plant Industry \\ Frederick D. Richey, Chief. \\ Bureau of Public Roads \\ Thomas H. MacDonald, Chief. \\ Weather Bureau \\ Willis R. GREGG, Chief.
}

This circular is a contribution from

Forest Service Ferdinand A. Silcox, Chief. Branch of Research EARLE H. Clapp, in charge. 
